\title{
Chronique des fouilles et découvertes archéologiques dans le Bosphore cimmérien (mer Noire septentrionale)*
}

\author{
par Christel MÜLLER \\ avec la collaboration de Andrei ABRAMOV, Mikhail ABRAMZON, \\ Ekaterina ALEXEIEVA, Igor BEZRUCHENKo, Alexei EFIMOV, Youri GORLOV, \\ Vladimir KUZNETSOV, Alexandre MASLENNIKOV, Alexei MALYSHEV, \\ Elena SAVOSTINA, Vladimir TOLSTIKOV et Alexei ZAVOIKINE
}

L'intérêt des archéologues et des historiens occidentaux pour les colonies grecques de la mer Noire septentrionale connaît depuis une dizaine d'années un renouveau dont les causes, évidentes, ont à peine besoin d'être rappelées ici : contacts noués, au-delà des cercles d'habitués, avec les chercheurs des anciens pays de l'Est, possibilités soudaines d'accès aux sources, ouverture des archives, etc. Ce phénomène a commencé de se traduire en termes bibliographiques, comme en témoigne par exemple la publication récente d'un colloque consacré aux territoires des cités grecques ${ }^{1}$, où pas moins de six communications sont dues à des auteurs russes, ukrainiens ou polonais. Mais il se manifeste également par des collaborations de terrain, comme celles que mènent l'auteur de ces lignes avec des membres de l'Institut archéologique de l'Académie des sciences de Russie ou une autre "ancienne " de l'École française d'Athènes, Véronique Chankowski, en Bulgarie. C'est dans ce contexte qu'a surgi l'idée d'ajouter, à la Chronique traditionnelle du $B C H$, un chapitre exclusivement consacré au Pont Nord, avec l'intention de proposer des matériaux inédits et réputés inaccessibles à des lecteurs non russophones.

\footnotetext{
* Une chronique du $\mathrm{BCH}$ sur la mer Noire a été inscrite dans les projets faisant partie de l'accord, signé en avril 1994, entre l'Institut archéologique de Moscou et l'École française d'Athènes. Cette chronique a été confiée à Chr. Müller, qui codirige les travaux de la mission franco-russe de Taman. Elle devrait connaître une suite régulière et il est souhaitable que ces chroniques hors Grèce et Chypre se dévelop-
}

pent dans le $B C H$ pour toute la zone où l'EFA déploie ses activités [R. Étienne].

1 M. BRUNET (éd.), Territoires des cités grecques, Actes de la Table ronde internationale organisée par l'École française d'Athènes, 31 octobre-3 novembre 1991, BCH Suppl. 34 (1999). 


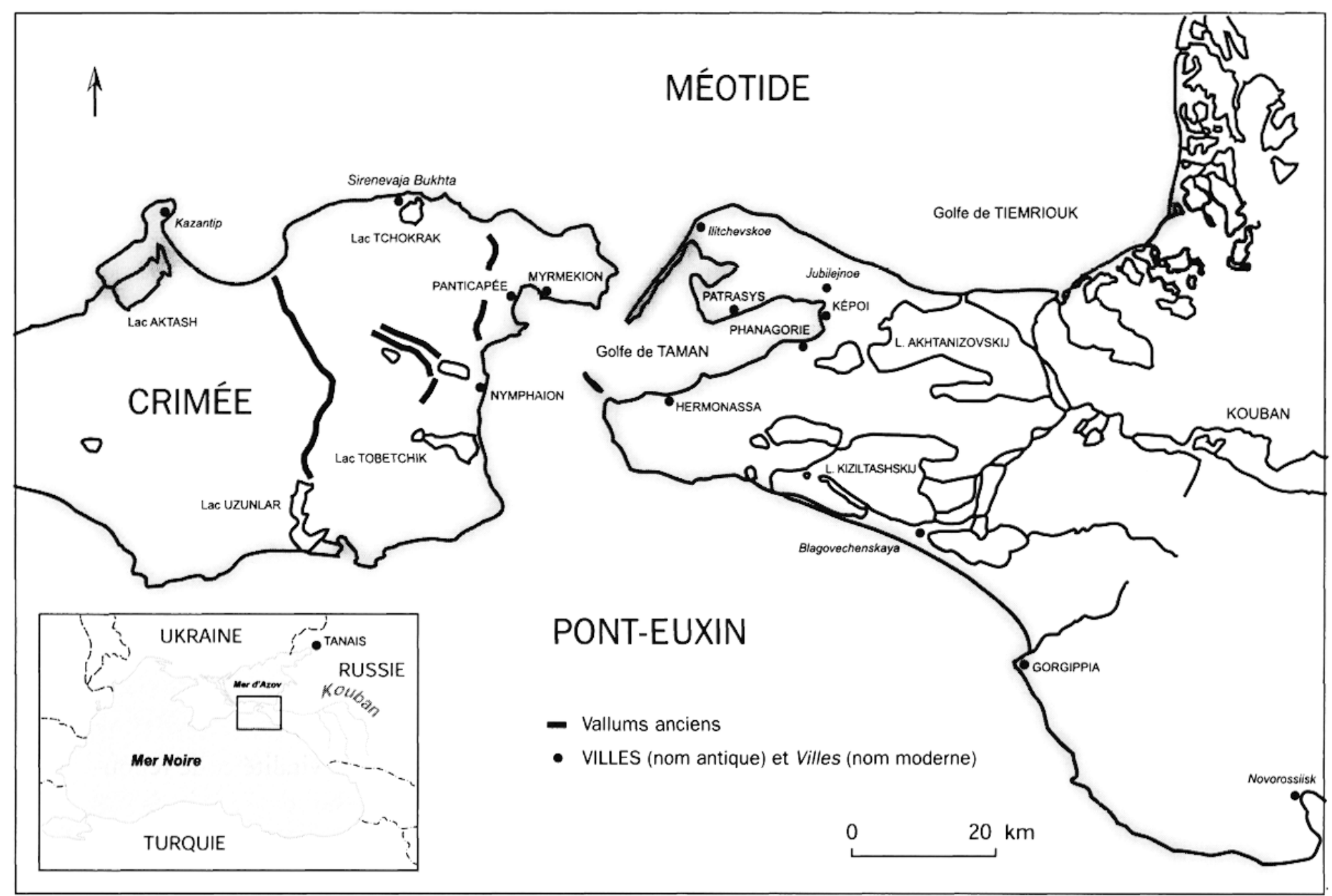

Fig. 1. Le Bosphore cimmérien (dessin G. Garbuzov).

En termes d'extension géographique, on a cependant choisi de se limiter à l'ancien royaume du Bosphore cimmérien (fig. 1), laissant volontairement de côté des cités aussi passionnantes que Chersonèse : le dépouillement de la bibliographie, en effet, aurait largement dépassé les capacités d'une seule personne. Ce choix n'est pas totalement arbitraire : outre la cohérence historique de cette entité, il se trouve que la plupart des archéologues antiquisants de Moscou mènent leurs recherches dans cette région. Aussi a-t-on voulu commencer, de façon fort pragmatique, par ce que l'on maîtrisait le moins mal.

Encore fallait-il se donner une "date bibliographique de départ": on a choisi de prendre, comme terminus post quem, le volume paru en $1984^{2}$ et consacré aux États antiques de la mer Noire dans la collection intitulée "Archéologie de l'URSS ". Cette formidable synthèse - de celles qui ne sont plus possibles depuis le délitement de l'empire - avair, en son temps, fait le point sur tous les sites de la région, bien audelà du Bosphore cimmérien auquel était consacré le chapitre cinq de la première partie. La deuxième moitié des années 1980 ayant été une période particulièrement difficile pour la Russie, c'est donc, grosso modo, la décennie 1990-2000 qui est concernée par la présente chronique.

2 G. A. KoChelenko, I. T. KRUGLikova et V. S. DOLgORUKOV (éds), Antichnye Gosudartsva Severnovo Prichernomorie [Les Etats antiques du Nord de la mer Noire] (1984), Moscou. Un autre recueil est paru, quelques années après, qui se voulait une manière d'approfondissement des trop courts articles rédigés pour le volume général. Mais ce recueil se limite à quelques sites, sans perspective d'ensemble: G. A. KOCHELENKO et al. (éds), Ocherki archeologii i istorii Bospora [Etudes d'archéologie et d'histoire du Bosphore] (1992), Moscou. 
L'ampleur de la tâche s'étant, dès le début, manifestée comme un obstacle potentiel à la réussite de l'entreprise, on a choisi de demander aux directeurs des différentes "expéditions", selon le terme russe qui désigne les missions archéologiques sur tel ou tel site, une chronique partielle relative à leurs propres recherches. Tous, ou presque ${ }^{3}$, ont répondu à l'appel et fourni leurs contributions ${ }^{4}$, qui figurent ci-après sous leur propre nom. Mais on a souhaité également commencer une recension plus large prenant en compte les publications en langue russe parues depuis une dizaine d'années, au-delà des deux revues les plus connues en Occident, le Vestnik Drevny Istorii et Rossiskaya Archeologia : ce sont les notices qui apparaissent après les contributions.

Il convient ici d'évoquer brièvement le maquis que constitue, pour un non-initié, cette bibliographie russe. Les publications archéologiques ont été, comme le reste de la société, frappées de plein fouet par les crises successives que connaît le pays depuis le début de la perestroika : crise financière et matérielle de nombreuses revues ont tout simplement disparu dans la tourmente, faute de moyens -, mais aussi intellectuelle et méthodologique. Dans ce climat de tension et d'effervescence, on a ainsi vu surgir des revues nouvelles à l'existence irrégulière, voire éphémère, dont les trois plus importantes pour notre propos sont : à Moscou, le Bosporski Sbornik [Recueil du Bosphore], dont le premier numéro a paru en 1992, mais qui semble avoir rendu l'âme depuis l'apparition de son concurrent direct, Drevnosti Bospora [Antiquités du Bosphore], né en 1998 ; et à Saint-Pétersbourg, les Archeologicheskye Vesti [Nouvelles archéologiques], parues pour la première fois en 1992 et qui se sont maintenues tant bien que mal jusqu'à aujourd'hui. Il est, en général, possible d'acquérir ces publications au fur et à mesure de leur parution, ce qui n'est pas le cas pour les revues provinciales: il est à peu près impensable de faire le tour des volumes locaux à diffusion confidentielle, même s'ils sont en principe déposés à l'INION ${ }^{5}$, le grand centre de documentation en sciences humaines de Moscou. Ces créations un peu anarchiques sont en même temps signe de vitalité et de renouveau, tout comme les publications rćoentes de monographies, qui respectent aujourd'hui des standards très différents des anciens standards soviétiques, en particulier dans le domaine de l'illustration : on pense notamment à la synthèse qu'a donnée A. Maslennikov ${ }^{6}$ sur la chôra du Bosphore européen en 1998.

L'obtention des informations archéologiques ayant donc présenté un caractère notoirement aléatoire, il a été impossible de procéder de façon aussi ordonnée que pour la Chronique traditionnelle. Mais l'essentiel était de commencer et il faudra, bien sûr, poursuivre dans le prochain volume ${ }^{7}$.

Liste des abréviations utilisées

AV: Archeologicheskye Vesti (Institut de la culture matérielle, Saint-Pétersbourg) (entièrement dépouillé)

BS : Bosporski Sbornik (LARAN, Moscou) (entièrement dépouillé)

DB: Drevnosti Bospora (IARAN, Moscou)
IA : Institut archéologique

IARAN : Institut archéologique de l'Académie des sciences de Russie (Moscou)

RA: Rossiskaya Archeologia

TS : Tamanskaya Starina [Taman au temps jadis], Musée national de l'Hermitage, SaintPétersbourg (entièrement dépouillé)

VDI: Vestnik Drevny Istorii
3 On regrette fort l'absence d'article sur Hermonassa, malgré les demandes répétées adressées à l'auteur des fouilles. 4 Ces contributions ont fait l'objet de deux traductions successives, dont la première est due à Andrea Rychtecky, que nous tenons à remercier ici, et la deuxième à l'auteur de ces lignes, qui a également retravaillé les textes.

5 Institut d'information scientifique pour les sciences humaines: il s'agit d'une grande bibliothèque créée en 1969 par l'Académie des sciences d'URSS et destinée à donner aux chercheurs russes accès à la bibliographie occidentale.
On signalera l'ouverture au sein de I'INION, en avril 2001, d'un Centre franco-russe en sciences sociales et humaines, qui sert d'agence de facilitation et de documentation pour les chercheurs des deux pays (uww.obsmoscou.net).

6 A. A. MASLENNIKOV, Une chôra hellène à la limite de l'oikouméné (1998), Moscou (avec dix pages de résumé en anglais). 7 L'ordre géographique adopté pour la présentation des sites est celui du volume de 1984 consacré à l'archéologie des États antiques de la mer Noire. 


\section{Panticapée}

\section{Travaux antérieurs}

Durant les fouilles programmées de la mission archéologique du Musée Pouchkine des Beaux-Arts de Moscou sur le site de Panticapée - actuelle Kertch en Crimée (Ukraine) -, des secteurs importants du territoire de la ville avaient été étudiés sur la colline dite du Premier Trône sur le Mont Mithridate (fig. 2), sur la pente Nord-Est de celui-ci, ainsi que sur le plateau Ouest : ces fouilles avaient permis de mettre en lumière, sur de larges surfaces, les spécificités stratigraphiques de ce secteur central important de la ville et d'analyser les vestiges architecturaux depuis le $\mathrm{VI}^{\mathrm{e}} \mathrm{s}$. av. J.-C. jusqu'aux premiers siècles de notre ère. Dans une grande mesure, on avait également déterminé les limites de l'acropole et observé l'évolution de la construction de ce territoire aux différentes étapes de la longue histoire de Panticapée.

\section{Travaux récents}

Sont présentés ici, après un bref rappel sur les sources écrites, les principaux résultats de l'étude de l'un des secteurs de l'acropole de Panticapée, appelé "Plateau Ouest du Premier Trône " (fouilles dites " centre " et " centre Nord "), sur lequel se sont concentrés les efforts récents de la mission (fig. 3).

Polyen $^{8}$ a perpétué la tradition selon laquelle Leukôn I ${ }^{\text {er }}$, dynaste bosporan ayant régné de 389/8 à $349 / 8$ av. J.-C., disposait d'une résidence à Panticapée, appelée "palais " dans le texte ( $\beta \alpha \sigma i ́ \lambda \varepsilon t \alpha)$. Selon Diodore de Sicile? , les rois du Bosphore avaient leur résidence permanente à Panticapée, où vécut Prytanos, fils du défunt roi Pairisadès $\mathrm{I}^{\text {er, }}$, qui avait disputé le pouvoir royal à son frère Eumélos lors d'un combat armé. La description des circonstances de la mort d'Eumélos qui régna, selon Diodore, cinq ans et cinq mois $^{10}$, permet de conclure que la résidence royale, à nouveau appelée $\beta \alpha \sigma i ́ \lambda \varepsilon\llcorner\alpha$, se trouvait au sommet de la colline de Panticapée. Malgré leur caractère fragmentaire, les propos de Diodore montrent qu’à l'époque du règne de Prytanos et Eumélos, soit dans les années 310-303 av. J.-C., s'élevait au centre de Panticapée, sur l'acropole, une résidence royale monumentale. Strabon ${ }^{11}$ a laissé une description courte mais suggestive de Panticapée, qui certifie l'existence de l'acropole : "Panticapée se présente comme une colline, peuplée de tous côtés, d'un périmètre de 20 stades ; à l'Est, se trouvent un port et des docks qui peuvent accueillir une trentaine de navires; il y a également une acropole. "Le témoignage d'Appien ${ }^{12}$ renvoie l'image du plan en terrasses de l'acropole : le roi Mithridate VI Eupator, assiégé sur l'acropole par les insurgés, observait leurs opérations depuis la terrasse supérieure. Le récit des dernières années de la vie du roi permet de conclure qu'en 63 av. J.-C. l'acropole était encore suffisamment fortifiée et que, protégée par une garnison, elle pouvait soutenir un siège. Dion Cassius ${ }^{13}$ rapporte qu'à cette époque, sur l'acropole, se trouvait un palais dans lequel Mithridate régla ses comptes avec l'existence. Dans son roman édifiant Toxaris ou l'amitié, Lucien de Samosate ${ }^{14}$ livre le curieux témoignage selon lequel un temple était situé près du palais du roi du Bosphore. Cette rapide indication, qui remonte à des sources bosporanes, mérite l'attention. Enfin, l'existence à Panticapée de fonctionnaires spéciaux, chargés selon la tradition de l'administration de la résidence royale, est établie avec certitude par la documentation épigraphique des premiers siècles de notre ère.

8 Polyen, Strateg. VI 9, 2.

9 Diodore, $X \times 23,30-40$.

10 Diodore, XX 25, 25-30.

11 Strabon, VII 4, 4.
12 Appien, Mithr. 111.

13 Dion Cassius XXXVII 12.

14 Lucien, Tox. 50. 


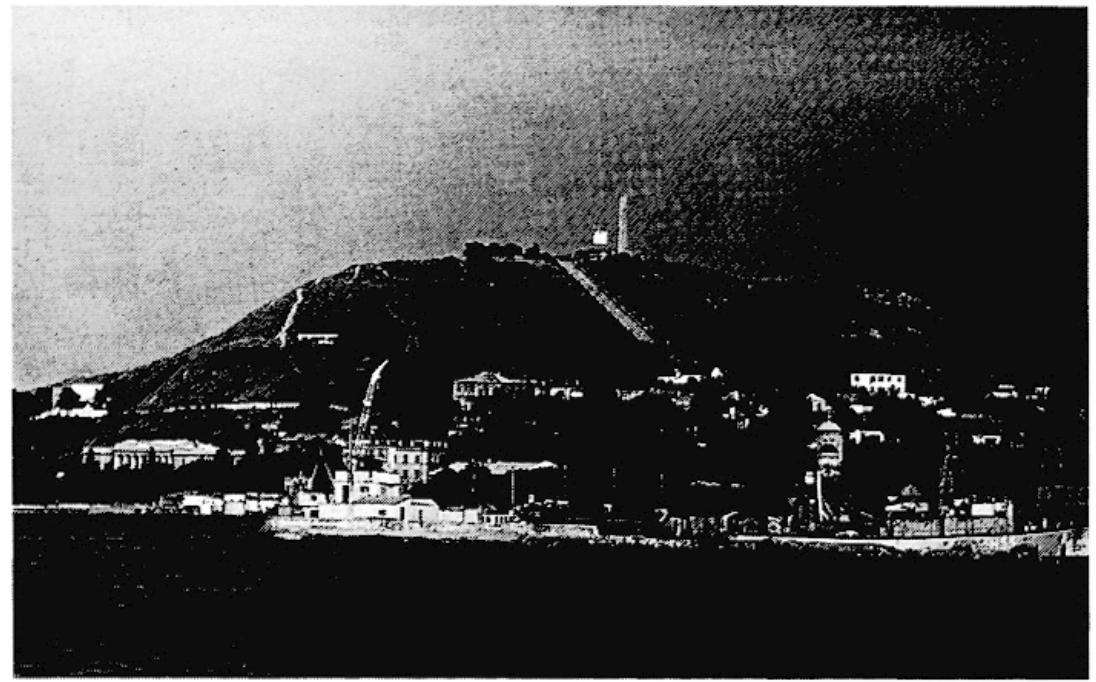

Flg. 2. L'acropole de Panticapée sur le Mont Mithridate. Vue depuis le Nord-Est.

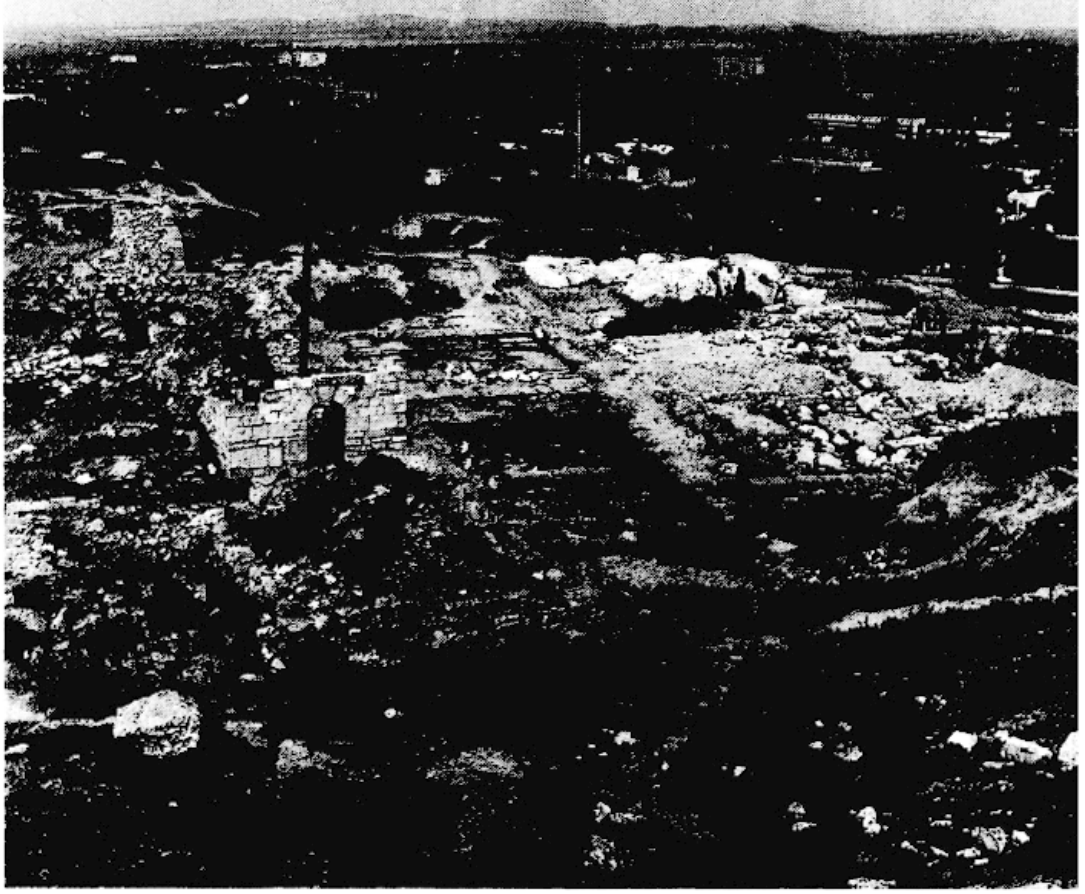

Fig. 3. Panticapée. Plateau Ouest de l'acropole. Fouilles du centre et du centre Nord. 
Malgré le portrait ainsi dressé de l'acropole, les sources écrites ne donnent aucune information sur les limites de celle-ci aux différentes périodes de la vie agitée de Panticapée, ni sur l'aspect architectural du palais des Spartocides. Seule l'archéologie peut répondre à ces questions.

Les plans et la description des auteurs $\mathrm{du}$ XIX ${ }^{\mathrm{e}}$ siècle permettent de conclure que le territoire de l'acropole comprenait, au-dessus des cotes $+80 /+81 \mathrm{~m}$, le plateau supérieur de la colline, sur le versant occidental de laquelle s'élève un rocher avec des traces de taille, le Premier Trône de Mithridate. Ce massif rocheux, d'une altitude de $92 \mathrm{~m}$, est le point culminant de l'acropole et de l'ensemble du site. Son versant occidental escarpé descend en direction du plateau Ouest, secteur relativement plat du Mont Mithridate, d'une altitude de 75-77 m. Les limites Est et Sud du plateau supérieur sont nettement dessinées par des versants naturels escarpés et, à certains endroits, par des rochers saillants. On y remarque encore des traces de taille qui ont servi de fondations aux fortifications, dont les vestiges ont été mis au jour par les fouilles de 1930-1931 sur le versant Sud du plateau supérieur, entre les cotes +68 et $+76 \mathrm{~m}$. La question de la limite occidentale de l'acropole était restée ouverte jusqu'à présent. Cette limite n'est pas indiquée sur les plans du XIX ${ }^{\mathrm{e}}$ siècle, car la ligne des fortifications avait déjà disparu à cet endroit. Seul un énorme massif rocheux, qui forme l'angle Nord-Ouest du plateau occidental, partiellement fouillé en 1886, laisse percevoir là les vestiges des fondations de l'une des tours, qui entrerait dans le système de défense du front Ouest des fortifications de l'acropole. Toute la surface de ce massif rocheux est soigneusement équarrie, ce qui lui donne l'allure d'une plate-forme rectangulaire. La face Ouest a la forme d'un muret vertical qui émerge de 2 à $3,5 \mathrm{~m}$ au-dessus du sol du versant pour une longueur connue de $21 \mathrm{~m}$. La hauteur de la face Nord atteint $8-9 \mathrm{~m}$.

Les fouilles de la mission actuelle ont montré que cette plate-forme rocheuse avait pu effectivement, dans l'Antiquité, constituer les fondations de la tour d'angle Nord-Ouest du plateau occidental (tour I). On a pu montrer récemment qu'un peu plus au Nord, plus bas sur le versant, se trouvait encore une tour (tour II), dont le rocher servant de fondations a pu être fouillé (fig. 4). À partir de cette tour, la ligne des fortifications avançait par redans vers le Nord en direction d'un autre massif rocheux situé à environ $80 \mathrm{~m}$. Cette

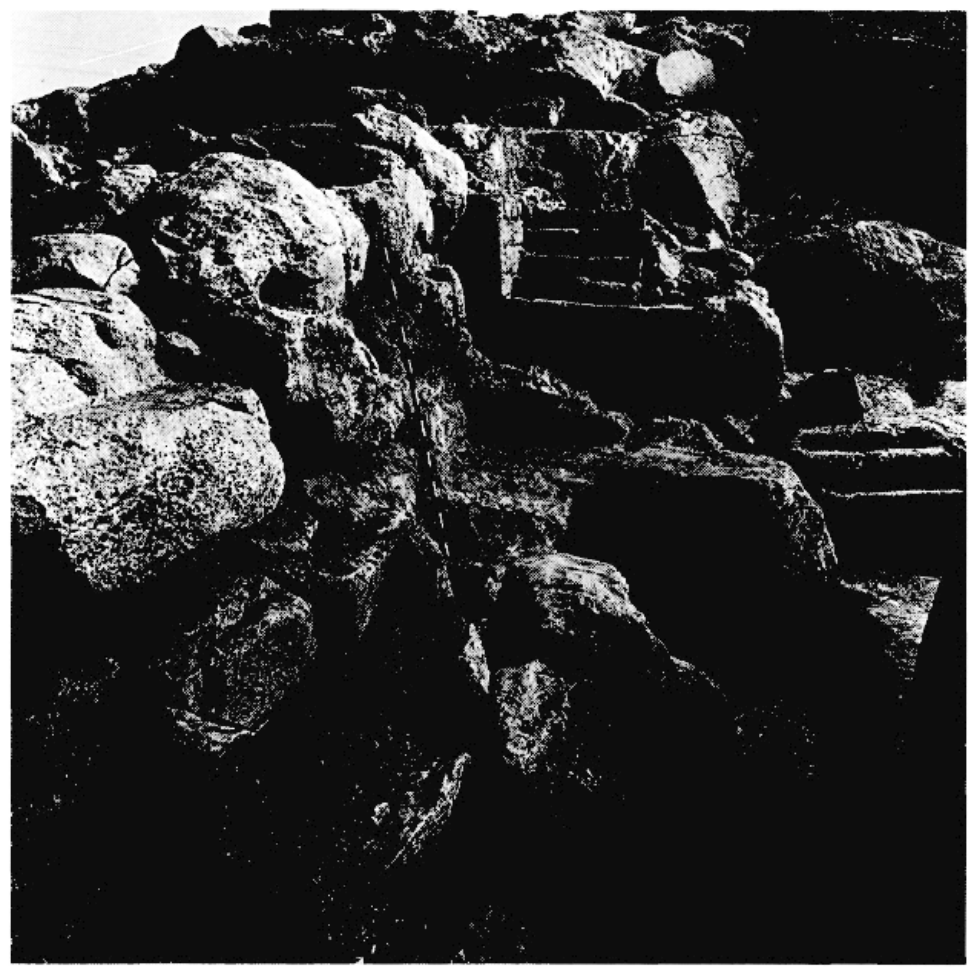

Fig. 4. Panticapée. Escalier de la porte de sortie de la tour II de l'acropole. Vue depuis le Nord. 


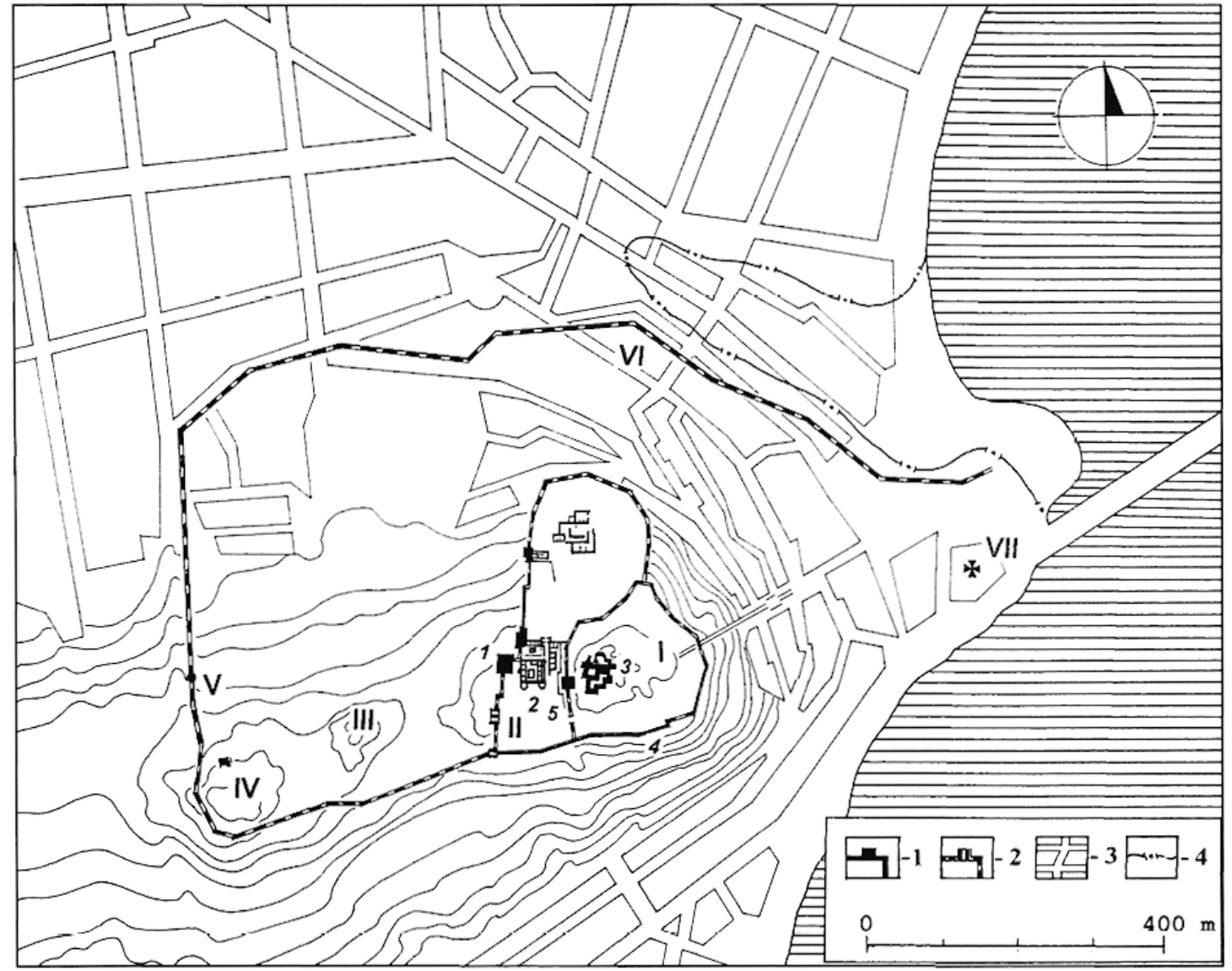

Fig. 5. Ibid. Schéma du système défensif de l'acropole à l'époque hellénistique.

émergence rocheuse servait également de fondations à une autre tour de l'acropole. Ces trois tours faisaient partie du système de défense du front Ouest des fortifications de l'acropole que l'on a pu, pour la première fois, préciser sur une longueur de $180 \mathrm{~m}$ (fig. 5). Découverte significative qui a montré que le territoire de l'acropole, à l'époque hellénistique, était au moins trois fois plus grand que ce que l'on supposait jusqu'alors. De plus, il est désormais avéré que toutes les constructions monumentales - dont, par exemple, le bâtiment à colonnade dorique découvert dans les années 1960 et considéré comme le "prytanée " (fig. 6) -, étaient situées à l'intérieur des limites de l'acropole, ce qui invite à considérer sous un nouvel angle la question de leur destination fonctionnelle.

Les fouilles ont montré que l'élément architectural le plus significatif du plateau Ouest de l'acropole à l'époque hellénistique est un ensemble de constructions couvrant une superficie d'au moins $1350 \mathrm{~m}^{2}$ (fig. 7), orientées selon les points cardinaux et qui occupent la totalité de la partie centrale. C'est là l'objet principal de notre recherche.

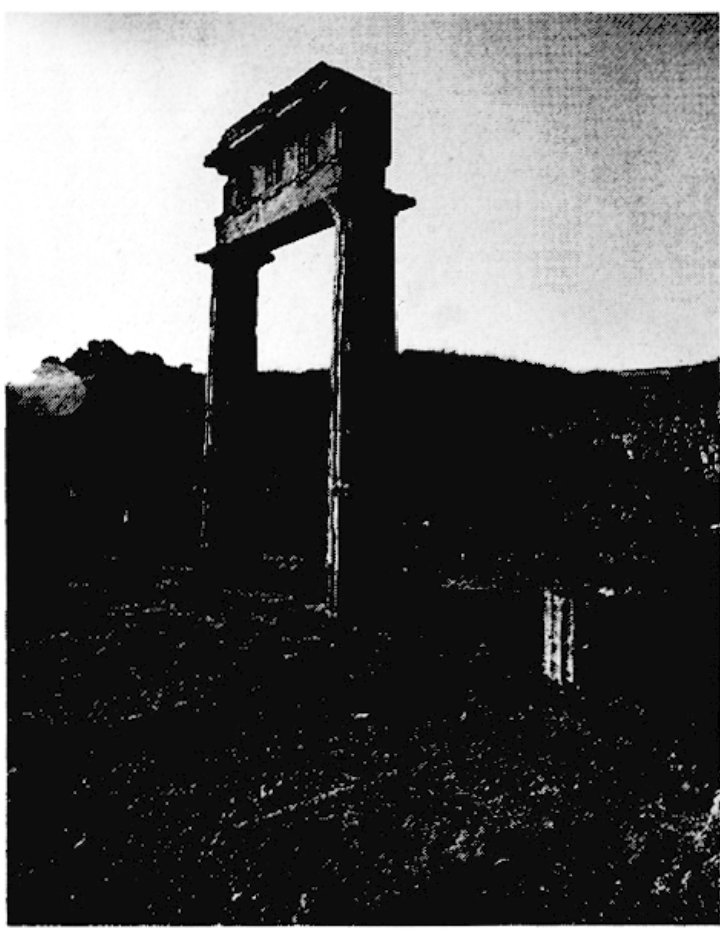

Fig. 6. Ibid. Prytanée. Élément de la colonnade de la cour à péristyle. Vue depuis l'Est. 


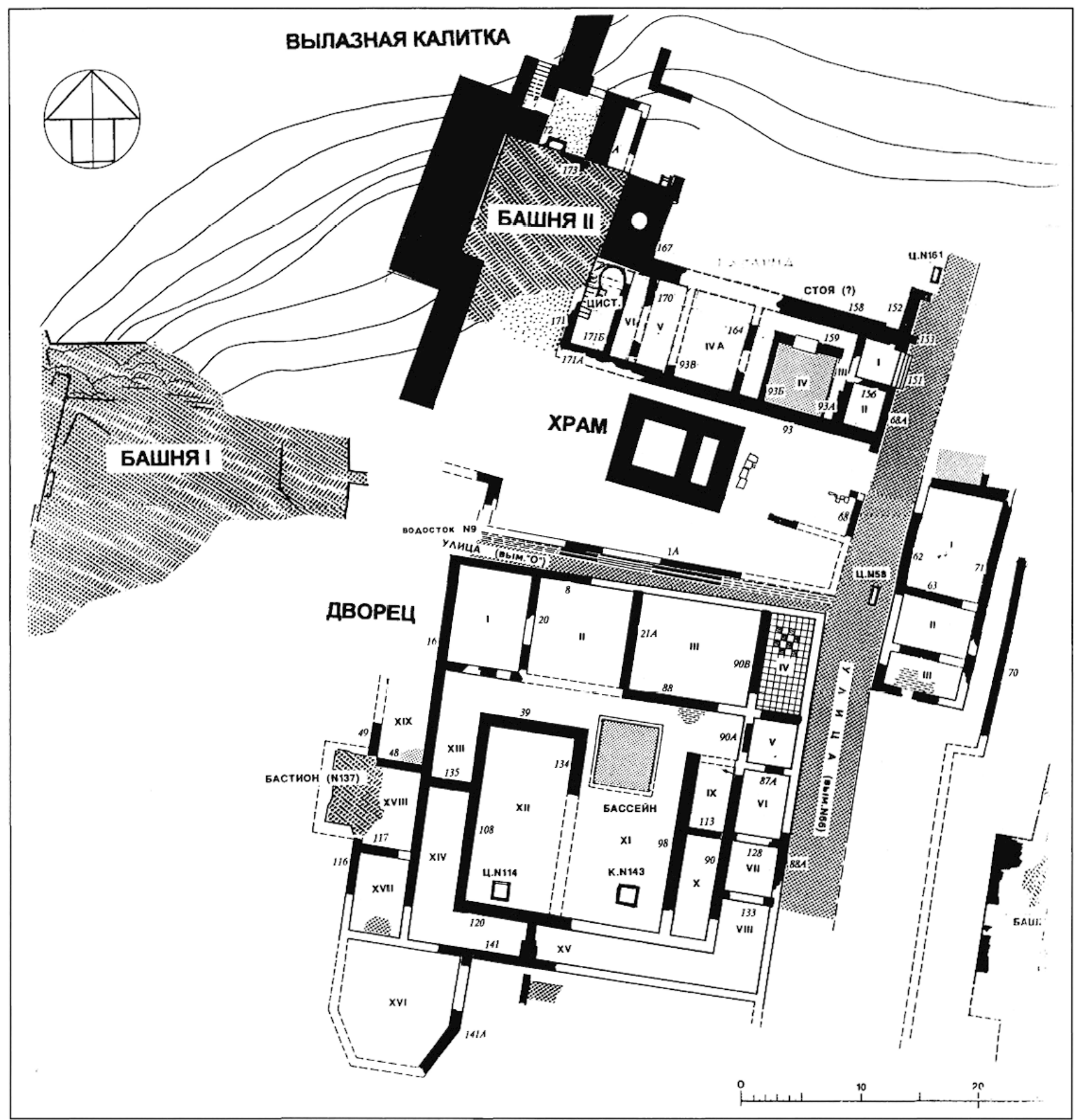

Fig. 7. Panticapée. Plan des constructions d'époque hellénistique sur le plateau Ouest de l'acropole. 


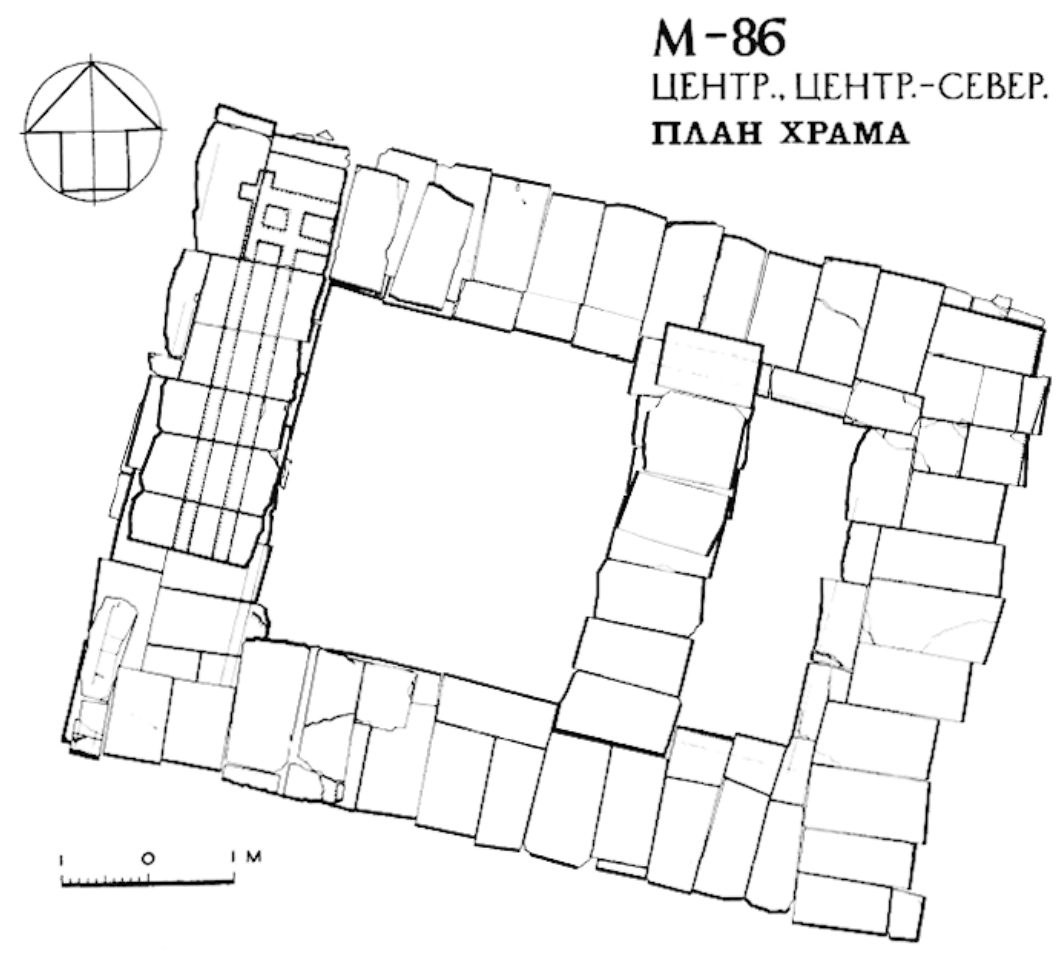

Fig. 8. Ibid. Plan des fondations du temple à antes du palais.

Les vestiges de cet ensemble sont associés à des couches contenant du matériel de la seconde moitié du II $^{\mathrm{e}}$ s. av. J.-C., mais les fondations, qui s'enfoncent jusqu'au sol vierge, traversent une couche du troisième quart du IV $\mathrm{I}^{\mathrm{e}} \mathrm{s}$. av. J.-C. et recoupent aussi plus bas des couches antérieures. La période d'existence de ce complexe est comprise à l'intérieur de ce cadre chronologique. Il est clair que ce complexe déterminait l'ensemble de la structure architecturale de ce secteur de l'acropole, puisqu'il en constituait l'élément dominant. Le plan de toutes les autres constructions et la direction des rues sont subordonnés à son plan rectangulaire.

A l'Est du complexe central, de l'autre côté de la rue, était situé un bâtiment dont le plan était fortement étiré dans le sens Nord-Sud, c'est-à-dire dans le sens des rues. Ce bâtiment rectangulaire, dont les dimensions étaient environ de $8 \times 18 \mathrm{~m}$, se composait de trois pièces, avec entrée au Sud. Les nombreux fragments d'enduit polychrome découverts dans la pièce Nord témoignent de la large utilisation de ce type de décor dans le bâtiment.

$\AA$ environ $7 \mathrm{~m}$ au Nord du complexe central, les fouilles ont révélé les fondations rectangulaires d'un petit temple à antes d'ordre dorique très bien conservé, dont les dimensions en plan étaient de 10,5 x 7,4 m (fig. 8). Le temple était orienté selon un axe O-NO/E-SE et doté d'une façade orientée à l'Est. La partie conservée des fondations du temple forme une construction monumentale composée de plusieurs assises épaisses de blocs de calcaire soigneusement équarris et ajustés sans mortier, enfoncées dans le sol vierge et, en partie, dans une couche comportant du matériel des VI $\mathrm{IIV}^{e}$ s. av. J.-C. On peut raisonnablement supposer que l'on avạit placé des poutres en bois goudronné dans les rainures spéciales creusées dans les blocs supérieurs des fondations de ce temple, pour assurer ainsi une plus grande solidité à toute la construction. On peut parler d'une construction de type antisismique (fig. 9).

En ce qui concerne les bâtiments de la fin du IV $\mathrm{V}^{\mathrm{e}}$ s. av. J.-C. et de la première moitié du $\mathrm{II}^{e} \mathrm{~s}$. av. J.-C., il convient de s'arrêter également sur un autre bâtiment, étudié dans son intégralité ces dernières années. Il fermait l'ensemble du côté Nord et était long de $27 \mathrm{~m}$ pour une largeur de $10 \mathrm{~m}$. L'entrée se trouvait du côté de la façade orientale en bois et donnait sur la rue. Un escalier monumental de trois marches menait à 


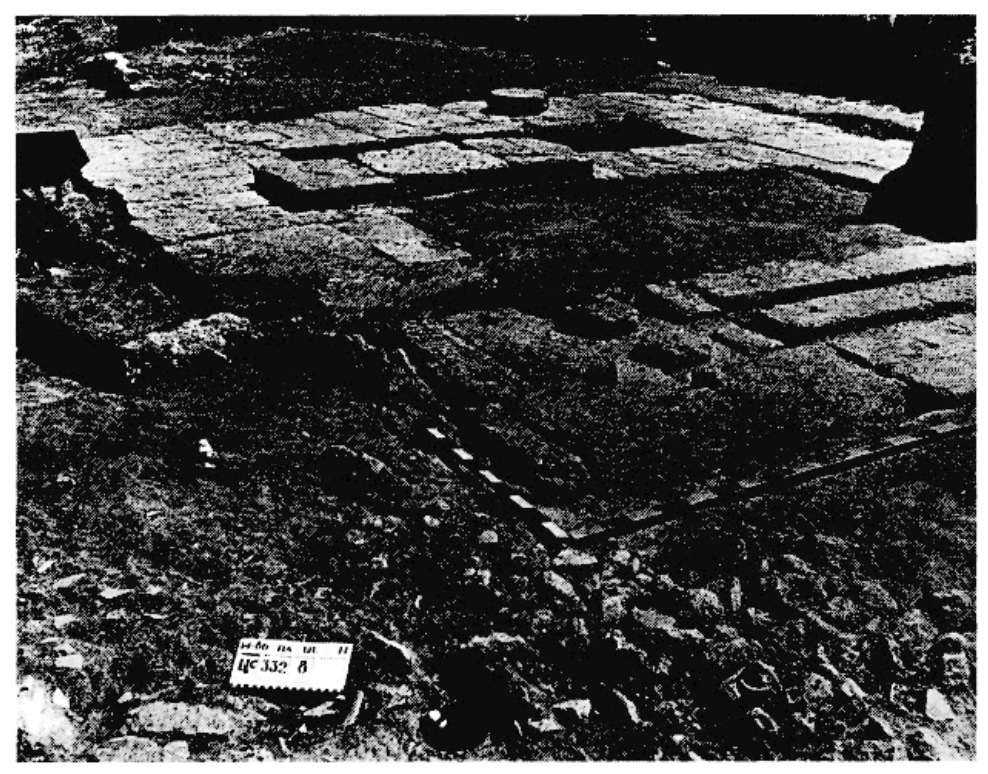

Fig. 9. Panticapée. Rainures destinées aux poutres dans les fondations du temple. Vue depuis le Nord-Ouest.

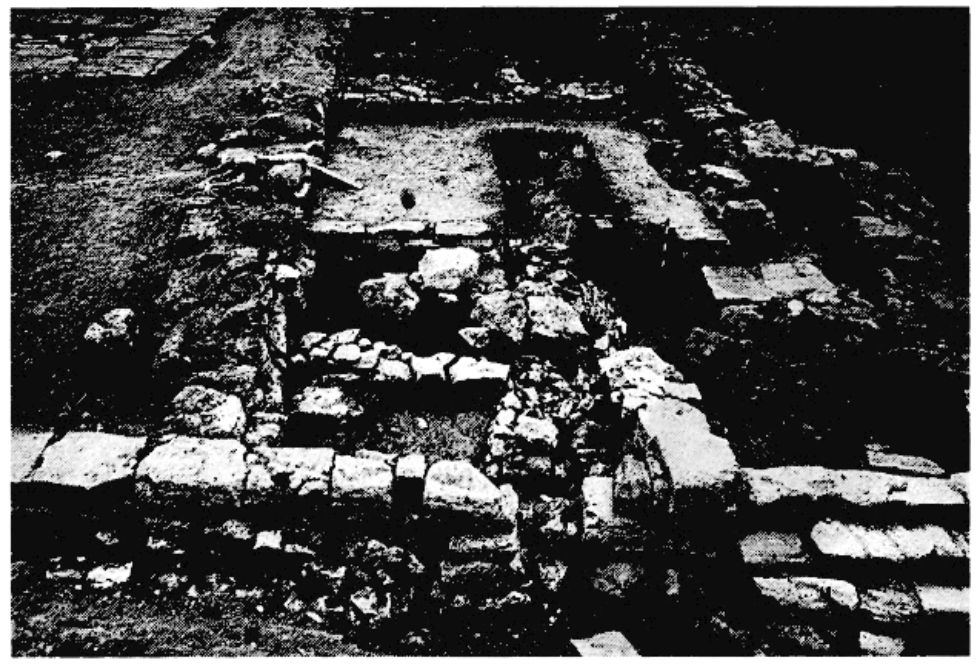

Fig. 10. Ibid. Porte d'entrée de la caserne. Vue depuis l'Est.

une baie de $3 \mathrm{~m}$ formant l'entrée (fig. 10). Cette baie précédait un vestibule pavé de dalles (pièce I) et plus loin étaient disposés des locaux contigus. Dans le dernier d'entre eux (pièce VI), qui jouxtait à l'Est la tour II déjà mentionnée, se trouvait une chambre souterraine destinée à la distribution de l'eau avec puits et citerne (fig. 11). On peut voir dans cette construction une caserne destinée à une garnison qui défendait la tour et ce secteur de l'acropole.

Il est significatif que les éléments principaux des fortifications de l'acropole soient intrinsèquement liés, en termes de plan, au système unique de tracé des constructions déjà citées.

Pour en revenir au complexe central, le bâtiment dessinait en plan un rectangle régulier et possédait des murs extérieurs à bossage reposant sur des fondations massives (fig. 12). Il comportait au moins deux étages et disposait d'une cour à péristyle entourée d'une colonnade, d'ordre dorique au rez-de-chaussée, ionique à l'étage. Enfin, il était pourvu d'un système d'approvisionnement en eau soigneusement construit et agencé, qui comprenait un bassin destiné à récolter l'eau et un puits de $12 \mathrm{~m}$ de profondeur. 
M-95 4.- С.

пл. 297-298; 299-300

$\frac{0.00}{0.00}$

4 CEBEP

цистерна №176

фасировка стен

sarma $>4$ ior
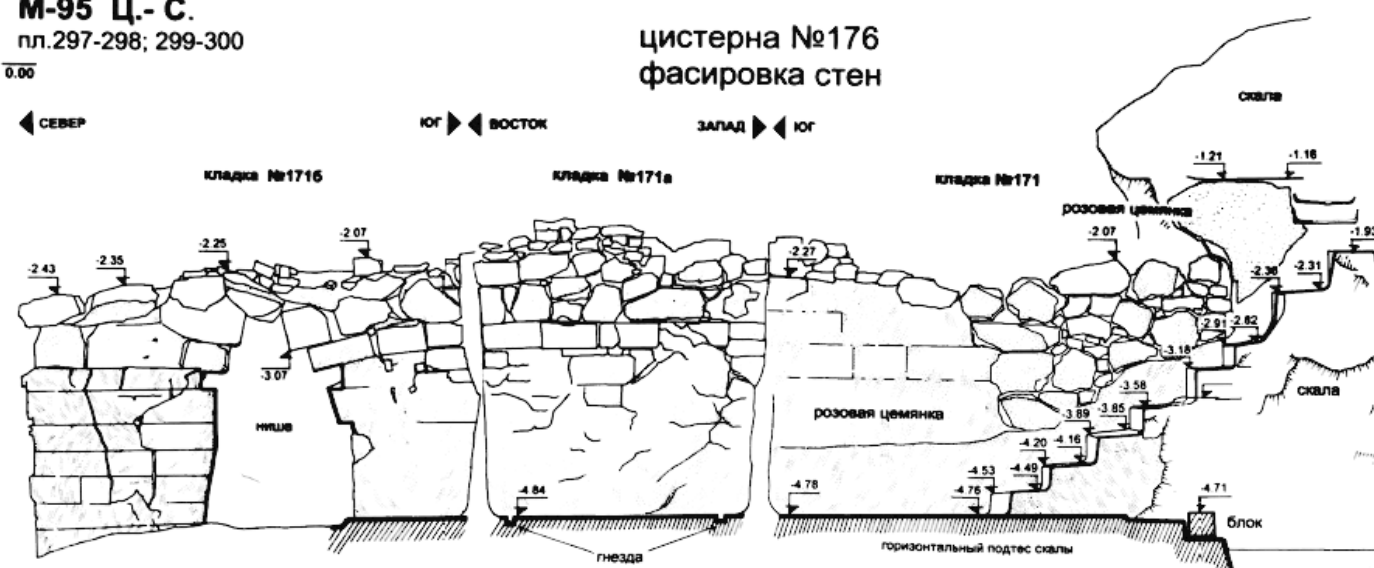
unace minis
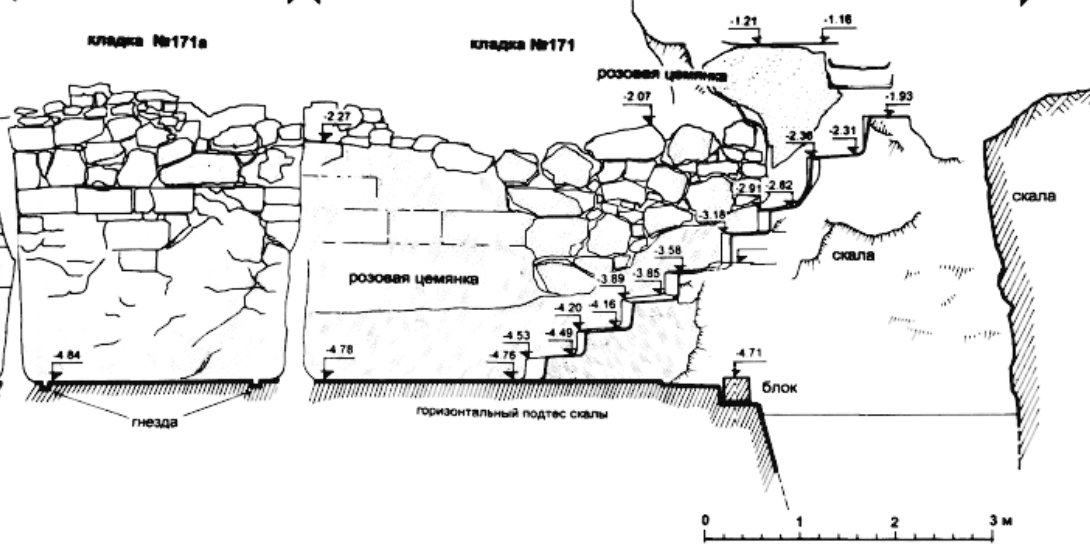

$\overline{0.00} \quad \overline{0.00}$

CEBeP

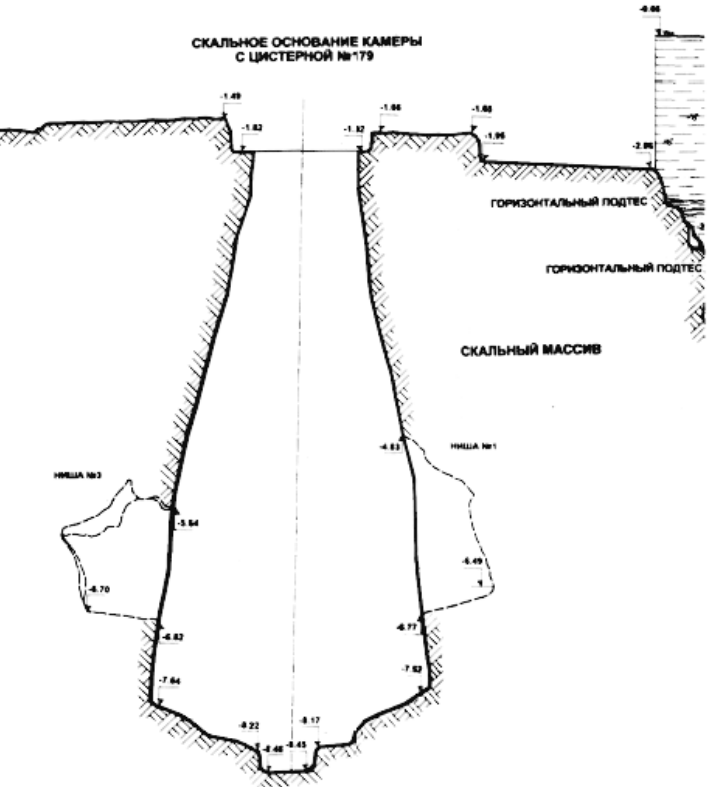

Fg. 11. Ibid. Chambre de distribution d'eau de la caserne. Murs et coupe de la citerne de la tour II. 


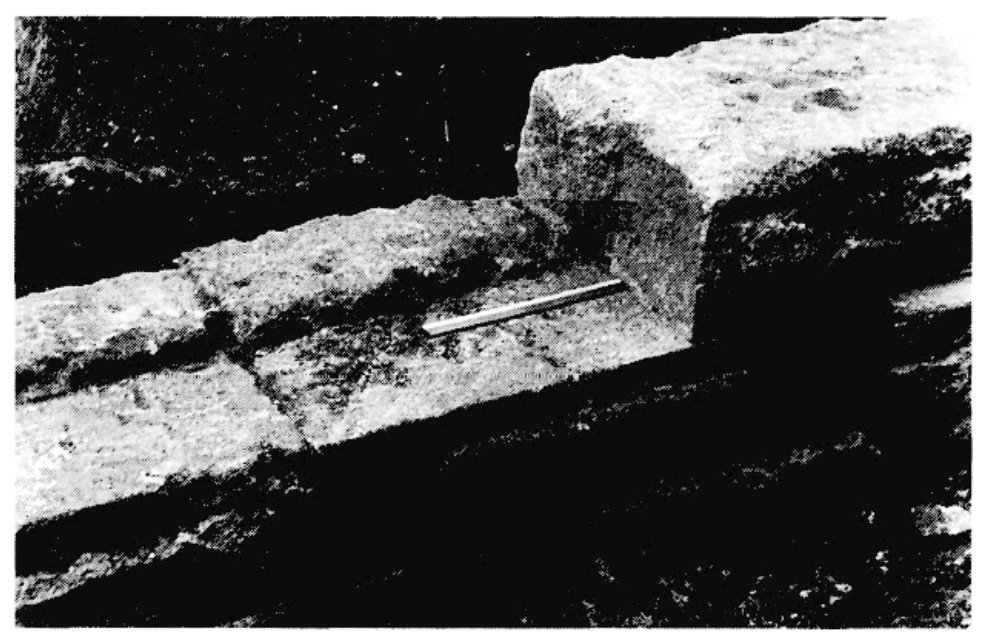

Flg. 12. Panticapée. Tronçons d'une assise du mur Nord du palais. Vue depuis le Nord-Est.

La position dominante de ce complexe au centre de l'acropole, sur le plateau occidental lui-même très fortifié, ses dimensions considérables, la présence largement attestée en cet endroit d'éléments de différents ordres et de splendides pièces de sculptures en marbre (fig. 13), permettent de considérer cette construction comme le palais des Spartocides, rois du Bosphore, mentionné par plusieurs sources.

Au cours des fouilles du palais, on a découvert, aussi bien dans les limites de celui-ci (au sein de sa couche de destruction) que dans le voisinage immédiat (en remploi dans des constructions postérieures), des éléments ou des fragments d'ordre architectural se rapportant à la construction étudiée. Leur étude permet de reconstituer de façon substantielle la disposition du bâtiment. Cette reconstitution se fonde sur deux principes : d'une part, la constance des relations de proportion au sein d'une période donnée; d'autre part, l'analyse proportionnelle des fragments d'ordre d'après l'étude de constructions conservées du même ordre et proches dans le temps.

La cour à péristyle, élément-clé de la structure, constitue le point de départ de la reconstitution graphique. Dans la mesure où nous disposons des fondations de la colonnade sur la presque totalité de son périmètre et de la dalle angulaire Sud-Ouest du stylobate avec la marque de

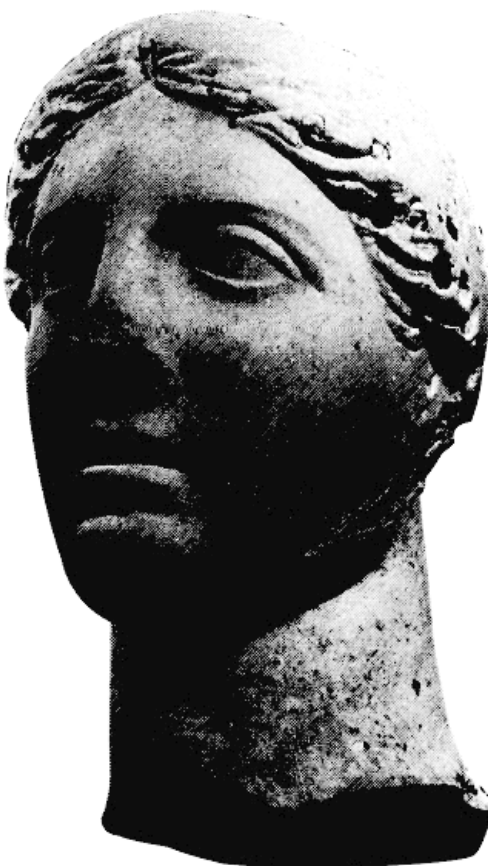

Fig. 13. Ibid. Tête de déesse en marbre provenant du palais. la colonne, nous pouvons restituer la colonnade dorique entourant la cour. L'assise de fondations du long côté du péristyle s'étendait sur 16,20 m et celle du petit côté sur $9,70 \mathrm{~m}$, pour une largeur de $1,10 \mathrm{~m}$ d'après les fondations conservées. La largeur des dalles du stylobate oscillait entre 0,80 et $0,85 \mathrm{~m}$.

L'une des tâches essentielles de la reconstitution est la mise en évidence de la valeur métrique de référence utilisée par l'architecte pour le bâtiment. Le diamètre de la trace de colonne, qui est d'environ $66,5 \mathrm{~cm}$, peut servir de clé. Les études de constructions bien conservées et servant d'étalon en Méditerranée ont permis de mettre en évidence des valeurs métriques précises de longueur (en pieds), utilisées par les Grecs.

Si l'on compare la valeur numérique du diamètre de la colonne susnommée avec les valeurs connues du pied, il est évident qu'aucune d'entre elles ne s'accorde avec l'exemple en question. Par conséquent, il 


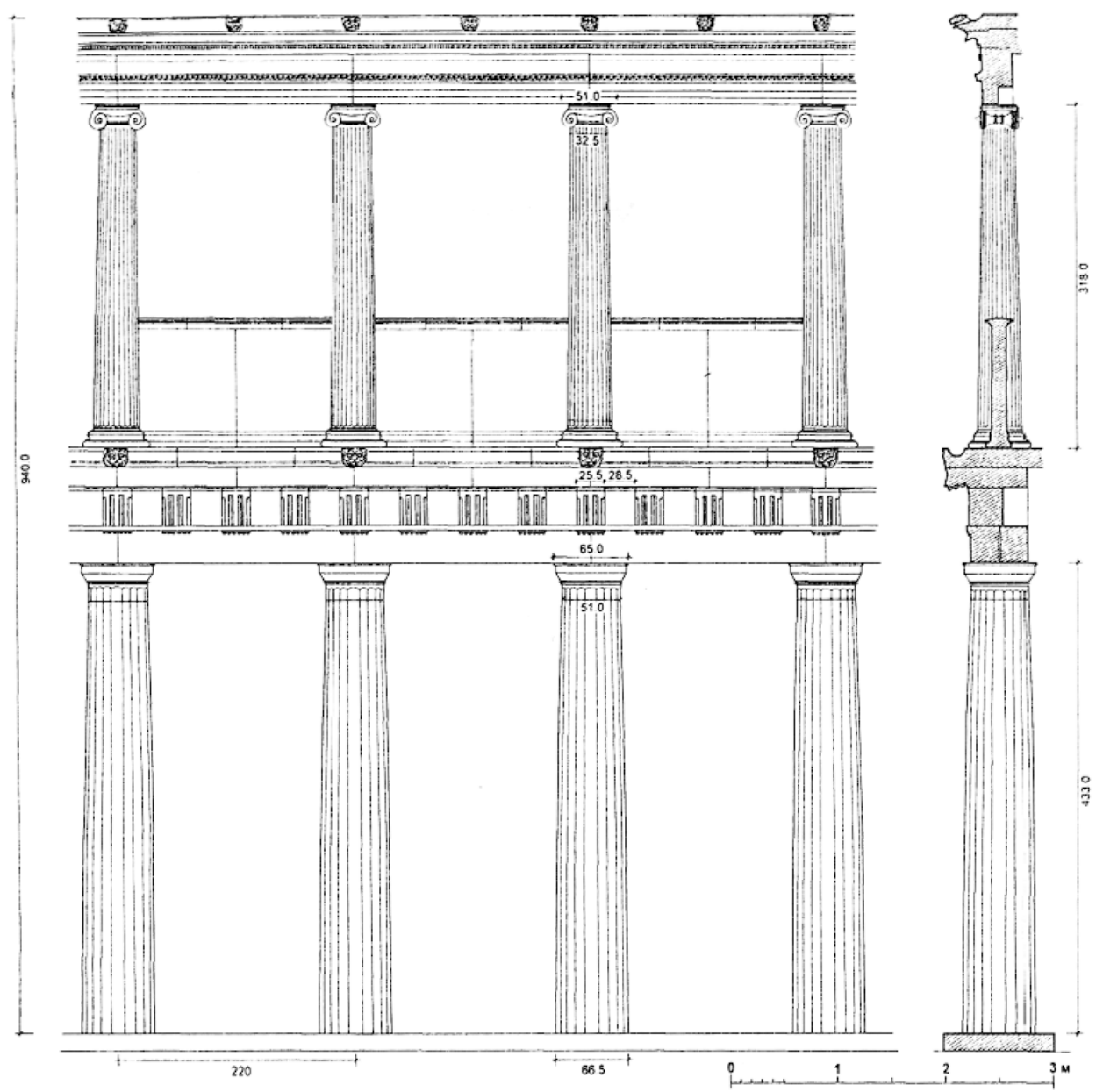

Fig. 14. Ibid. Reconstitution de la colonnade du péristyle du palais ( $2^{\circ}$ état).

convient dans ce cas de chercher une autre unité de mesure, comme le dactyle par exemple. Les calculs montrent que celui qui convient le mieux est le dactyle (d) dit du " du petit pied ionien $(29,9 \mathrm{~cm})$ ", soit environ $1,87 \mathrm{~cm}$. Dans ce cas-là, le diamètre inférieur de la colonne est égal à 35,5 dactyles.

Les éléments d'ordre ionique, de taille relativement faible, et plus précisément des fragments de base, un chapiteau, des parties d'entablement et un fragment de couronnement d'une balustrade de clôture, prouvent qu'il existait un étage d'ordre ionique. Les calculs montrent qu'il pouvait atteindre $4 \mathrm{~m}$ de haut avec l'entablement.

Ayant déterminé une hauteur théorique de $433 \mathrm{~cm}$ pour la colonnade dorique de l'étage inférieur et examiné les fragments d'entablement et les détails de l'ordre ionique de l'étage supérieur, nous sommes en mesure de proposer un schéma de restitution pour la colonnade de la cour à péristyle du palais (fig. 14).

Les colonnades à deux étages de ce type sont largement répandues dans les riches demeures et complexes palatiaux des $\mathrm{III}^{\mathrm{e}}-\mathrm{II}^{\mathrm{e}}$ s. av. J.-C. On peut citer, comme parallèles, le palais macédonien d'Aigai, les complexes palatiaux de Pergame et les péristyles des maisons de Délos.

Le matériel des fouilles permet de supposer que, dans son premier état, le palais était de dimensions modestes et ne comportait, probablement, qu'un péristyle dorique à un étage. Vers le milieu du III s. av. J.-C., après la destruction du palais consécutive à un violent tremblement de terre, celui-ci fut reconstruit ; c'est dans ce second état que le péristyle fut doté d'une colonnade à deux étages et que la superficie totale du palais fut plus que doublée (fig. 15). 
Fg. 15. Panticapée. Reconstruction axonométrique du palais des Spartocides sur l'acropole. Vue depuis le Nord-Ouest (dessin V. Tolstikov).

Vers le milieu du II s. av. J.-C., le palais subit à nouveau des réparations qui, toutefois, ne furent pas menées à terme. Alors qu'il était en pleine restauration, il fut détruit de fond en comble et ne retrouva jamais son aspect originel.

\section{Conclusion}

En guise de bilan, on proposera quelques remarques relatives aux circonstances de la destruction du palais et aux problèmes de sa chronologie.

La seconde période d'activité du complexe palatial s'est achevée, comme on l'a noté, par la destruction complète de celui-ci. Cette catastrophe intervint vers le milieu du II ${ }^{\mathrm{e}} \mathrm{s}$. av. J.-C. et s'accompagna d'un incendie dont on observe les traces avant tout dans la partie Sud-Ouest. La destruction eut lieu alors que d'importants travaux de reconstruction concernaient la colonnade du péristyle. On avait préparé, dans cette perspective, des tambours de colonnes. La nouvelle colonnade utilisait ces tambours non terminés et les fûts 
de colonnes de la période antérieure retravaillés. La présence de marques verticales sur les côtés des tambours inachevés ainsi que les trous creusés au centre des tores indiquent précisément que ces tambours étaient déjà en place au moment de la destruction. Les colonnes étaient probablement couronnées de chapiteaux, sur les échines desquels avaient été peintes en rouge des marques de cannelures. Il restait à achever l'équarrissage et les stucs. Mais, au stade final de sa réparation, le palais fut détruit et brûlé. Les éléments d'ordre, les tambours non achevés, les éclats de tuiles et les fragments de sculptures en marbre furent jetés dans un puits. Les ruines du palais servirent rapidement de carrière et, sur les fondations restantes, on érigea des constructions plus petites. Les raisons de la destruction du palais et les événements de l'histoire du Bosphore liés à cette destruction devront faire l'objet d'une recherche particulière [V. Tolstikov ${ }^{15}$ ].

— Fouilles de sauvetage conduites en 1992 à la limite Nord-Ouest du site (au Sud de la rue Tche$l o v$ ), où l'on voyait d'ordinaire la frontière occidentale de l'acropole: les fouilles y ont révélé des vestiges d'habitation, dont deux murs, d'époque hellénistique et romaine (III $-\mathrm{I}^{\mathrm{er}} \mathrm{s}$. av. J.-C.), premiers vestiges de ce type dans ce secteur. La deuxième fouille (programmée) s'est poursuivie sur le site dit Osoviny I, sur la deuxième terrasse du cap Varzovka, à $900 \mathrm{~m}$ de la mer d'Azov, et a mis au jour deux séries de murs superposées, l'une datant de l'époque médiévale et la seconde des $\mathrm{I}^{\mathrm{er}}-\mathrm{II}^{\mathrm{e}} \mathrm{s}$. ap. J.-C. BS 4 (1994), p. 153-158.

\section{Nymphaion}

- En 1992, le musée de l'Hermitage a créé, à Nymphaion, une nouvelle mission archéologique avec, pour objectifs, la prospection du territoire de la cité et l'établissement de la carte archéologique, la fouille du site de Geroevka 2 et l'exploration de la nécropole, mission dont les travaux, menés entre 1992 et 1995, ont fait l'objet de différents comptes rendus. L'exploration de la frontière occidentale de la cité permet de considérer que les sites Ogonki 1 au Sud et Churubash 1 au Nord, situés chacun à la source d'une rivière, contrôlaient la partie Ouest de la chôra. Mais l'essentiel des sites ruraux est localisé en bord de mer, comme celui de Geroevka 2, découvert lors des prospections des années 1950-1970 à 1,7 km au Sud du village actuel d'Eltigen et fouillé de 1992 à 1994 sur une superficie de plus de $600 \mathrm{~m}^{2}$. Les travaux ont révélé deux phases (IVe s. av. J.-C. et IVe-VII ${ }^{e}$ s. ap. J.-C.). Les vestiges du IV $V^{e}$ s. av. J.-C. (dont deux cabanes semienterrées, une série de fosses domestiques et un kourgane), qui formaient sans doute un domaine appartenant à une seule grande famille, ne présentent pas des traits typiquement grecs. Enfin, la fouille de la nécropole de la ville elle-même, qui a couvert environ $600 \mathrm{~m}^{2}$, a révélé 42 tombes dont la moitié avait été pillée. Ces tombes, généralement à fosse, sont datées entre la fin du $\mathrm{VI}^{\mathrm{e}} \mathrm{s}$. av. J.-C. et les premiers siècles ap. J.-C. et abritent des squelettes d'adultes, mais aussi trois squelettes d'enfants. La nécropole fut recouverte par des habitations au début de l'époque médiévale. BS 4 (1994), p. 159-163 et $A V 5$ (1998), p. 187-204.

- Fouilles de sauvetage de la nécropole en 1994, menées par la mission archéologique locale de Kertch. Le secteur étudié $(80 \times 60 \mathrm{~m})$, largement pillé par les fouilleurs clandestins, est situé à l'Ouest du site et a fait l'objet d'un relevé topographique préalable à la fouille. On y a mis au jour 16 tombes, les vestiges de 3 dépôts de repas funéraires, ainsi qu'une fosse dans le rocher d'une profondeur d'au moins $3 \mathrm{~m}$. Les tombes sont de quatre types : on compte 7 tombes à fosse sans couverture, d'orientations et d'époques diverses ; 5 tombes à fosse couverte de dalles de pierre et, dans un cas, de tuiles du Bosphore ; 2 tombes à ciste couvertes et, surtout, 2 tombes creusées dans le rocher et situées dans l'ouverture déjà mentionnée. 
Dans l'une d'elles, se trouvait une monnaie bosporane datée des années 375-340 av. J.-C. L'espace entre les tombes s'est révélé beaucoup plus riche en matériel que les tombes elles-mêmes, puisqu'on a constaté la présence de 7 poches bourrées de fragments amphoriques et de plats à vernis noir, dont l'une contenait des fragments de cratère (430-420 av. J.-C.) et d'askos à figures rouges portant tous deux le graffito BAT. Cet espace peut être considéré comme un endroit où l'on dressait un foyer devant une tombe. Les tombes datent, pour la plupart, des $\mathrm{V}^{\mathrm{e}}$-III ${ }^{\mathrm{e}} \mathrm{s}$. av. J.-C. et quelques-unes des premiers siècles de notre ère. V. KUTAISOV (éd.), Recherches archéologiques en Crimée en 1994 (1997), Simphéropol, Publication de l'IA de l'Académie des sciences d'Ukraine, p. 8-10.

- Dans un article de synthèse sur la chôra de Nymphaion du $\mathrm{VI}^{\mathrm{e}}$ au IV $\mathrm{IV}^{\mathrm{e}}$ s. av. J.-C., publication de l'un des 21 kourganes de Tcheliadinovo-Est, au Nord-Ouest de Geroevka 1, kourganes cartographiés en 1995. Le kourgane $\mathrm{n}^{\circ} 16$ (diam. $8 \mathrm{~m}$, haut. $0,65 \mathrm{~m}$ ) recouvrait une tombe orientée Est-Ouest, formée de blocs calcaires parfaitement travaillés et ajustés et couverte de deux dalles, selon un modèle répandu dans les nécropoles bosporanes et, entre autres, à Nymphaion. La tombe renfermait le squelette d'une femme d'environ 55/60 ans et le matériel mis au jour (fragments de lécythes à vernis noir, pointes de flèches, etc.) permet de dater la tombe de la première moitié du IVe s. av. J.-C. À l'Ouest de cette tombe, se trouvent les vestiges d'un tombeau en pierre à dromos daté de la deuxième moitié du IV $\mathrm{V}^{\mathrm{e}}$ s. av. J.-C. La présence, au sein du même kourgane, de six tombes à fosse supplémentaires indique qu'il s'agit là d'un tombeau de famille utilisé par au moins deux générations au cours du $\mathrm{IV}^{\mathrm{e}} \mathrm{s}$. av. J.-C. Le matériel découvert, qui comporte des éléments grecs et barbares, témoigne peut-être d'un mélange ethnique. $D B 1$ (1998), p. 86-104.

\section{Myrmékion}

Publication d'une cabane semi-enterrée découverte en 1951 dans la fouille $\mathrm{C}$ : la cabane, quadrangulaire, disposait d'une superficie utile de $5,50 \mathrm{~m}^{2}$ et s'enfonçait de $0,60 \mathrm{~m}$ sous le niveau du sol vierge. Les parois en étaient revêtues de pierres, ce qui constitue une particularité notoire de sa construction. Le matériel découvert permet de dater la période d'utilisation de la cabane du deuxième quart à la fin du VI $s$. av. J.-C. BS 4 (1994), p. 59-64.

\section{La chôra du Bosphore en Crimée orlentale}

\section{Situation géographique et travaux antérieurs}

L'étude archéologique des monuments de la chôra de la partie européenne de l'État du Bosphore (actuelle Péninsule de Kertch) n'a commencé véritablement que dans les années 1950. Depuis 1975, ces travaux sont poursuivis par la mission de l'Institut archéologique de l'Académie des sciences pour la Crimée Orientale. Il s'agit de recherches complexes, menées sur plusieurs plans, qui portent sur des objets de types et d'époques divers et ont pour but la reconstitution la plus complète et la plus large possible de l'histoire de la chôra de cet État. Ainsi, une attention particulière est accordée à l'organisation du territoire rural, à la typologie et à la chronologie des sites, à la composition ethnique et à la culture de la population locale, aux capacités de production et aux relations commerciales de la région, aux particularités de la paléogéographie et de la paléoécologie, à l'établissement de cartes archéologiques et à l'application à cette recherche des méthodes de prospection issues des sciences naturelles. 
Depuis 1975, ont été mises au jour plusieurs dizaines d'objets archéologiques — sites et nécropoles - dont une grande partie a fait l'objet de fouilles plus ou moins poussées. Ainsi, dans six enclos funéraires allant du $\mathrm{VI}^{\mathrm{e}}$ s. av. J.-C. au VI $\mathrm{VI}^{\mathrm{e}}$. ap. J.-C. ont été exhumées plus de 350 tombes de formes diverses, faisant intervenir de nombreux rituels funéraires distincts, grecs comme barbares. On a fouillé, sur une vaste étendue atteignant jusqu'à $3500 \mathrm{~m}^{2}$ (et parfois dans leur intégralité), des fermes et des villages barbares d'époque hellénistique, des sites fortifiés de l'hellénisme tardif, des postes de garde, des petites forteresses et des sites divers des premiers siècles de notre ère jusqu'aux $\mathrm{III}^{\mathrm{e}}-\mathrm{IV}^{\mathrm{e}} \mathrm{s}$. ap. J.-C. Parmi les objets les plus significatifs mis au jour, on retiendra un important trésor monétaire du Irr $s$. av. J.-C. et environ 700 monnaies essentiellement bosporanes d'époques différentes; plusieurs centaines de graffiti; des statuettes en terre cuite entières ou fragmentaires; une collection significative de timbres amphoriques (env. 3500 ) et une série d'autres objets rares et importants sur le plan culturel et chronologique.

\section{Travaux récents}

Des fouilles particulièrement intensives ont été et sont encore menées dans le secteur de la Crimée proche de la mer d'Azov, où se concentre un grand nombre de sites assez bien conservés. Les quatre dernières missions de terrain, de 1994 à 1997, se sont focalisées sur les points suivants : un complexe rural de la fin du IVe-premier tiers du III ${ }^{e}$ s. av. J.-C. sur le site nommé Baklanja Skala; un établissement des premiers siècles de notre ère, Zelenyj Mys; la nécropole d'un autre site de la même époque, Sirenevaja Bukhta; et enfin une prospection sur les levées de terre à but défensif d'époque antique, connues sur la Péninsule.

Toures les étapes du travail sur la ferme de Baklanja Skala ont été précédées par des mesures géophysiqucs soigneuscs, pcrmettant avant le début des fouilles de mettre en lumière les anomalies principales dans les constructions, les accumulations de cendres, les foyers, etc. La superficie étudiée ici a été d'environ $1600 \mathrm{~m}^{2}$. Il est apparu que la ferme (fig. 16) consistait en trois groupes principaux de constructions. Le premier se présentait comme un assez grand bâtiment $(20 \times 14 \mathrm{~m})$, dont les murs extérieurs, appareillés avec soin, étaient épais de 1,20 m et atteignaient par endroits une hauteur de 2,20 m. L'édifice possédait en son centre une petite cour, manifestement couverte, où se trouvaient trois citernes rectangulaires, presque carrées, d'une profondeur légèrement supérieure à $1 \mathrm{~m}$, qui faisaient partie d'un pressoir à vin. À proximité il y avait un pithos, ainsi qu'un contrepoids massif appartenant au pressoir. La partie Ouest du bâtiment était occupée par les aires de piétinement du pressoir - en très bon état de conservation - et par une cave. De petites pièces situées à l'Est de la maison comportaient des foyers et servaient, semble-t-il, à la vie domestique. A cet endroit furent mis au jour les vestiges d'un escalier en pierre menant à un deuxième étage non conservé, ainsi que la porte d'entrée du bâtiment. Au total, la quantité de matériel découvert était faible, à l'exception d'une abondance notable de fragments de tuiles de couverture, importées essentiellement de Sinope. Le pressoir lui-même était unique à la fois par son état de conservation et son mode de construction.

La deuxième partie de la ferme s'étendait immédiatement à l'Ouest du bâtiment que l'on vient de décrire. Il s'agit d'une grande pièce de $18 \times 7,80 \mathrm{~m}$ construite selon un axe Est-Ouest, avec des murs dont les assises sont soigneusement disposées, quoique conservées sur une moindre hauteur. Cette pièce avait, semble-t-il, une fonction économique et était, elle aussi, couverte de tuiles. Là se trouvait un autre pressoir, en moins bon état et d'une construction relativement simple, ainsi qu'un grand pithos. On y a découvert peu de matériel. L'Ouest de cette construction jouxtait un bâtiment assez petit $(7 \times 11 \mathrm{~m})$, composé de trois pièces, avec entrée au Nord du côté de la vaste cour de la ferme.

Enfin, le troisième bloc de constructions circonscrivait, pour ainsi dire, l'espace de la ferme au Nord et au Nord-Ouest. Malgré le piètre état de conservation des vestiges, on a pu voir qu'étaient disposées là, à angle droit, deux rangées principales de pièces relativement petites $(6,50 \mathrm{~m}$ de largeur). La rangée Ouest attei- 


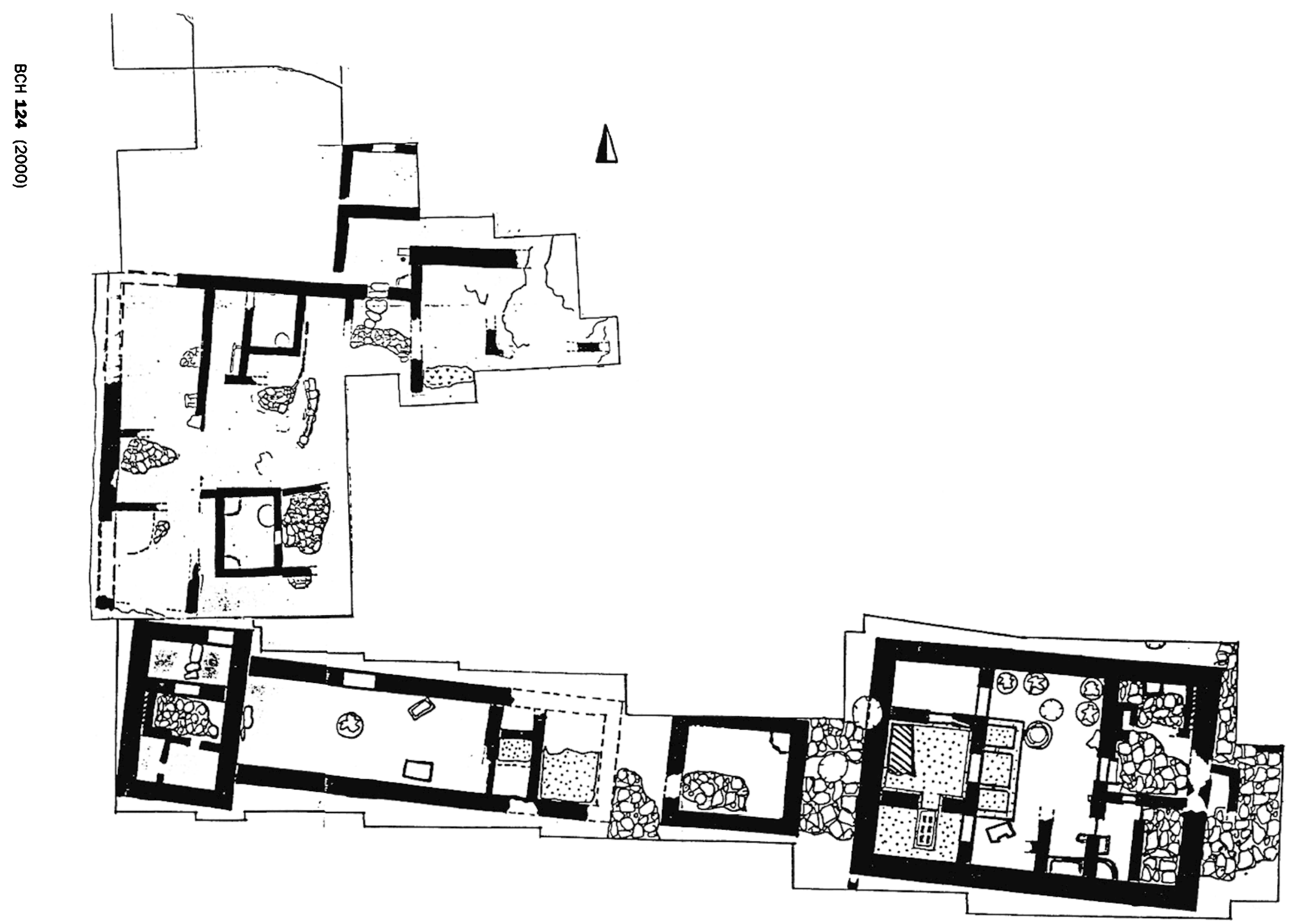

Fig. 16. Baklanja Skala (Crimée orientale). Plan de la ferme. 
gnait $19 \mathrm{~m}$ de long, la rangée Nord pas moins de $30 \mathrm{~m}$. Les murs extérieurs étaient naturellement plus puissants et plus épais (jusqu'à $1 \mathrm{~m}$ ). Dans les pièces, on a retrouvé des foyers et des tuiles brisées. La grande quantité de tuiles témoigne, là encore, de l'existence d'une couverture, où dominaient à nouveau sensiblement les importations sinopéennes, malgré la présence de tuiles en argile locale. Les autres objets découverts sur place sont moins significatifs : il s'agit avant tout de fragments amphoriques, essentiellement sinopéens, de vaisselle de cuisine et de table et, plus rarement, de plats à vernis noir. On rencontre également quelques monnaies bosporanes de cuivre, des timbres amphoriques, des graffiti et des fragments de statuettes en terre cuite.

Dans l'angle Sud-Ouest de la cour, on a mis au jour un local semi-enterré de dimensions assez réduites $(7,50 \times 7 \mathrm{~m})$ doré d'une fosse profonde à usage domestique, d'un foyer entouré de pierres et de clôtures de pierres plates.

A présenté un intérêt particulier, sur le plan du matériel et de la chronologie de la ferme, la fouille d'une décharge de cendres et de détritus d'une superficie relativement importante, située dans une dépression naturelle jouxtant au Nord-Ouest l'angle du bâtiment décrit plus haut. L'épaisseur de la stratigraphie y atteignait $2,50 \mathrm{~m}$. Là, outre des couches de terre mêlée de cendres de consistance diverse, des coquillages marins concassés, des pierres et de l'argile, on a trouvé une grande quantité de fragments d'amphores provenant de centres divers, de vaisselle variée, de tuiles et d'os d'animaux. On soulignera la découverte d'une centaine de timbres amphoriques essentiellement sinopéens, de quelques monnaies, de pesons de terre cuite pour la pêche et le tissage, de fragments de terre cuite, de graffiti sur des tessons de vaisselle de table à vernis noir et pâte rouge et des lampes. A en juger par les terres cuites et les graffiti, les habitants de la ferme vénéraient les dieux du panthéon grec : Déméter, Koré, Héraklès, Cybèle.

La ferme était située au cœur du territoire rural, assez loin des centres urbains, et, par son apparence et son organisation, se distinguait notoirement des petites propriétés suburbaines connues jusque-là et appartenant à des citadins ordinaires. Elle était, semble-t-il, l'un des éléments importants de la propriété rurale royale. Ainsi, nous disposons d'une nouvelle source permettant de mieux saisir le caractère et les particularités du système agraire de la chôra bosporane, à l'époque de son développement économique - avec, en particulier, le commerce du blé - et plus précisément à la fin de cette période.

Des résultats très intéressants ont été obtenus lors des fouilles du site Zelenyj Mys. Là, sur les vestiges de construction des II ${ }^{\mathrm{e}}$-III ${ }^{\mathrm{e}}$ s. ap. J.-C., qui comprenaient de même un pressoir à vin et une série de pièces et de fosses, furent mis au jour des murs de bâtiments des $\mathrm{IV}^{\mathfrak{e}}-\mathrm{VI}^{\mathfrak{e}}$ s. ap. J.-C., en bon état de conservation. On découvrit une quantité non négligeable de fragments d'amphores et de plats à vernis rouge de la même époque ainsi que quelques monnaies bosporanes des III -début IV $s$. ap. J.C. Mais une découverte particulièrement remarquable fut celle, dans l'une des fosses-dépotoirs, d'une tête féminine en marbre presque grandeur nature, bien conservée, représentant probablement une déesse (fig. 17). Elle date, semble-t-il, de l'époque hellénistique et constitue une trouvaille très rare dans l'archéologie du Nord de la mer Noire, surtout pour un site rural.

Dans la nécropole mentionnée précédemment, en dehors des tombes simples creusées, des tombes à ciste et des tombes à élargissement latéral, dotées comme il se doit d'un mobilier

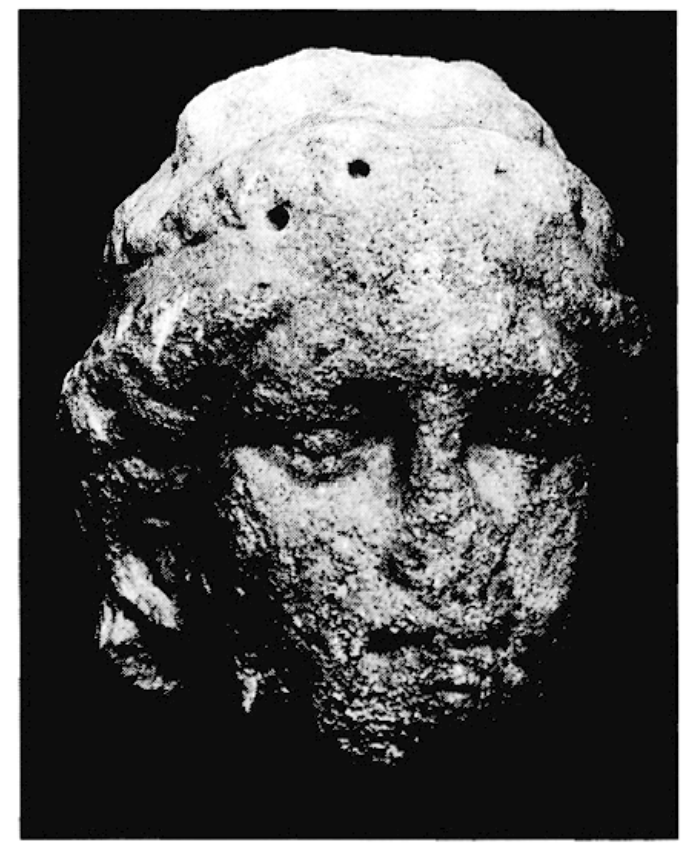

Fig. 17. Zelenyj Mys (Crimée orientale). Tête en marbre. 
assez pauvre, ont été fouillés plusieurs tombeaux construits en pleine terre datant des $\mathrm{III}^{\mathrm{e}}-\mathrm{VI}^{\mathrm{e}} \mathrm{s}$. ap. J.C. Appartenant tous à peu près à la même époque, ils se présentaient comme des constructions massives faites d'une ou, plus rarement, de deux chambres d'une superficie moyenne de $25 \mathrm{~m}^{2}$ et d'un dromos à degrés d'une profondeur allant jusqu'à 4,50 m. Dans les murs des chambres se trouvaient des niches destinées aux cercueils. Bien que presque tous les tombeaux aient été pillés dès l'Antiquité, certains objets autorisent quelques conclusions sur la chronologie, la culture et la composition ethnique de la population qui en faisait usage. Des parallèles précis nous conduisent en Méditerranée orientale et dans le Sud de la mer Noire [A. Maslennikov ${ }^{16}$ ].

On se reportera, pour plus de détails, aux ouvrages de synthèse dus à A. Maslennikov et parus depuis 1984 :

- Les tombes en pierre de la Crimée orientale. Contribution à l'bistoire de la population rurale du Bosphore européen aux $V T^{r}-F^{r}$ s. av. J.-C., BS 8 (1995). L'auteur y dresse un inventaire des tombes découvertes dans la chôra (considérées comme non grecques), suivi d'une typologie et surtout d'une tentative d'attribution ethnique, la question étant de savoir combien de tribus scythes on peut y reconnaître.

- Une chôra hellène à la limite de l'oikouméné (1998), Moscou (en russe avec dix pages de résumé en anglais) : l'auteur y publie le matériel découvert sur la côte orientale de la Crimée depuis le milieu des années 1970, date à laquelle il a pris la direction des fouilles et des prospections. Après l'étude des conditions naturelles, l'auteur fournit une analyse des sites ruraux et en dresse la typologie depuis le $\mathrm{VI}^{\mathrm{e}} \mathrm{s}$. av. J.-C. jusqu'au $\mathrm{VI}^{\mathrm{e}}$ s. ap. J.-C. Le dernier chapitre est consacré aux ouvrages défensifs durant la même période. L'ouvrage est richement illustré et comprend en particulier des cartes archéologiques distinctes selon les époques considérées.

\section{Cap Kazantip}

\section{Situation géographique et travaux antérieurs}

Le cap Kazantip se trouve au bord de la mer d'Azov, sur la péninsule de Kertch; il est baigné à l'Ouest par les eaux du golfe d'Arabat et à l'Est par celles du golfe de Kazantip. Le cap lui-même s'avance dans la mer d'Azov sur un peu plus de $20 \mathrm{~km}$. Il se termine par un ancien atoll, dont la lagune présente actuellement la forme d'une coupe concave particulière, remplie de sédiments et bordée par une chaîne de collines, dont la plus haute s'élève à $105 \mathrm{~m}$ au-dessus du niveau de la mer. Deux langues de terre relient le cap au continent, langues entre lesquelles est situé le lac salé Aktachsky qui est en voie d'assèchement rapide. Dans l'Antiquité, le lac formait un golfe marin et seule la langue Ouest existait. À l'extrémité du cap, un début d'exploration fut conduit dans les années 1950 , puis 1970 , par I. T. Kruglikova et B. G. Peters. De même, une prospection fut organisée qui révéla toute une série de structures antiques.

On peut diviser celles-ci en trois groupes : les sites dotés d'un plan régulier et occupant une superficie supérieure à $0,3-0,5$ ha ; les groupes de constructions isolées qui comprennent deux à trois habitations; les traces de lotissements antiques dans la plaine intérieure (l'ancienne lagune) et sur les baies, du côté extérieur du cap. 


\section{Travaux récents}

Depuis 1989, avec une interruption de 1993 à 1995, une série de structures a été découverte à Kazantip par la mission de l'Institut archéologique de l'Académie des sciences. Les fouilles ont été menées sous la direction de l'auteur et financées, depuis 1996, par le Fonds Russe pour les Sciences Humaines (RFFI). Pendant cette période, on a dégagé les trois structures les plus importantes (fig. $18, \mathrm{n}^{\mathrm{os}} 1,2$ et 3 ) et procédé à des mesures sur une série de levées de terre qui présentaient des vestiges de lotissement antique. Malheureusement, jusqu'à aujourd'hui, les tentatives de localisation de la nécropole ont échoué. Cette dernière a probablement disparu du fait de l'intense activité de construction sur le versant Sud.

Le plus ancien des sites étudiés est Mysovoe II, au Sud-Ouest de la terminaison du cap : il s'agit probablement d'un établissement rural, dont les bâtiments se présentent comme un ensemble de pièces rectangulaires regroupées autour d'une cour centrale et datant des IVe-III s. av. J.-C. (fig. 19). Dans la partie Nord de la fouille, on a trouvé une construction faite de blocs massifs en calcaire local, formant visiblement le soubassement d'un mur de défense. Mais la première installation est antérieure aux structures exhumées : les couches sur lesquelles elles reposent contiennent en effet de la céramique de la fin du $\mathrm{VI}^{\mathrm{e}}$ et du $\mathrm{V}^{\mathrm{e}} \mathrm{s}$. av. J.-C., soit le matériel le plus ancien découvert. L'état de conservation de la structure ne permet pas d'es-

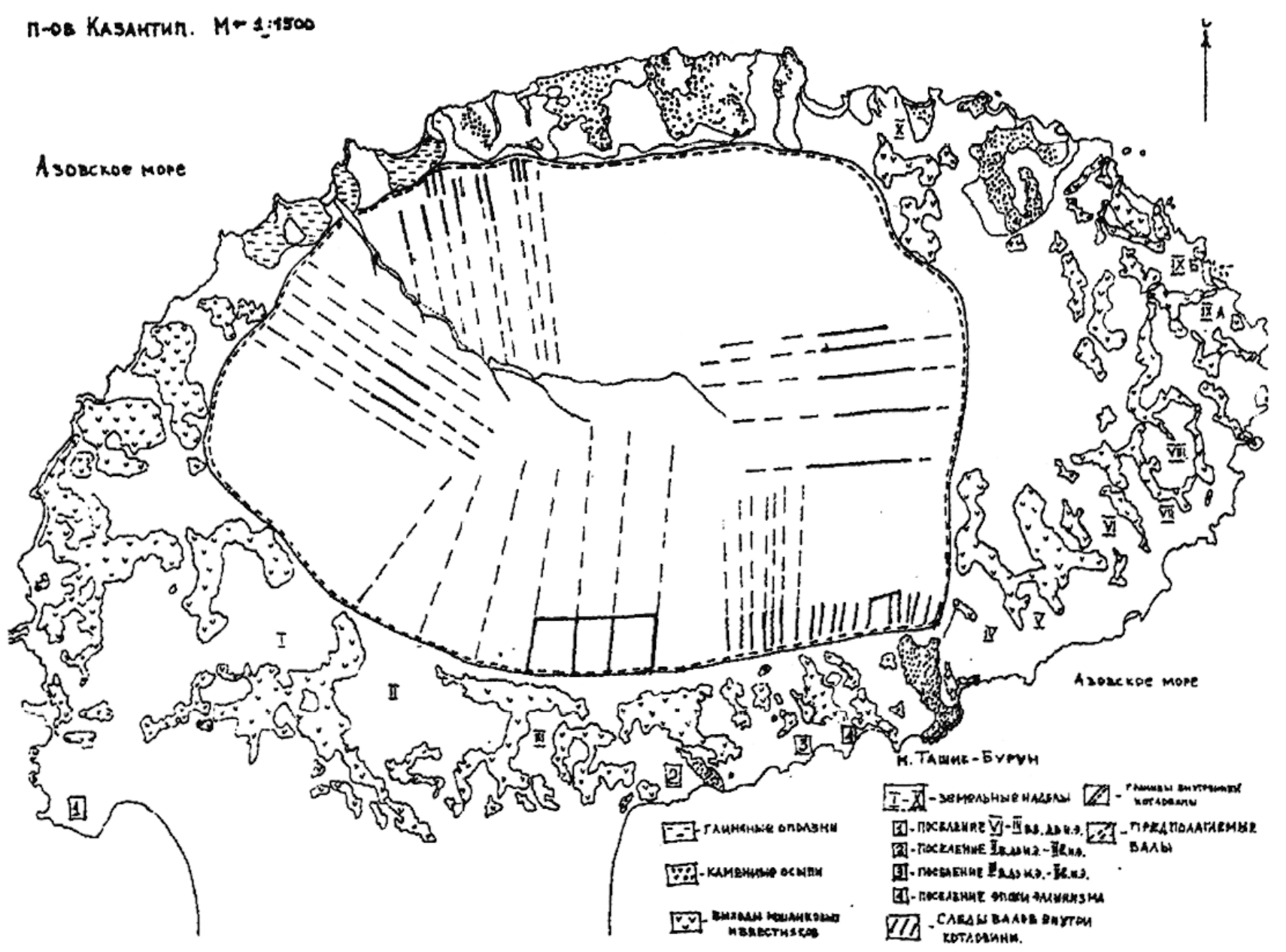

Fg. 18. Plan général du cap Kazantip. 1 : site des $v^{e}-\|\|^{e}$ s. av. J.-C. ; 2 : site des $\|^{e}$ s. av. - \|\|$^{e}$ s. ap. J.-C. ; 3 : site des $\| I^{e}$ s. av. $-\|^{e}$ s. ap. J.C. ; 4 : site hellénistique. Les lignes situées dans la plaine intérieure représentent des traces d'arpentage antique. 
pérer mieux. L'épaisseur de la stratigraphie n'excède pas 0,60-0,80 m sur la plus grande partie de la surface fouillée (elle a été partiellement détruite par des travaux de construction lors de la Seconde Guerre mondiale, le site ayant été recouvert par une forteresse roumaine). Au tournant des $\mathrm{III}^{\mathrm{e}}$ et $\mathrm{II}^{\mathrm{e}} \mathrm{s}$. av. J.-C., la vie du site s'interrompt, suite peut-être à l'ensablement du petit port situé à l'Ouest de la ferme. Sur le site, on n'a pas observé de traces d'incendie ni de destruction, mais cela pourrait être dû au mauvais état de conservation des vestiges : dans la plupart des pièces mises au jour, seuls subsistent les soubassements des murs, tandis que les sols ont disparu.

On peut, d'après le matériel de surface, dater de l'époque hellénistique une petite structure située à

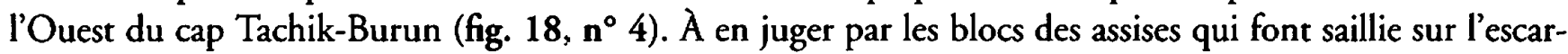
pement du rivage et d'après la topographie du vallon, s'étendaient là quelques constructions ainsi que, peutêtre, un bâtiment séparé. À cette époque, la vie se concentrait sur la berge occidentale de Kazantip, la partie orientale n'étant pas encore occupée.

Au tournant des $\mathrm{III}^{\mathrm{e}}-\mathrm{II}^{\mathrm{e}}$ s. av. J.-C., deux sites apparaissent sur la berge Est, vers laquelle se déplace manifestement la majorité des habitants. Le site Kazantip $I$ (fig. 18, $\mathbf{n}^{\circ} 3$ ) se présente comme un groupe de bâtiments érigés selon un même plan; la couche archéologique, qui atteint 3,80 m à 4,20 m, ne comprend pas moins de quatre phases de construction, depuis le tournant des $\mathrm{III}^{\mathrm{e}}-\mathrm{II}^{\mathrm{e}}$ s. av. J.-C. jusqu'au $\mathrm{II}^{\mathrm{e}}$ s. ap. J.-C. (fig. 20). L'établissement est situé sur l'escarpement du rivage, dont l'inclinaison est d'au moins 15 degrés, ce qui a déterminé son organisation en terrasses. Les vestiges permettent d'observer la déformation subie par les murs, probablement à l'occasion du tremblement de terre de 63 av. J.-C. Cela s'accorde bien avec le matériel céramique et la stratigraphie du site. Les limites de celui-ci ne sont pas perceptibles d'emblée, car le microrelief y a été bouleversé par un déversement de boue qui a recouvert la stratigraphie. L'événement est survenu après l'abandon général du site, qui s'est produit dans un contexte serein, comme en témoigne l'extrême indigence du matériel découvert. Parmi les diverses constructions, on peut souligner l'existence d'un local pavé de grandes dalles et daté du $\mathrm{II}^{\mathrm{e}}$ s. av. J.-C., visiblement utilisé comme moulin : on y a en effet retrouvé la partie supérieure d'une meule en pierre volcanique et des fragments d'autres éléments venant peut-être de la même meule. On remarquera aussi la présence de deux drains installés, vraisemblablement, après le tremblement de terre.

En même temps que Kazantip I, apparaît aussi le site d'Afanasievka (fig. 18, $\mathbf{n}^{\circ}$ 2). Il est vrai que l'on n'y a pas retrouvé de vestiges de construction antérieurs aux II $\mathrm{III}^{\mathrm{e}}$ s. ap. J.-C., mais le matériel provenant de la couche la plus profonde - couche de cendres - comprend des timbres amphoriques et de la céramique de la fin du $\mathrm{III}^{\mathrm{e}}$ et du $\mathrm{II}^{\mathrm{e}}$ s. av. J.-C. Sur le site, on a mis au jour une section de mur de défense d'une épaisseur de $3,50 \mathrm{~m}$, ce qui, compte tenu de la faible superficie du site, suscite à première vue la perplexité. En effet, les sites analogues de la chôra du Bosphore européen sont dotés de fortifications beaucoup moins imposantes, dont l'épaisseur est habituellement comprise entre 1,20 m et 2,20 m. La forte épaisseur s'explique ici par la présence de hauteurs dominantes tout autour du site : en cas de siège, en effet, le seul moyen de défense contre les tirs était un mur d'une hauteur convenable, hauteur qui a déterminé également l'épaisseur. Surgit alors logiquement une question : pourquoi Kazantip I était-il dépourvu d'un système défensif, alors qu'Afanasievka en possédait un ? La réponse est à chercher dans le revirement de la politique extérieure du Bosphore européen, dans la mesure où, au III ${ }^{\mathrm{e}}$ s. ap. J.-C., la menace principale pour la population de Kazantip venait non seulement des ennemis nomades de la steppe, mais surtout de l'union des tribus gothiques qui possédait une flotte importante. C'est au III ${ }^{\mathrm{e}}$ s. ap. J.-C. exactement qu'apparaît un mur fortifié sur le site d'Afanasievka (fig. 21), alors qu'auparavant, depuis le III ${ }^{e}$ s. av. J.-C., la défense de la péninsule consistait en une petite levée de terre longeant l'actuel village de Sémionovka, au commencement de la péninsule. Le danger venant de la mer a contraint la population à changer du tout au tout son système de défense et, manifestement, à abandonner Kazantip I : l'interruption de l'activité sur le cap est, à l'évidence, 


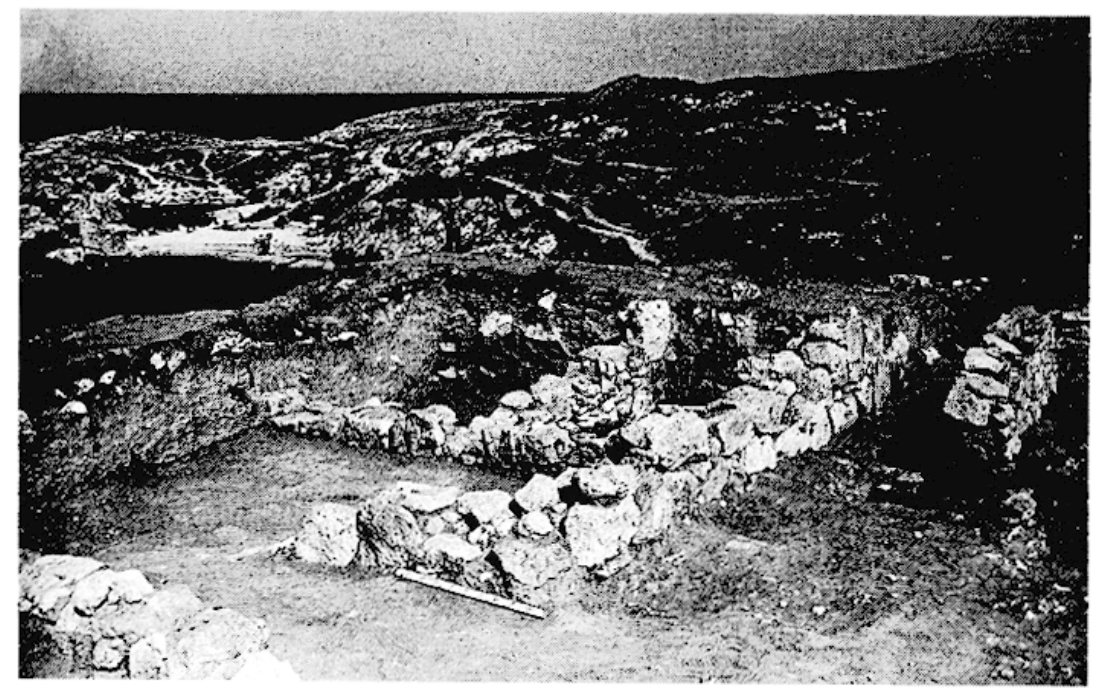

Fig. 19. Cap Kazantip. Ferme des $\left.v\right|^{e}-11 l^{e}$ s. av. J.-C., avec constructions du $2^{e}$ quart du Ive s. av. J.-C.

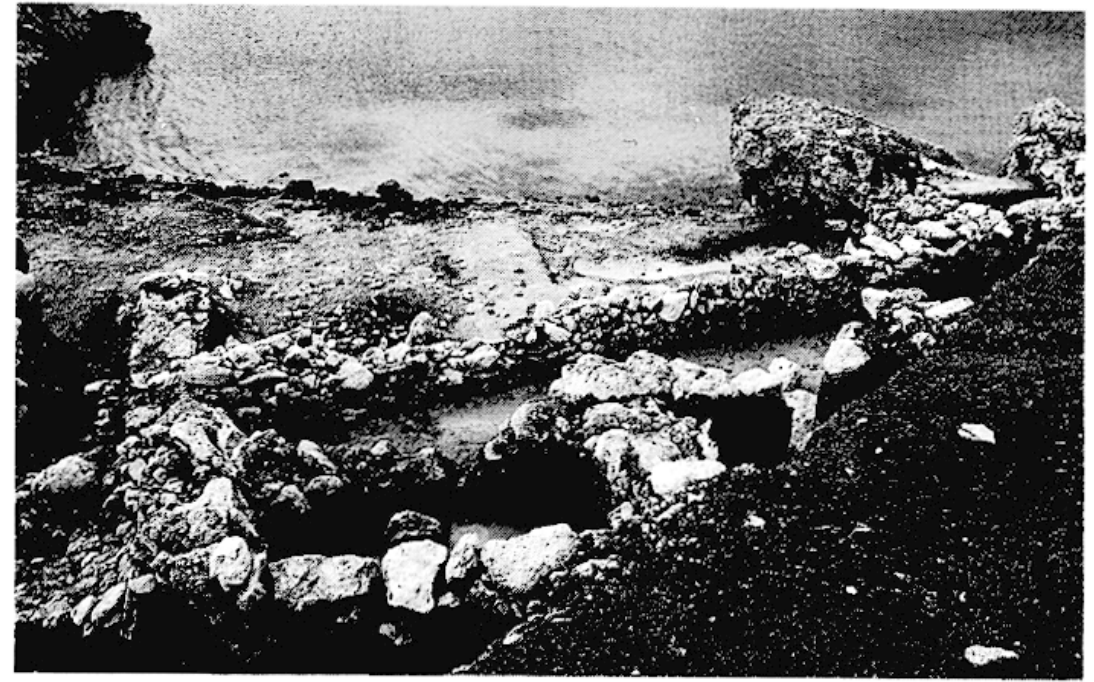

Fig. 20. Ibid. Site des $\|^{e}$ s. av. - $\|^{e}$ s. ap. J.C.

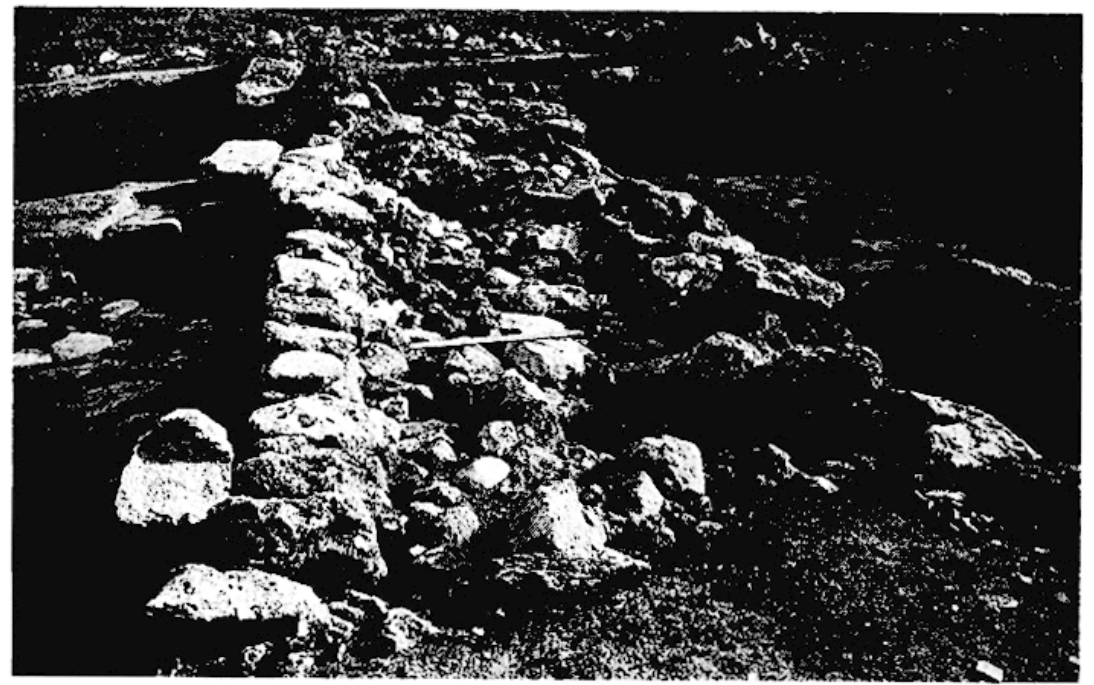

Fig. 21. Ibid. Site des $\|^{e}$ s. av. - $\|^{e}$ s. ap. J.C. Mur défensif du $\|^{e}$ s. ap. J.-C. 


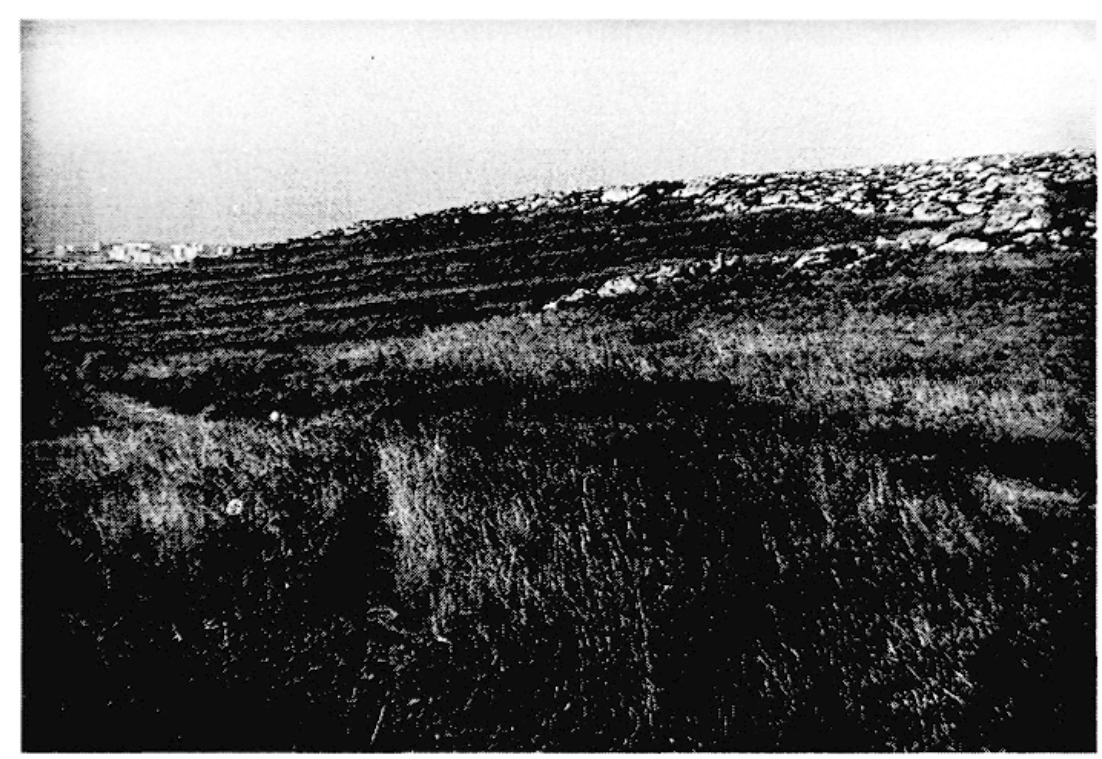

Fig. 22. Cap Kazantip. Traces d'arpentage antique.

liée à l'arrivée des Goths. À l'heure actuelle, on peut affirmer que le site grec de Kazantip n'a pas survécu à l'invasion des Goths dans les années 260-270 ap. J.-C. À l'exclusion de quelques fragments d'amphores un peu plus tardives, découvertes hors de tout contexte de construction, on ne voit plus sur le site aucune trace de population permanente.

L'analyse des traces d'arpentage antique sur le cap (fig. 22) a permis de tirer une série de conclusions sur le système et les principes d'une telle pratique, ainsi que sur le statut social de la population et son importance numérique. On peut observer deux procédés d'arpentage : l'un pour la partie intérieure de la péninsule, territoire situé dans l'ancienne lagune, et l'autre pour les lots du rivage oriental et de la partie méridionale de la chaîne. Les lots de la plaine intérieure évoquent davantage des principes réguliers et égalitaires dans la répartition de la terre. Un relief relativement plat et des conditions agraires homogènes ont permis de découper des parcelles égales, de configuration rectangulaire, d'une superficie moyenne de 2,5 ha, ce qui n'autorise pas à considérer leurs propriétaires comme aisés : il s'agit, conformément aux normes admises pour l'Antiquité, de propriétés de petite taille. Les lots de la partie Sud et Est ne présentent pas une configuration régulière, mais sont disposés conformément au relief local, dont le trait principal réside dans les affleurements de calcaire de forme fantaisiste. En dehors de cela, les levées de terre entre les lots jouent un rôle non seulement de délimitation, mais aussi de rétention d'humidité. La taille des parcelles est un peu plus importante que dans le premier cas, ce qui pourrait être lié non au statut social plus élevé des propriétaires, mais aux conditions moins favorables et à une terre moins fertile, riche en roches sédimentaires. $\mathrm{Au}$ total, on peut supposer l'existence, au moment de l'activité la plus intense, d'environ 160 parcelles de terre, ce qui peur correspondre à une population de 600 à 800 personnes. Le plus probable est que cela concerne la période allant du $\mathrm{II}^{\mathrm{e}}$ s. av J.-C. au II ${ }^{\mathrm{e}}$ s. ap. J.-C.

Dans l'existence des sites antiques de Kazantip, un fait suscite la surprise : leur extrême isolement par rapport aux autres villages d'époque grecque. Kazantip est situé en dehors des dispositifs généraux de défense du Bosphore européen et, en cas d'attaque depuis la steppe, ne pouvait attendre de secours de nulle part. L'hypothèse selon laquelle Kazantip se serait peuplé à la fin du VIe s. av. J.-C. en liaison avec le foncrionnement permanent de la route commerciale reliant Panticapée à Tanaïs n'est pas dépourvue de fondement. Mais la situation de l'établissement sur une route commerciale aussi fréquentée devrait, dans cette hypothèse, aller de pair avec une certaine aisance de la population, qui précisément ne s'observe point. Sur aucun site, on ne 


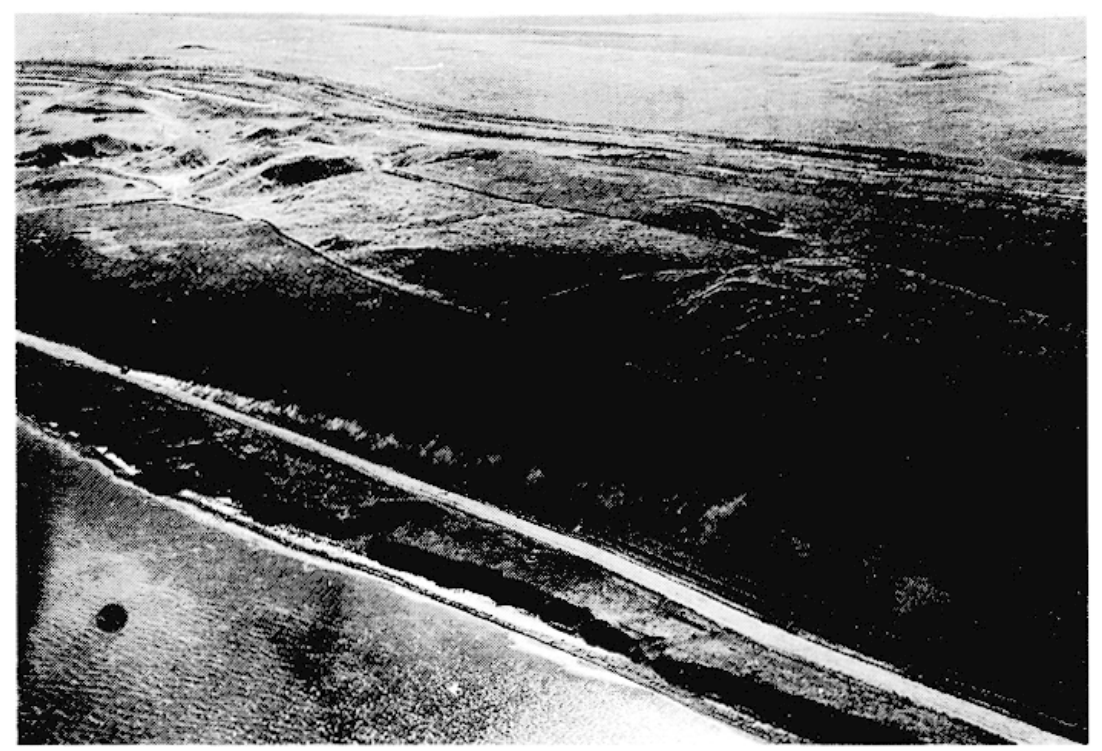

Fig. 23. Phanagorie vue d'avion au début des années 1960.

peut parler d'un large usage de la tuile, dont les fragments sont très rares. D'une manière générale, les fouilles de Kazantip ont fourni un matériel pauvre et peu diversifié : les timbres, monnaies, terres cuites, objets métalliques sont très rares, se réduisant à quelques unités. Le matériel céramique est pauvre lui aussi et ne comprend presque pas de forme complète. Comment expliquer ce qui apparaît comme une contradiction flagrante avec une position apparemment aussi favorablc sur ccttc route commerciale? La cause réside dans la spécificité de la navigation sur la mer d'Azov. La navigation à voile depuis le détroit de Kertch jusqu'à l'embouchure du Don (Tanaïs) s'effectuait et s'effectue, à cause des vents, le long du rivage oriental évitant Kazantip et c'est seulement sur le chemin du retour que les bateaux à voile étaient inévitablement emportés vers Kazantip, où ils avaient la possibilité de faire escale. A ce stade du voyage, les navires marchands faisaient route complètement chargés, après avoir accompli toutes les opérations commerciales. Kazantip n'avait rien de plus à offrir aux marchands que ce qu'ils pouvaient acheter à Tanaïs. Il va de soi que le cap devait posséder un phare, dont on n'a pas encore pu retrouver les vestiges, et la population aidait sans doute les équipages à réparer leurs bateaux, mais son occupation principale consistait à faire pousser du blé, élever du bétail et pêcher, comme en témoigne le matériel découvert (os, pesons de filets, etc.). Mais, manifestement, elle ne tirait aucun avantage particulier de sa position sur cette route commerciale [M. Bezruchenko $\left.{ }^{17}\right]$.

\section{Phanagorie}

\section{Situation géographique et travaux antérieurs}

Phanagorie est une colonie de Téos, fondée à la même époque qu'Abdère, soit vers 540 av. J.-C. Le site antique s'étend sur deux plateaux, sur la côte Sud du golfe de Taman (fig. 23). Une partie du plateau inférieur a été submergée par la mer (jusqu'à $250 \mathrm{~m}$ de profondeur, comme l'ont montré les recherches sousmarines de V. Blavatsky). La superficie totale de Phanagorie avoisinait les 65-70 ha et la cité a existé depuis le milieu du $\mathrm{VI}^{\mathrm{e}}$ s. av. J.-C. jusqu'au $\mathrm{X}^{\mathrm{c}}$ s. ap. J.-C. 
Les premières fouilles eurent lieu dès la fin du XVIII" siècle, quand la péninsule de Taman devint une partie de la Russie. A partir du milieu du XIX ${ }^{e}$ siècle, Phanagorie commença à attirer l'attention des archéologues de Saint-Pétersbourg, de Moscou et d'autres villes. Cependant, ceux-ci s'intéressèrent exclusivement à la fouille des nécropoles, où ils espéraient trouver des objets de valeur et des vases pour les musées de la capitale. Dans les nombreux kourganes qui entourent Phanagorie sur trois côtés, ils mirent au jour différents types de constructions funéraires et une grande quantité d'objets antiques (vases peints, vaisselle d'argent, bijoux en métaux précieux, etc.). C'est en 1936 que commencèrent à Phanagorie des fouilles scientifiques programmées, sous la direction du professeur V. Blavatsky, puis à partir de 1945, sous celle du professeur M. Kobylina.

Phanagorie, comme les autres sites antiques de la péninsule de Taman, présente une particularité architecturale, celle de la mauvaise conservation des bâtiments en pierre. La raison en est l'absence de carrières de pierres sur la péninsule, ce qui a contraint les habitants à démonter les constructions anciennes pour réutiliser le matériau. Malgré cela, au cours des fouilles, ont été découverts des quartiers urbains appartenant à différentes périodes de la vie de la cité, depuis l'époque archaïque jusqu'au Moyen Âge. En dehors des habitations, des rues et des places, on peut souligner en particulier la découverte de bâtiments collectifs (temples, gymnases ?...), celle d'un mur de défense datant du $\mathrm{V}^{\mathrm{e}}$ s. av. J.-C. et celle d'un quartier d'artisans à la lisière Sud de la cité, qui exista du V's. av. J.-C. jusqu'à l'époque romaine : on y a trouvé des ateliers de bronziers et de potiers, dont un atelier de coroplastes de la fin de l'époque archaïque. Parmi les objets découverts, on mentionnera l'énorme quantité de tessons d'amphores de différentes origines, de céramique peinte, de terres cuites, les monnaies en bronze, en argent et en or, les fragments de statues et de statuettes en marbre, les inscriptions et les graffiti.

\section{Travaux récents}

Ces dernières années, les recherches se sont concentrées sur l'une des collines du plateau supérieur, où s'étendait la partie la plus ancienne de la cité (fig. 24) : les fouilles ont ici mis au jour des quartiers d'habitation contemporains de la fondation de la cité. Les maisons des premiers habitants étaient construites en brique crue, sans fondation de pierre et d'une superficie de 10 à $20 \mathrm{~m}^{2}$. En général, n'est conservée que la partie inférieure de la maison, ce qui rend difficile la reconstitution de son aspect extérieur : une seule maison se trouve dans un très bon état de conservation. Ses murs atteignent $1,50 \mathrm{~m}$ de hauteur et sa superficie est de $12,50 \mathrm{~m}^{2}$.

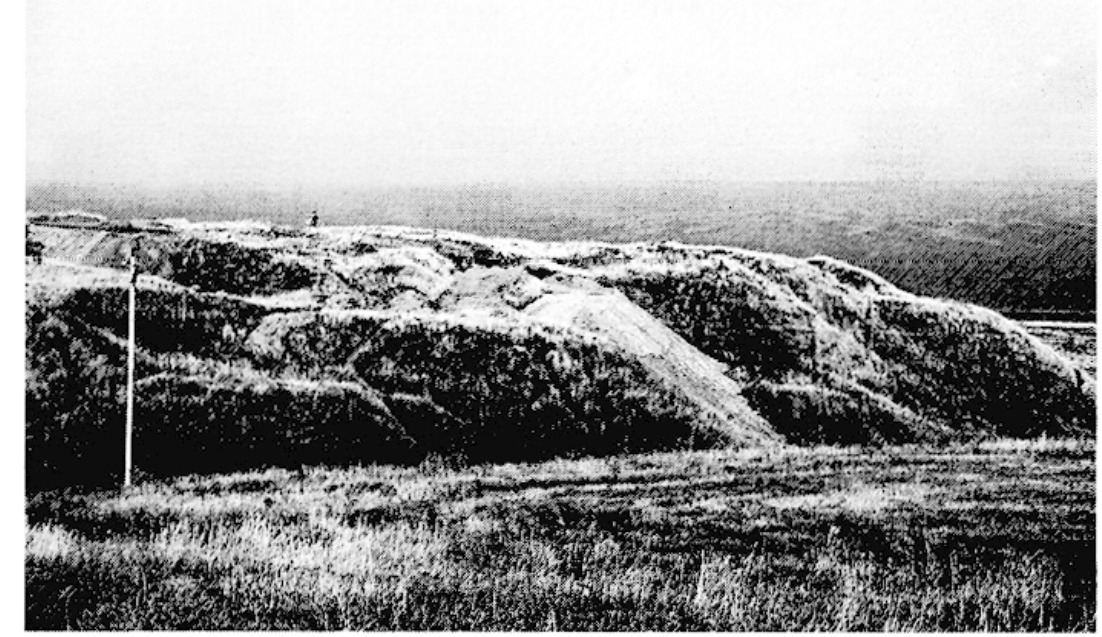

Fig. 24. Vue de la colline où fut fondée Phanagorie. 
L'espace intérieur était rempli de briques crues effondrées sur plus de $2 \mathrm{~m}$, ce qui permet d'affirmer que la maison consistait en un local semi-enterré à une profondeur de $0,70 \mathrm{~m}$, et d'un étage d'habitation au-dessus. La hauteur totale de l'édifice n'était pas inférieure à $5 \mathrm{~m}$. À $4 \mathrm{~m}$ de là, on a découvert un atelier de bronzier, où avait été fondue une statue de bronze de taille humaine, si l'on en juge par les fragments de moule où étaient imprimés les orteils de la statue. Compte tenu du fait que l'atelier est contemporain de la maison (fin $V^{c}$-début $V^{e} s$. av. J.-C.) et de la découverte, dans le local semi-enterré, de fragments d'une statuette en marbre (une koré, semble-t-il), on peut supposer que, dans cette maison, vivait un sculpteur de Phanagorie.

Les quartiers d'habitation de l'ancienne Phanagorie étaient densément construits et les rues très étroites (largeur moyenne $0,50 \mathrm{~m}$ ). Il s'agissait d'économiser l'espace, ces quartiers occupant une colline de dimensions réduites (env. $100 \times 100 \mathrm{~m}$ ). Parmi le matériel découvert dans la couche archaïque de la colline, on compte des amphores (Chios, Clazomènes, Samos, Lesbos), de la céramique peinte ionienne (bols, coupes, cratères du Wild Goat Style, amphores et œnochoés) et attique (coupes des Petits Maîtres, coupes de Droop et de Kassel, olpès, amphores), des statuettes de terre cuite, des monnaies de bronze et des graffiti. Les objets les plus anciens confirment la date de fondation (milieu du VI ${ }^{\mathrm{e}}$ s. av. J.-C.) [V. Kuznetsov ${ }^{18}$.

- Publication du "plan archéologico-topographique " du site, qui consiste en un schéma général (mais sans levé topographique réel) accompagné d'un historique des travaux cartographiques menés depuis le XIX ${ }^{e}$ siècle et d'un descriptif des fouilles et prospections, carré par carré, établi essentiellement à partir des archives déposées à l'IARAN. BS 2 (1993), p. 111-148.

— Publication de deux dioboles "sindes" découverts in situ en 1983 dans la partie Sud du site. Tête d'Héraklès au droit et tête de cheval au revers avec inscription $\Sigma I N \Delta O N$. Dernier quart du Ve s. av. J.-C., mais on ne sait pas à qui en attribuer la frappe. $R A$ 1998/3, p. 141-145.

— En 1996 a eu lieu la première campagne de fouille d'un projet nouveau, commun à l'université de Londres et à l'Institut d'archéologie de Moscou. Les difficultés financières ayant empêché la poursuite des travaux de terrain, les responsables ont décidé de réorienter le projet vers la publication des fouilles antérieures et du matériel inédit déposé au Musée de Taman, en particulier la céramique grecque archaïque et classique. On doit à Catherine Morgan le premier volume de cette série, qui consiste en un catalogue (en anglais) de la céramique attique conservée à Taman. L'ensemble comporte quelques pièces archaïques, mais surtout des vases d'époque classique et du début de l'époque hellénistique (VI ${ }^{\mathrm{e}}$ s.-2c quart du $\mathrm{III}^{\mathrm{c}}$ s. av. J.-C.), après quoi l'importation de cette céramique se raréfie.

Le volume contient par ailleurs une brève présentation préliminaire des fouilles anglo-russes de 1996. La partie anglaise de la fouille, dite "tranchée 1 ", a été ouverte dans une ancienne fouille du siècle dernier. Le nettoyage de cette tranchée sur presque trois mètres de profondeur a permis d'atteindre la couche antique en place, que l'on peut dater de l'époque romaine (II ${ }^{\mathrm{e}}-\mathrm{IV}^{\mathrm{e}} \mathrm{s}$. ap. J.-C.). Cette couche compte 16 fosses, ainsi que des restes de bâtiment (dallage, murs en brique crue, etc.) qui s'articulent de la manière suivante : la construction d'un dallage au $\mathrm{II}^{e}$ s. ap. J.-C. a entraîné la disparition d'un bâtiment circulaire en brique crue. Le dallage se rapportait à un bâtiment en pierre détruit au cours d'un incendie. Enfin, les vestiges d'un bâtiment en bois, également disparu au cours d'un incendie à la fin du III ${ }^{c}$-début du IV c s. ap. J.-C., se rapportait peut-être à la dernière phase de fonctionnement de cette partie de la "ville haute " en tant que lieu d'habitation. C. MORGAN, Catalogue de la céramique attique du Musée de Taman, TS 2 (1999), Saint-Pétersbourg (pour partie en russe, pour partie en anglais). 


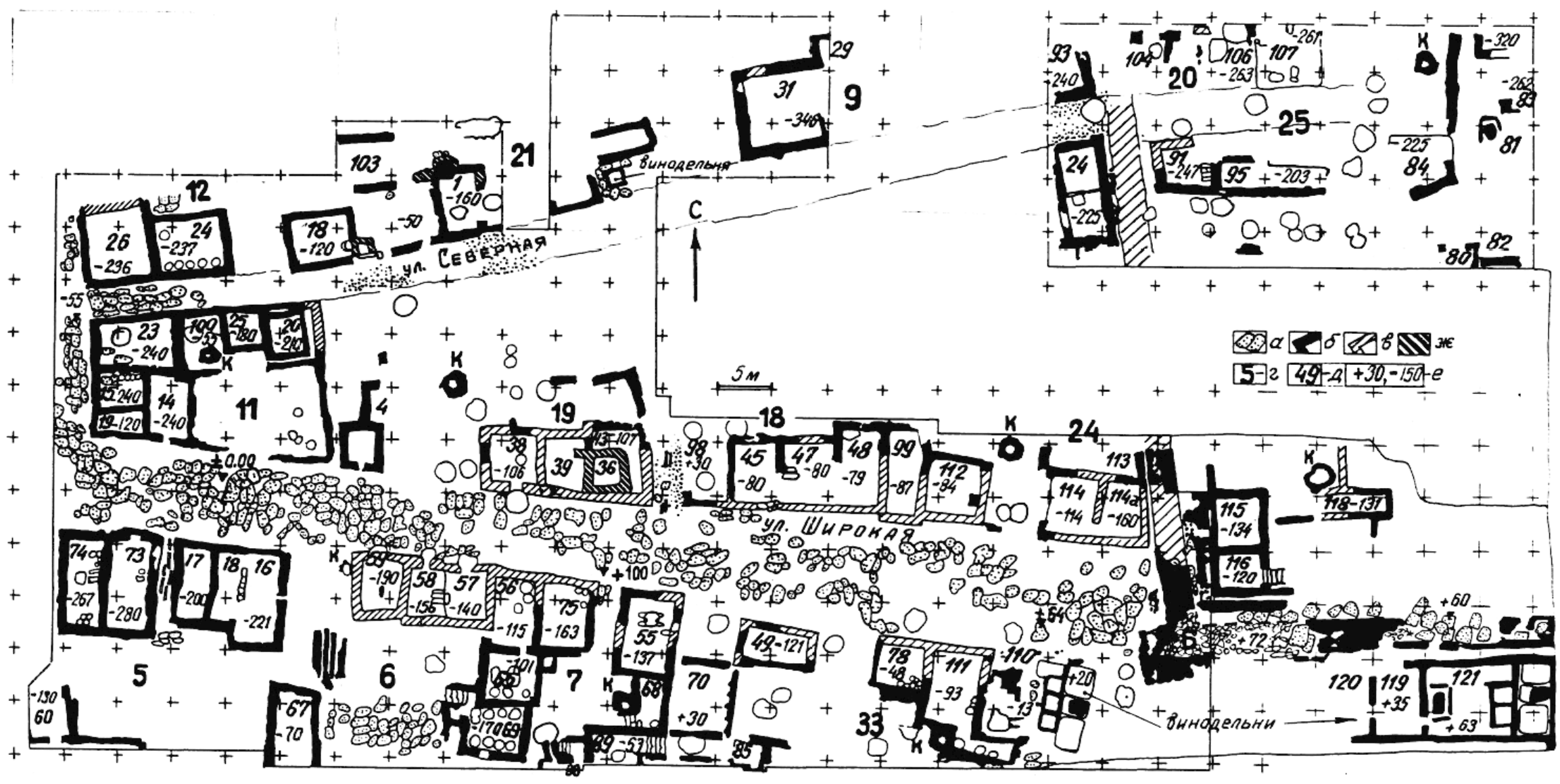

Fig. 25. Gorgippia. Limite Nord-Est de la ville, avec plan du zapaviednik (zone archéologique).

Plan des constructions des $\|^{\mathrm{e}} \mathrm{s}$. et $1^{\mathrm{re}}$ moitié du $\|^{\mathrm{e}} \mathrm{s}$. ap. J. C. (deux rues, caves de maisons et vestiges de la citadelle). 


\section{Gorgippia}

\section{Situation géographique et travaux antérieurs}

Gorgippia, l'une des cités antiques les plus importantes du royaume du Bosphore, est située au cœur de la station balnéaire d'Anapa au bord de la mer Noire, dans le Caucase septentrional. L'Institut archéologique de l'Académie des sciences y poursuit des recherches depuis 1960 et mène des fouilles tant sur les emplacements de futures constructions (aux frais des entrepreneurs) que sur le territoire du zapaviedni $k^{19}$ (fig. 25), où les fouilles et la restauration sont financées par l'État.

La cité fut fondée par des Ioniens dans le dernier quart du $\mathrm{VI}^{\mathrm{e}} \mathrm{s}$. av. J.-C., mais nous ne connaissons pas son nom d'origine. Au tournant des Ve et IVe s. av. J.-C., elle fut incluse dans l'État du Bosphore en formation et, par la suite, se développa à l'intérieur de celui-ci. Elle fut appelée, au IV s. av. J.-C., du nom de Gorgippos, frère de Leukôn, roi du Bosphore, qui incorpora au royaume les terres fertiles de la région du Kouban et l'actuelle péninsule de Taman (ancienne Sindikè). À un moment donné de ces conquêtes, la cité fut, semble-t-il, la résidence de Gorgippos : il y possédait ses propres fabriques de tuiles, qui apposaient sur la production son sceau personnel (ce type d'ateliers, le plus lucratif, appartenait, dans le Bosphore, à la famille royale). Le nom de Gorgippia est confirmé par les découvertes épigraphiques et monétaires ainsi que par les tuiles estampillées.

Gorgippia fut détruite en 240 ap. J.-C. dans un immense incendie, au début de l'époque de la migration des nomades dans les steppes, connue sous le nom de migration des "Goths ": d'après les chercheurs, ce sont des tribus d'Alains qui furent responsables de la vague de destructions.

\section{Travaux récents (1987-1997)}

Dans les dix dernières années, les chercheurs ont étudié les niveaux urbains, certains secteurs de la nécropole et la chôra de Gorgippia. La ville occupait environ 40 ha et la nécropole plus de 100.

La ville antique a été fouillée à plusieurs endroits. La stratigraphie, quoique ne dépassant pas $3 \mathrm{~m}$ de hauteur, y est complexe, puisque la ville s'est développée au même endroit pendant huit siècles et a connu des périodes d'épanouissement mais aussi de nombreuses catastrophes. Les fondations et les caves de la ville tardive ont entamé les couches plus anciennes, qu'elles ont contribué à perturber.

Au centre de la partie de la ville antique située en bord de mer, ont été découverts des quartiers de la cité grecque ancienne, comprenant quatre périodes de construction qui se succèdent entre la fin du $\mathrm{VI}^{\mathrm{e}}$ et le début du IV $\mathrm{V}^{\mathrm{e}}$ s. av. J.-C. Les maisons ont été détruites par des incendies. Les couches d'incendie ont préservé une énorme quantité de fragments de vases importés de divers centres de la Méditerranée (fig. 26). A été mis au jour également un fossé lié à la fortification de la ville ancienne. A l'époque hellénistique,

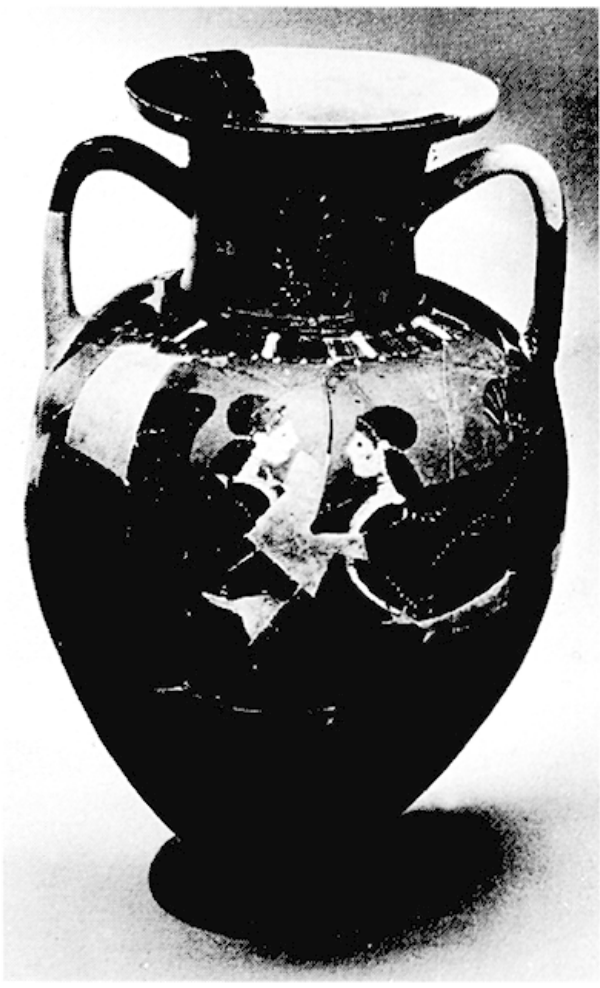

Fig. 26. Ibid. Amphore de Clazomènes (vie s. av. J.-C.). 


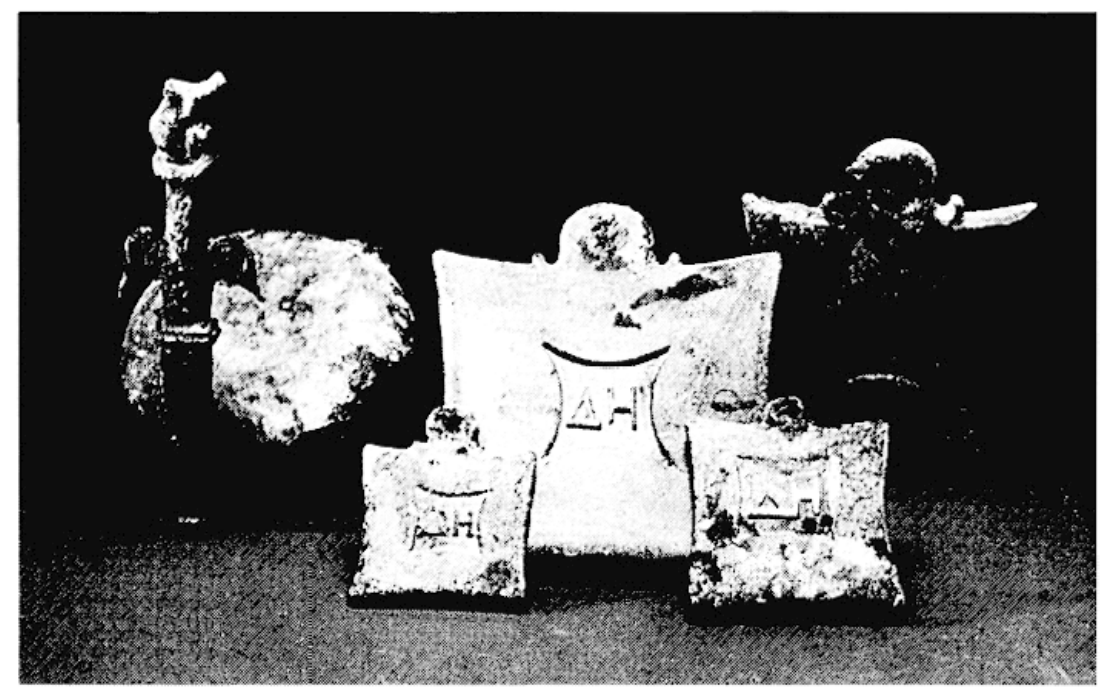

Fig. 27. Gorgippia. Poids en bronze et fragment de balance découverts dans un des pressoirs du III ${ }^{\mathrm{e}}$ s. ap. J.-C.

ce secteur était occupé par un édifice monumental construit en blocs de calcaire taillés, remplacé à l'époque romaine par une maison de plus de $800 \mathrm{~m}^{2}$, pourvue de nombreuses caves. Ces caves des $\mathrm{II}^{\mathrm{e}}$-III $\mathrm{s}$. ap. J.-C., creusées dans le rocher, ont fortement perturbé les couches antérieures, mais ont fourni d'admirables ensembles de trouvailles de l'époque impériale.

On a commencé par l'exploration de l'angle Sud-Ouest du site, où l'on a trouvé les fondations de fortifications urbaines d'époque hellénistique et du $\mathrm{I}^{\mathrm{er}} \mathrm{s}$. ap. J.-C. On a fouillé là une maison-tour du $\mathrm{I}^{\text {er }} \mathrm{s}$. ap. J.-C. renfermant une importante quantité de vases, détruite dans un incendie, et l'on a découvert le quartier urbain des potiers, avec des fours dont la chronologie s'échelonne entre le IV $V^{e}$. av. J.-C. et le III $s$. ap. J.-C.

On a poursuivi les recherches, déjà anciennes, sur le secteur consacré à Anapa à un musée de plein air ${ }^{20}$, territoire qui couvre environ $15000 \mathrm{~m}^{2}$, dont près de 10000 ont été fouillés avec deux rues et des quartiers d'habitations pourvues de nombreuses caves, chaque maison couvrant de 400 à $800 \mathrm{~m}^{2}$. Le zapaviednik occupe l'angle Nord-Est de la ville ancienne. Ces dix dernières années, on a fouillé deux pressoirs (fig. 27) dont les citernes pouvaient contenir respectivement six et neuf tonnes de moût, ainsi que les fondations des fortifications urbaines de la Gorgippia tardive, dont une puissante citadelle avec des murs épais de $3 \mathrm{~m}$. Dans cette partie de Gorgippia, s'étendait parallèlement à la mer une rue large de $8 \mathrm{~m}$ qui, hors des limites de la ville, constituait la route commerciale principale traversant la partie la plus riche de la nécropole. On suppose que les maisons bordant cette rue possédaient des boutiques et que le quartier lui-même était commerçant. La profusion de monnaies dans les caves et sur la chaussée le confirme, ainsi que l'abondance et la fréquence de trouvailles du même type excédant largement les besoins d'une seule famille. Dans ce secteur, à la limite de la ville, on a découvert les traces d'un atelier de verrier, sous la forme de rebuts de production, de verres et de fragments de verre destinés à être refondus, provenant de vases les plus divers, importés à Gorgippia de tous les points de l'empire romain. Les caves des maisons, conservées sur une hauteur de $2,50 \mathrm{~m}$ à $3 \mathrm{~m}$ et remblayées par une couche d'incendie, ont préservé un matériel représentatif des $\mathrm{II}^{e}-\mathrm{III}^{e}$ s. ap. J.-C. La Gorgippia tardive, dans ce secteur également, a détruit presque entièrement les strates des époques antérieures, même s'il est établi que le plan de cette partie de la ville est resté inchangé depuis le IV $V^{e}$ s. av. J.-C. Les quartiers urbains ont recouvert la nécropole de la cité ancienne. 
Les fouilles de la nécropole de Gorgippia ont été menées, ces dix dernières années, dans la partie centrale de celle-ci, à l'emplacement d'un chantier de construction d'une maison qui s'étend tout le long d'un quartier d'Anapa. Ces fouilles ont mis au jour 67 sépultures témoignant de rituels funéraires divers (fig. 28-31) et inégalement conservées. De nombreuses tombes avaient été pillées pendant l'Antiquité, mais d'autres ont révélé, entre autres découvertes, de la vaisselle en verre (fig. 32) et des bijoux en or. La plupart des tombes sont enfouies à une profondeur de 3 à $4 \mathrm{~m}$ sous la surface actuelle du sol et nombre d'entre elles sont situées au niveau de la roche tendre dans laquelle elles ont été creusées et fermées par des poutres. Au total, plus de 400 tombes ont été fouillées dans la nécropole.

Dans la chôra de Gorgippia, on a procédé à la cartographie de nombreux sites fixés par GPS : établissements ruraux et fermes isolées, tombes en pleine terre ou kourganes. Ces territoires étaient habités par des tribus locales, intégrées dans la sphère d'influence d'une grande cité. À la population autochtone, rurale et sédentaire - connue, d'après les témoignages des auteurs anciens, sous le nom collectif de Méotes -, se mêlèrent progressivement, à partir de l'époque hellénistique, les tribus nomades des Sarmates [E. Alexeieva ${ }^{21}$.

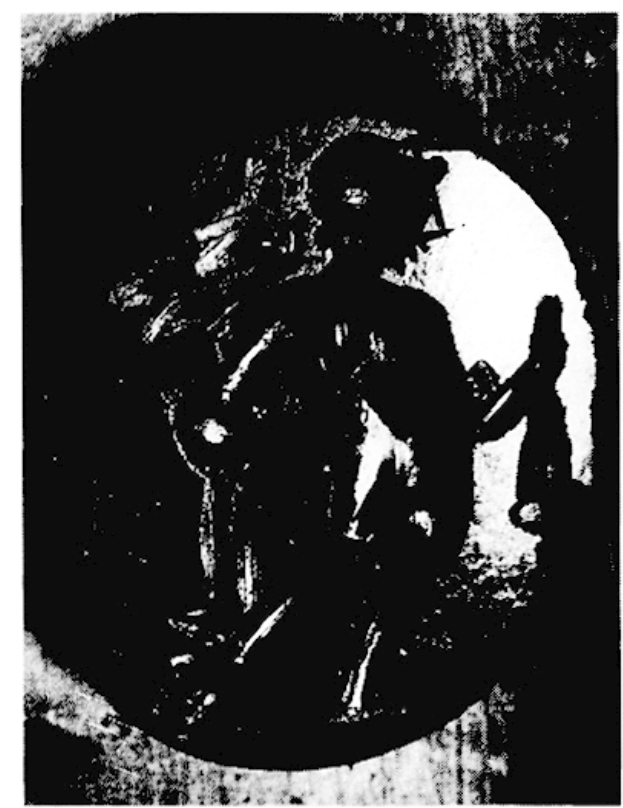

Fig. 29. Ibid. Gemme en cornaline représentant Hermès, trouvée dans une tombe ( $\mathrm{I}^{\mathrm{er}} \mathrm{s}$. ap. J.-C.).

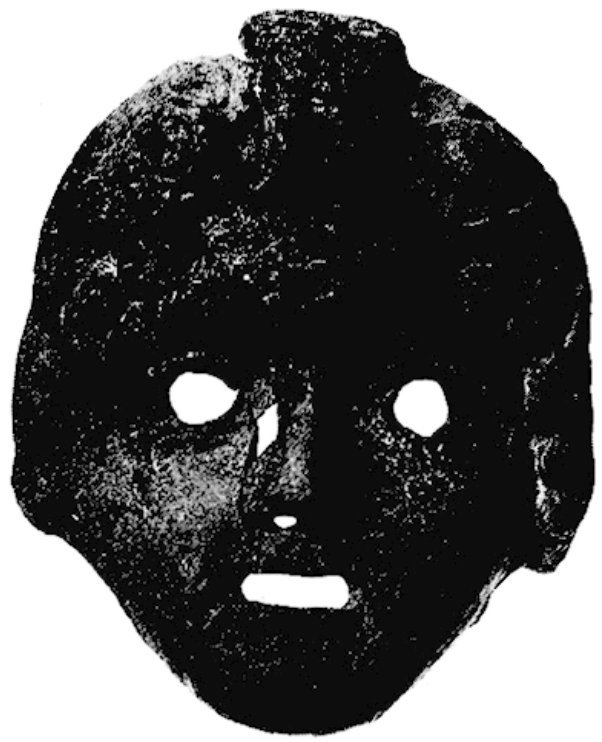

Fig. 28. Nécropole de Gorgippia. Masque en terre cuite du jeune Dionysos découvert dans une tombe d'enfant

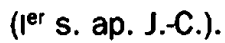

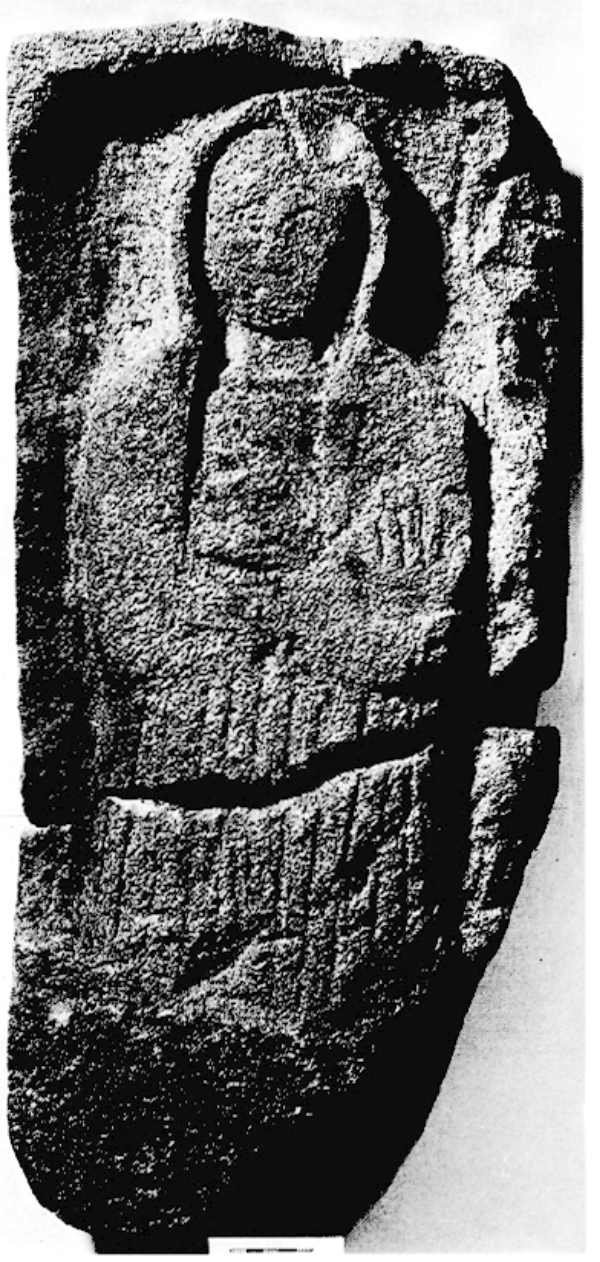

Fig. 30. Ibid. Stèle funéraire en calcaire (premiers siècles ap. J.-C.). 


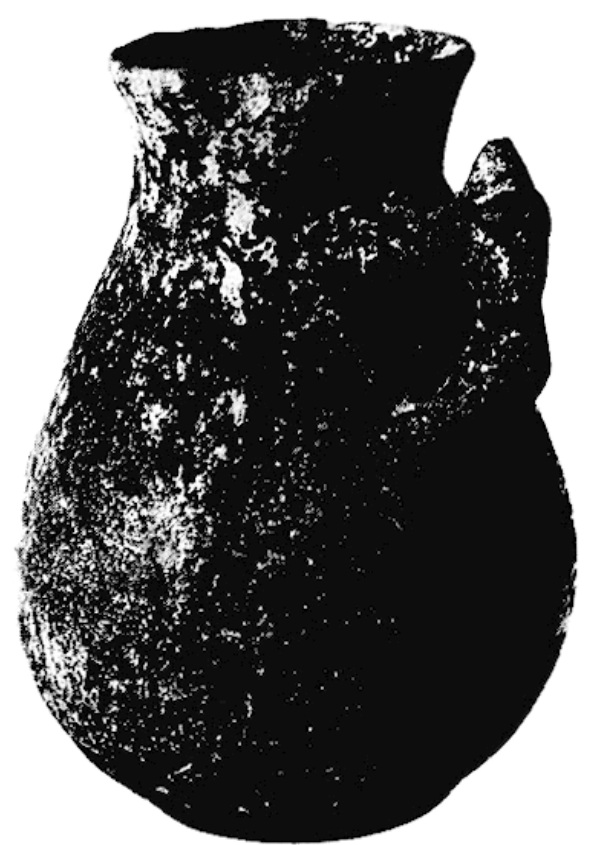

Fig. 31. Nécropole de Gorgippia. Cruche avec anse zoomorphe trouvée dans une tombe ( $\|^{e}$ s. ap. J.-C.), manifestant une influence de la culture sarmate du Caucase septentrional.

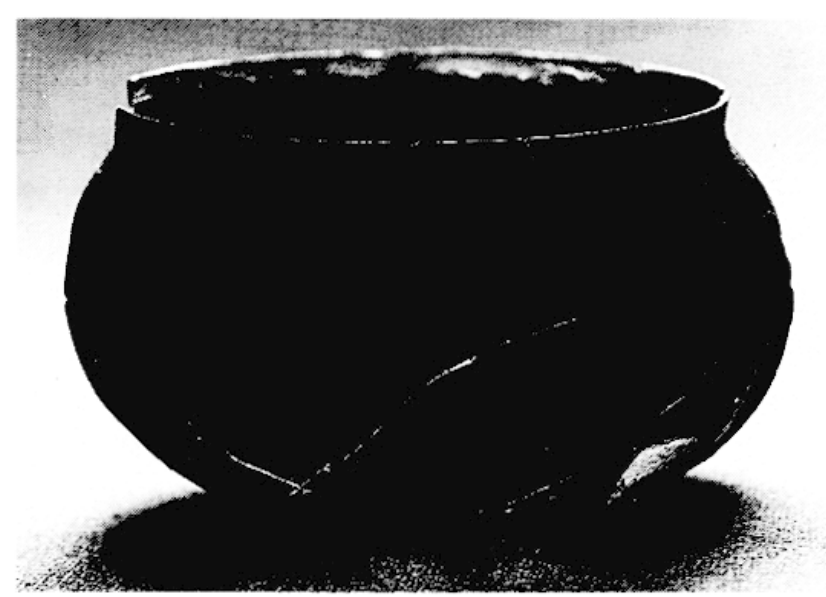

Fig. 32. Ibid. Phiale en verre violet trouvée dans une tombe ( ${ }^{\text {er }}$ s. ap. J.C.).

- On se reportera, pour plus de détails, à deux ouvrages de synthèse dus à E. ALEXEIEVA : La colonisation grecque du Caucase Nord-Ouest (1991), Moscou, et, surtout, Gorgippia, ville antique (1997), Moscou. Dans ce dernier ouvrage, l'auteur publie le matériel découvert depuis 1973, date à laquelle elle a pris la direction des fouilles, et livre, abondamment illustrée, une monographie de la cité durant ses huit siècles d'existence.

— Fouilles de 1991-1992 sur le site Andreevskaya Tchel (chôra de Gorgippia), découvert en 1978. La stratigraphie a révélé deux phases principales : l'une datant des premiers siècles ap. J.-C. et la seconde de l'époque hellénistique, le matériel découvert dans l'une des fosses permettant de rapporter l'apparition du site à la deuxième moitié du IV $\mathrm{e}$ s. av. J.-C. L'ensemble fut ensuite recouvert d'une sépulture des $\mathrm{X}^{\mathrm{e}}-\mathrm{XII}^{\mathrm{e}} \mathrm{s}$. ap. J.-C. BS 4 (1994), p. 172-174.

— Poursuite en 1992 de la fouille de la nécropole découverte en 1981 à $10 \mathrm{~km}$ à l'Est de la ville, dans la propriété dite Anapa, et mise au jour de huit tombes dont sept tombes à fosse (avec ou sans tumulus) et une tombe à ciste datant des années 450-400 av. J.-C. Ibid., p. 164-168.

\section{Képoi}

\section{Situation géographique et travaux antérieurs}

La petite cité de Képoi se trouve à environ $3 \mathrm{~km}$ au Nord-Est de Phanagorie, également au bord du golfe de Taman. Képoi est connue par le fait qu'y vécut le grand-père de Démosthène, Gilôn. La cité s'étendait sur une petite colline et occupait une superficie de 20 à 25 ha. Les fouilles commencèrent en 1957, sous la direction de N. Sokolsky, qui détermina les limites du site et en fixa la chronologie, du $\mathrm{VI}^{\mathrm{e}} \mathrm{s}$. av. J.- 

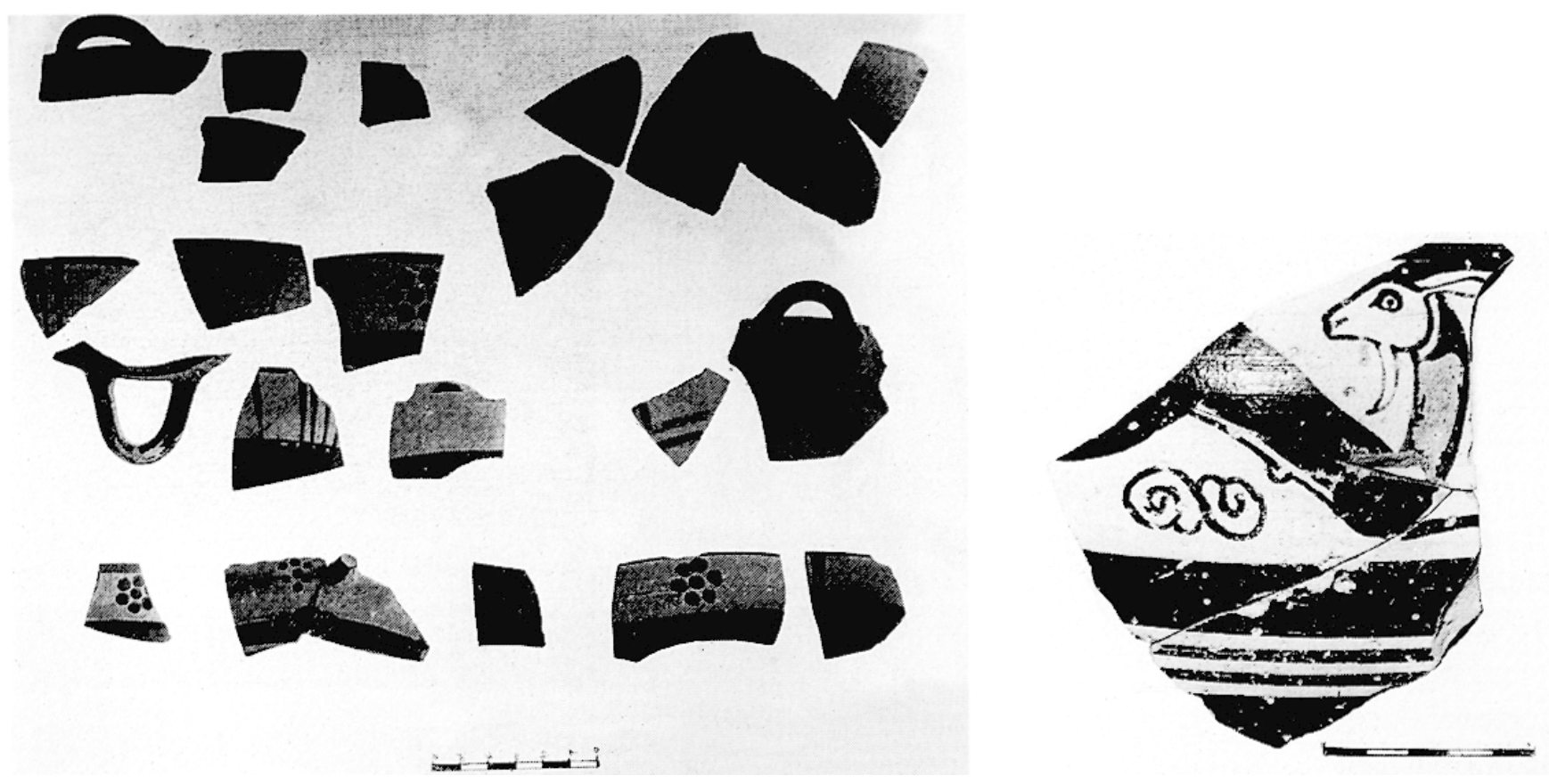

Fig. 33. Képoi. Cratères et coupes ioniens.

C. au IV ${ }^{c}$ s. ap. J.-C. Elles se poursuivirent ensuite jusqu'en 1972, sous la direction de N. Sorokina et É. Nikolaeva. La stratigraphie de Képoi est très mal conservée, à cause de l'absence de pierres sur la péninsule de Taman et des multiples réaménagements urbains survenus dans l'Antiquité.

\section{Travaux récents}

De 1984 à 1989, des fouilles ont été entreprises sur le site, dont le résultat le plus intéressant fut la découverte de plusieurs centaines de fragments céramiques d'époque archaïque ( $2^{\mathrm{c}}$ et $3^{\mathrm{e}}$ quarts $\mathrm{du} \mathrm{VI}^{\mathrm{e}}$ s. av. J.-C.). Malheureusement, aucune construction de cette époque n'est conservée, à cause des destructions intervenues dès l'Antiquité. La céramique archaïque se répartit en deux groupes. Le premier comprend la céramique ionienne, avec les types suivants (fig. 33) : cratères, amphores et œnochoés de la dernière phase du Wild Goat Style; assiettes et kalathoi bordés de méandres; calices de Chios décorés de figures d'animaux (animal figure chalices); bols à lotus et rosettes; coupes ioniennes de type A2-B2 et B3 (classification ValletVillard). Le deuxième groupe comprend la céramique attique peinte (fig. 34), avec des coupes des cômastes, des coupes de Siana et des coupes des Petits Maîtres, des amphores et des lékanés. Cette céramique comporte un certain nombre de fragments percés de trous avant la cuisson : il s'agit d'offrandes destinées
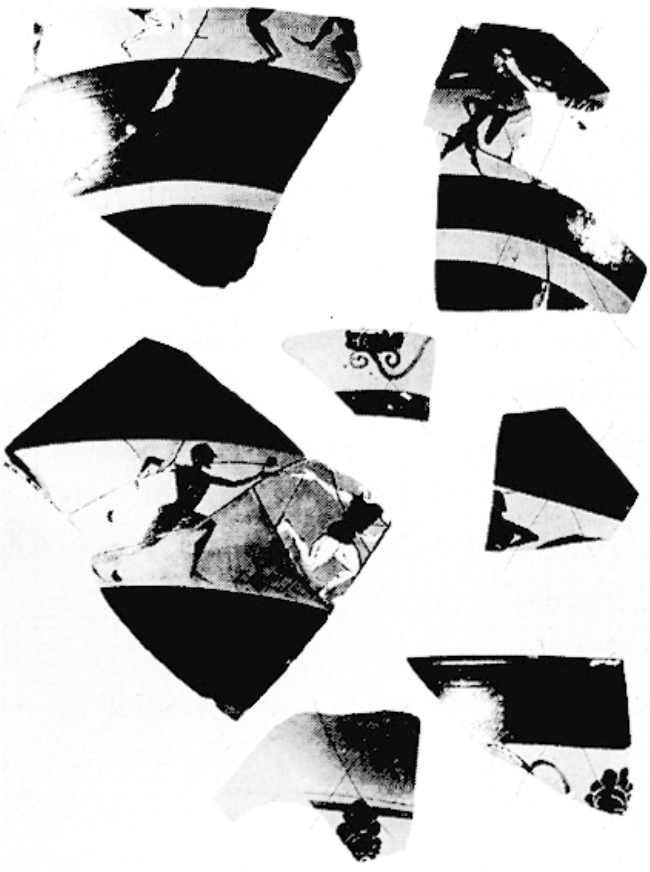

Fg. 34. Ibid. Fragments de coupes attiques. 
à un sanctuaire, compte tenu du fait que N. Sokolsky a découvert, à proximité immédiate, un graffiti portant une inscription qui permet d'affirmer qu'à cet endroit se trouvait, à l'époque archaïque, un sanctuaire d'Aphrodite - détruit par un incendie dont le sol sableux a gardé la trace. On a découvert là une petite tête d'époque hellénistique appartenant à une Aphrodite en marbre (fig. 35).

Les fouilles des années 1994-1996 ont concerné la périphérie orientale du site, qui avait longtemps servi de base à une mission géologique. Pendant les travaux préliminaires de 1994, on procéda à deux sondages d'une superficie totale de $18 \mathrm{~m}^{2}$. Il fut établi que la stratigraphie atteignait là $4 \mathrm{~m}$ d'épaisseur environ, mais qu'elle était détruite sur $2,50 \mathrm{~m}$ à $3 \mathrm{~m}$, l'endroit ayant été occupé, pendant la Seconde Guerre mondiale, par des bâtiments du génie maritime et, plus tard, par la pompe à essence et le garage de la mission géologique. Il ne subsiste plus en place qu'une épaisseur de $1 \mathrm{~m}$ à $1,5 \mathrm{~m}$ de stratigraphie et les niveaux

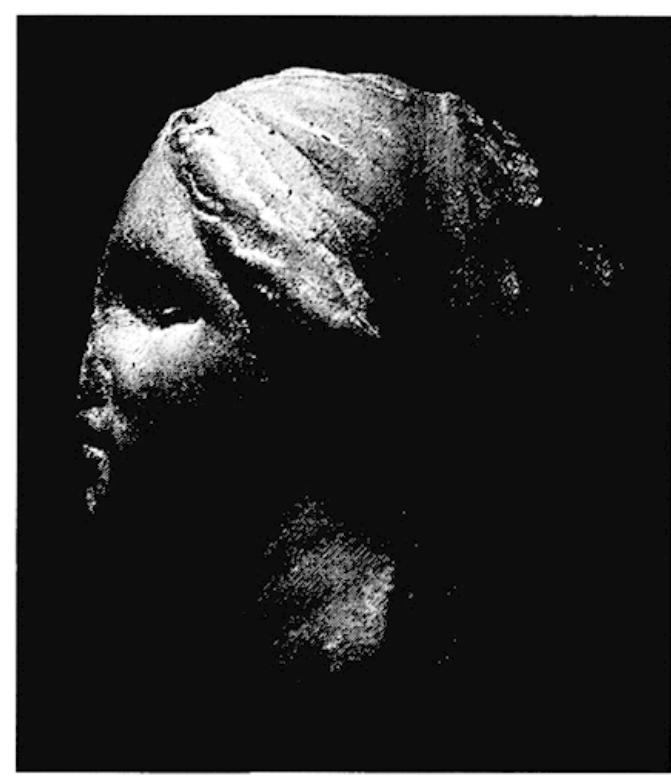

Fig. 35. Képoi. Tête d'Aphrodite en marbre. inférieurs des fosses de rejet creusées dans le sable du sol naturel.

En 1995-1996, on a fouillé à trois endroits différents sur une surface totale de $140 \mathrm{~m}^{2}$. Les objets découverts hors contexte stratigraphique, dans la couche endommagée, permettent de conclure que les niveaux détruits correspondent, dans l'ensemble, aux II $\mathrm{I}^{\mathrm{e}}-\mathrm{IV}^{\mathrm{e}} / \mathrm{V}^{\mathrm{e}}$ s. ap. J.-C. Pendant cette période, on a construit sur le site des maisons en brique crue sur fondations de pierre : les murs intérieurs étaient recouverts d'enduit et la couverture des toits consistait probablement en remplois de tuiles hellénistiques du Bosphore et de Sinope. On maintenait des liens commerciaux, avant tout, avec les centres de la mer Noire du Nord et du Sud. Le matériel ostéologique montre que le gros bétail à cornes dominait (75 à $80 \%$ ) au sein du cheptel domestique.

Dans le sol vierge, fut mise au jour une couche du $\mathrm{I}^{\mathrm{er}} \mathrm{s}$. av. J.-C.-milieu du $\mathrm{I}^{\mathrm{er}}$ s. ap. J.-C. Cette particularité s'explique par le fait que, vraisemblablement, au tournant des $\mathrm{II}^{\mathrm{e}}-\mathrm{I}^{\mathrm{er}} \mathrm{s}$. av. J.-C., furent menés, au moins dans la partie orientale du site, d'amples travaux de terrassement et de réorganisation de l'urbanisme qui entraînèrent la destruction des couches antérieures. Cette conclusion repose sur l'existence, dans le secteur 2, d'une terrasse artificielle. Une situation analogue avait surgi dans la partie Nord-Ouest du site, pendant les fouilles de 1984. A cette couche se rapportaient des vestiges de construction : fondations et substructions de murs de maisons, construits eux-mêmes en brique crue. Les substructions étaient formées de galets et de fragments de céramique ; leur épaisseur était d'environ $0,10 \mathrm{~m}$ et leur largeur de $0,70 \mathrm{~m}$ à $0,80 \mathrm{~m}$. Cette technique de construction se rencontre souvent sur les sites ruraux de Taman, en particulier dans la ferme fouillée par E. Savostina sur le site de Jubilejnoe et, de même, sur le site voisin de Phanagorie. Les constructions découvertes présentaient un plan régulier et étaient orientées, avec un léger décalage, selon les points cardinaux. Elles comportaient des caves et des fosses de rejet.

Une épaisse couche d'incendie, qui recelait des pointes de flèches, un boulet de pierre venant d'une catapulte ainsi que des ossements d'enfants et d'adultes, témoignent des dommages subis par la ville dans les années 45-49 ap. J.-C., époque de la guerre entre Mithridate III et Cotys I ${ }^{\mathrm{er}}$. Dans la couche d'incendie fut découverte une monnaie de cuivre bosporane de la reine Hypépyris, qui régna en 37-38 ap. J.-C. La fouille de 1984 avait donné des résultats similaires dans la partie Nord-Ouest.

Les fragments d'amphores mis au jour suggèrent que les relations économiques du site à cette époque se limitaient au Pont Nord. Le matériel ostéologique comprend essentiellement (75\%) des restes de gros bétail à cornes. 
La deuxième couche date des $\mathrm{II}^{\mathrm{e}}-\mathrm{IV}^{\mathrm{e}} \mathrm{s}$. ap. J.-C. et présente de nombreuses fosses de rejet. Les vestiges d'un pressoir presque entièrement détruit, dont nous avons pu, en partie, reconstituer la structure, constituent une exception. Il se présentait comme une construction temporaire (longueur Est-Ouest : $5,40 \mathrm{~m}$ ), composée de deux pièces contiguës. Celle de l'Est qui, manifestement, constituait une annexe, comprenait deux aires de piétinement. On y a reconnu deux états de construction. Parmi les blocs de remploi, on a découvert un fragment de corniche.

La faible importance des vestiges témoigne du fait que la construction a respecté les traditions de la période antérieure. Dans certains secteurs, on trouve deux niveaux de construction : l'un du II $^{\mathrm{c}} \mathrm{s}$.-première moitié du III s. ap J.-C., l'autre de la seconde moitié du III s. ${ }^{\mathrm{e}}$-IV ${ }^{\mathrm{e}}$ s. ap. J.-C. Il est presque certain qu'à cette époque la partie orientale du site, après la destruction du milieu du $\mathrm{I}^{\mathrm{er}} \mathrm{s}$. ap. J.-C., ne fut pas reconstruite, mais utilisée comme dépôt d'ordures et, probablement, de produits d'artisanat, puisqu'on y a retrouvé des déchets liés à la production du verre. Les relations économiques se limitaient, pour cette époque, aux centres pontiques; le gros bétail à cornes dominait dans le cheptel domestique. La caractéristique de cette période réside dans l'augmentation du pourcentage de la vaisselle barbare modelée et tournée.

Les deux couches comprenaient une quantité significative de matériel des $\mathrm{VI}^{\mathrm{c}}-\mathrm{II}^{\mathrm{e}}$ s. av. J.-C., avec de la céramique de Chios, de Samos, de Thasos, de Rhodes, de Cos, de Sinope, de Colchide, d'Héraclée, d'Attique et du Bosphore, mais aussi des graffiti, des dipinti et des sceaux de Rhodes et du Bosphore. Mais aucun vestige de construction ou d'exploitation d'époque grecque ne fut découvert à la périphérie orientale du site. Peut-être cette particularité s'explique-t-elle par le fait que la colonie d'origine occupait la partie Nord-Ouest du site [V. Kuznetsov, Y. Gorlov², M. Abramzon²3].

\section{Patrasys}

\section{Situation géographique et travaux antérieurs}

L'établissement que l'on rapporte généralement à l'antique Patrasys est situé sur la rive Nord du golfe de Taman, à la lisière occidentale du village actuel de Garkoucha. La chronologie du site couvre une période qui s'étend de la fin du II $^{c}$ millénaire av. J.-C. jusqu'à l'époque médiévale tardive. La stratigraphie est perceptible le long de l'escarpement du rivage sur une distance d' $1,2 \mathrm{~km}$. Le long de cette ligne et jusqu'à $100 \mathrm{~m}$ du rivage, ont été découverts sous l'eau 18 complexes archéologiques, gisant à une profondeur qui peut atteindre $1,50 \mathrm{~m}$. Ces complexes datent d'une période comprise entre le dernier quart du $\mathrm{VI}^{\mathrm{c}} \mathrm{s}$. et le deuxième quart du Irs s. av. J.-C. Sur la terre ferme, un ravin peu profond, orienté NO-SE à l'intérieur du site, divise celui-ci en deux parties, l'une occidentale, l'autre orientale, de superficie à peu près égale. On peut raisonnablement supposer, en se fondant sur le microrelief du fond marin, que ce ravin pouvait se prolonger dans la mer sous la forme d'un petit golfe qui existait dans l'Antiquité.

Dans la partie Est du site, se trouvent les vestiges d'une forteresse d'époque romaine, la batareyka ("forteresse") de Patrasys, monument qui, le premier, attira l'attention des archéologues. En 1928, A. Bachkirov entreprit les premières fouilles, qui se prolongèrent, avec quelques interruptions, jusqu'en 1962. De 1964 à 1970, l'exploration de Patrasys fut menée par une mission de l'Institut archéologique placée sous la responsabilité de N. Sokolsky. Ces travaux ont permis d'établir que, dans la première moitié du III' s. av. J.-C. existait déjà, dans le secteur oriental de Patrasys, un établissement grec comportant 
des maisons en pierre et en brique crue. Cet établissement disparut, à la suite de guerres, dans les années 70 av. J.-C., date fournie par un trésor monétaire comportant des types du Bosphore comme de Sinope.

À la fin du Irer s. av. J.-C. ou au début du Ir s. ap. J.-C., on construisit à cet endroit une forteresse entourée d'un fossé et d'un remblai, sur lequel furent édifiées des murailles en brique crue d'une épaisseur atteignant jusqu'à $3,20 \mathrm{~m}$. Les structures les plus intéressantes mises au jour sont les vestiges de deux piliers séparés par un pavement, qui constituent les portes de la forteresse. L'exploration des locaux intérieurs a permis de mettre en évidence une couche de destruction datant de la fin du ${ }^{\text {er }} s$. ou du début du II ${ }^{e} s$. ap. J.C. On ne connaît pas moins de cinq monuments analogues de la péninsule de Taman qui ont subi un sort identique à la même époque. Les destructions postérieures s'accompagnent de l'enfouissement de trésors datant du milieu du $\mathrm{III}^{\mathrm{e}}$ s. et des années 330-340 ap. J.-C. À proximité de la forteresse, on a mis au jour deux pressoirs à vin et un four de potier datant des $\mathrm{II}^{\mathrm{e}}-\mathrm{III}^{\mathrm{e}}$ s. ap. J.-C. Par ailleurs, en 1965, des fouilles peu étendues ont révélé des vestiges d'un établissement antérieur, daté des $\mathrm{VI}^{\mathrm{e}}-\mathrm{IV}^{\mathrm{e}}$ s. av. J.-C., dans la partie occidentale de Patrasys.

\section{Travaux récents}

En 1985, une équipe de la mission de la péninsule de Taman (Institut archéologique de l'Académie des sciences) a repris les travaux, sous la direction de B. Peters et, depuis 1990, de A. Abramov. Depuis 1991, V. Taskaev dirige l'exploration archéologique sous-marine de la partie immergée du site.

A l'heure actuelle, les lignes directrices de la recherche sont les suivantes:

- dans la partie occidentale du site, une fouille menée sur la ligne du rivage, dont l'érosion est due à des facteurs naturels ;

- sur l'emplacement du vignoble qui jouxte directement le secteur étudié, une prospection intensive qui recense tant la densité du matériel de surface que la répartition spatiale des fragments datables;

— une étude détaillée du microrelief du site lui-même et de sa partie engloutie ;

- une prospection sous-marine.

Grâce à ces travaux, on a pu établir l'existence, à la fin du $\mathrm{II}^{\mathrm{e}}$ et au début du Irr millénaire av. J.-C., d'un établissement du Bronze Récent, voire du Premier Âge du Fer, dans la partie centrale du site de Patrasys. Aucun vestige d'habitation n'a encore été trouvé. Ont été fouillées une trentaine de fosses qui contenaient des fragments de vases ou des vases entiers, ainsi que des outils en pierre et en os. L'établissement grec le plus ancien, apparu dans la partie occidentale du site, occupait un cap et se trouvait limité au Sud par la ligne de rivage. Le ravin constituait sa limite Nord-Est. Du côté Nord-Ouest, l'établissement était protégé par un fossé, dont l'existence a été révélée en 1997 par l'étude du microrelief de la partie immergée du site, puis confirmée par les fouilles du rivage. La superficie de l'établissement atteignait 4,5 ha, mais une bonne partie de celui-ci se trouve aujourd'hui sous l'eau. La limite Sud est déterminée par une série de complexes, parmi lesquels deux puits construits en pierre, et par des dépôts d'amphores.

La date de fondation peut être fixée, grâce à des fragments d'amphores de Chios, d'Athènes et de Clazomènes, du deuxième quart du VI ${ }^{e}$ s. av. J.-C. Deux fosses contenaient du matériel du troisième quart du VI ${ }^{\mathrm{c}}$ s. av. J.-C., dont deux pots modelés, trouvés dans l'une d'elles et qui ont pu être entièrement recollés ; la forme des vases modelés n'a rien de commun avec la céramique du Bronze tardif et du début de l'Âge du Fer. Les vestiges de construction les plus anciens, mis au jour dans le secteur Ouest de Patrasys, consistent en des murs d'habitations, construits en brique crue et orientés Nord-Sud. Ils ne sont pas postérieurs à la fin du VIc ou au début du Ve s. av. J.-C. La fouille a permis d'établir qu'ils ont été coupés par une fosse contenant 14 amphores entières, dont neuf amphores de Chios du deuxième quart du $\mathrm{V}^{\mathrm{e}} \mathrm{s}$. et cinq fabriquées dans un centre éolien. 
À l'Ouest du site, s'étendait une zone d'activité économique de 5,3 ha. Grâce aux fouilles, on a pu établir avec précision sa limite Ouest, ainsi que sa limite Nord par comparaison avec le matériel récolté lors de la prospection. Celle-ci a en effet permis la localisation de plusieurs fermes isolées des $\mathrm{VIII}^{\mathrm{c}}$-IX ${ }^{\mathrm{c}} \mathrm{s}$. et XIII ${ }^{\mathrm{e}}$ $\mathrm{XV}^{\mathrm{e}}$ s. ap. J.-C., mais d'aucun établissement antique de ce type.

Dans la première moitié du III ${ }^{\mathrm{e}}$ s. av. J.-C., le site se déplace du côté Est du ravin. Le matériel de comblement du fossé peut être daté de la seconde moitié du IV ${ }^{e}$ s. et du début du III s. av. J.-C. On peut supposer que la raison de cet événement est d'ordre politique. C'est à cette époque que Porthmion est entièrement reconstruite et que Tanaïs apparaît.

Comme l'ont montré les fouilles de 1990, les constructions et les maisons situées en dehors de la forteresse étaient protégées par un second fossé dont le comblement remonte au IVe s. ap. J.-C. La couche la plus tardive du secteur oriental porte la trace de constructions en pierre des VIII ${ }^{\mathrm{e}}-\mathrm{IX}^{\mathrm{e}}$ s. ap. J.-C. et de quelques bâtiments isolés des XIII'- XV's. ap. J.-C.

L'exploration archéologique sous-marine de 1991 a conduit à la découverte d'un puits qui cessa d'être utilisé au début du $\mathrm{II}^{\mathrm{e}} \mathrm{s}$. av. J.-C. Cette structure a été étudiée dans son intégralité. Les blocs de pierre formant son assise reposaient sur des billes de chêne remarquablement conservées. Cet élément ayant été découvert à $700 \mathrm{~m}$ au Sud-Ouest de la limite du site contemporain, on peut supposer qu'il appartenait à une ferme isolée de la même période.

En conclusion, il faut souligner que la stratigraphie de la partie immergée ne s'est pas conservée et que nous sont parvenus seulement des éléments ou des structures enfouis dans l'argile continentale. La situation inverse s'observe à Phanagorie et une situation analogue à Hermonassa, selon V. Blavatsky [A. Abramov ${ }^{24}$ ].

- Compte rendu de l'ensemble des fouilles sous-marines menées dans le golfe de Taman, dont celles de 1990-1991 près de Patrasys. La découverte, à la fin des années 1980, à une distance de 7 à $106 \mathrm{~m}$ du rivage, de dix dépôts céramiques sous-marins darés entre le dernier quart du $\mathrm{VI}^{\mathrm{e}} \mathrm{s}$. et le troisième quart du IV s. av. J.-C., suggérait qu'il s'agissait d'une cargaison d'un bateau échoué. Mais les recherches ultérieures ont établi l'existence d'un puits, situé à $98 \mathrm{~m}$ du rivage à une profondeur de $1,6 \mathrm{~m}$ et construit au tournant du IV et du III' $s$. av. J.-C. Ce puits, fait de blocs de calcaire, présentait une ouverture d'un peu plus d' $1 \mathrm{~m}^{2}$ entourée de tous côtés par un dallage en pierres. À $30 \mathrm{~m}$ au Sud du puits, on a découvert une série de blocs travaillés disposés en demi-cercle, ainsi que, un peu plus loin encore, deux amas de blocs et, dans un rayon de $100 \mathrm{~m}^{2}$ autour d'eux, une grande quantité de fragments céramiques datés entre la deuxième moitié du $\mathrm{V}^{\mathrm{e}} \mathrm{s}$. et le III $\mathrm{s}$. av. J.-C. Ces constructions prouvent qu'il s'agit de la partie immergée de la cité. BS 1 (1992), p. 212-219.

- Publication du matériel découvert dans trois de ces dépôts céramiques sous-marins, dont le matériel de remplissage de la partie supérieure du puits (dépôt $n^{\circ} 8$ ), qui se distingue des deux autres par la présence dominante de cruches et non d'amphores. Le dépôt $\mathrm{n}^{\circ} 1$, découvert en 1990 à $100 \mathrm{~m}$ du rivage et 2,25-2,33 m de profondeur, provient d'une fosse de $1,40 \mathrm{~m}$ de diamètre et date, d'après le matériel amphorique, du dernier quart du $\mathrm{VI}^{\mathrm{c}} \mathrm{s}$. av. J.-C. Le dépôt $\mathrm{n}^{\circ} 2$ provient d'une fosse de $1,50-1,70 \mathrm{~m}$ de diamètre, située à $2,50 \mathrm{~m}$ de profondeur, et date du tournant entre le troisième et le dernier quart du Ve s. av. J.-C. Ibid., p. 147-172.

- Publication du "plan archéologico-topographique " du site, qui consiste en une série de schémas (sans levé topographique réel) accompagnés d'un historique des travaux archéologiques et cartographiques menés depuis le XIX ${ }^{\mathrm{c}}$ siècle et d'un descriptif des fouilles et prospections, carré par carré, établi essentiellement à partir des archives déposées à l'IARAN. BS 3 [1993], p. 136-162. 
- Compte rendu des fouilles de 1990-1991, avec la publication de la fosse (cf. contribution d'A. Abramov) comprenant 14 amphores entières du deuxième quart du $\mathrm{V}^{\mathrm{e}} \mathrm{s}$. av. J.-C. BS 4 (1994), p. 127-140.

- Publication d'un ensemble de plus de 70 fragments céramiques découverts en 1990 dans une fosse mise au jour lors de travaux dans une maison privée, à $260 \mathrm{~m}$ au Nord-Est de la batereika. La fosse contenait une sépulture sous laquelle se trouvait une poche contenant des amphores à pâte claire et col étroit, des amphores à pâte rosée, de la céramique à vernis rouge, des cruches, de la céramique à paroi fine, de la vaisselle de cuisine non tournée et des pesons, l'ensemble datant du III s. ap. J.-C. Ibid., p. 65-83.

- Publication du matériel découvert dans quatre fosses mises au jour en 1992, lors d'une fouille dans la partie Ouest du site destinée à déterminer l'extension de la stratigraphie dans cette direction. Le matériel date des $\mathrm{VI}^{\mathrm{e}}-\mathrm{IV}^{\mathrm{e}}$ s. av. J.-C. et comprend, entre autres, des amphores (Chios étant bien représentée), de la vaisselle de table et des lampes. La trouvaille la plus intéressante est un fragment d'anse d'amphore samienne datée du deuxième quart du VI $I^{e}$ s. av. J.-C. Compte tenu du nombre significatif de fragments du troisième quart du $\mathrm{VI}^{\mathrm{e}}$ s. av. J.-C. découverts par ailleurs, on peut supposer qu'il existait là un établissement dès cette époque. Ibid., p. 84-106.

- Publication détaillée des sépultures découvertes sur le site ou dans un rayon de moins de $2 \mathrm{~km}$. On compte trois tombes de l'Âge du Bronze (entre le milieu du III et le premier quart du II $^{e}$ millénaire) situées à l'Ouest du site, sous un kourgane fouillé en 1963, et une tombe de la fin de l'Âge du Bronze ou début de l'Âge du Fer découverte en 1991 sur le site d'époque correspondante. S'y ajoutent six sépultures antiques et deux d'époque médiévale (VII $-\mathrm{VIII}^{\mathrm{e}} \mathrm{s}$. ap. J.-C.). Pour les trois tombes classiques et hellénistiques se pose la question de leur attribution "ethnique ": leur orientation à l'Est et le matériel céramique (lécythes, skyphoi, amphores) qu'elles ont livré invitent à les attribuer à des Grecs locaux, malgré la présence d'armes dans l'une d'elles, élément qui conduit souvent à une attribution indigène. Ibid., p. 108-126.

\section{Ilitch}

\section{Situation géographique et travaux antérieurs}

Le site d'Ilitchevskoe est situé dans la partie Nord-Ouest de la péninsule de Taman, près du village d'Ilitch, à environ $2 \mathrm{~km}$ au N-NE de l'amorce du cordon sableux de Tchouchka, qui s'étendait sur $20 \mathrm{~km}$ vers le Sud-Ouest depuis le continent et séparait le détroit de Kertch du golfe de Taman. En d'autres termes, le site antique se trouvait sur le point le plus septentrional du Bosphore cimmérien, sur sa rive asiatique.

Le 17 juin 1794, P. Pallas fut le premier à visiter le site, que mentionnent ensuite Fr. Dubois de Montepereux, Ia. Lazarevsky et K. Gertz. En 1870, V. Tiesenhausen mena les premières fouilles sur la citadelle. En 1926, le site attira l'attention de A. Bachkirov par ses dimensions considérables. D. Chelov y mena en 1949 des fouilles de reconnaissance. De 1964 à 1967, des fouilles importantes furent conduites sur la citadelle par N. Sokolsky et de 1974 à 1993, E. Nikolaeva dirigea à son tour les travaux.

La taille du site est d'environ 12 à 16 ha. Le territoire qui le jouxte et sur lequel on trouve en surface des vestiges antiques occupe à peu près 42 ha. Dans la partie centrale du site, s'étendent les vestiges d'une forteresse construite en briques crues sur soubassement de pierre, qui date à peu près du début de notre ère. Le plan en est carré (100 x $100 \mathrm{~m}$ env.). A 50-80 m de là, sont conservées des levées de terre entourant la citadelle. Aux I ${ }^{\mathrm{er}}-\mathrm{II}^{\mathrm{e}}$ s. ap. J.-C., le site se concentrait à l'intérieur des limites de ces défenses. 
Plus tard, aux IV $\mathrm{V}^{\mathrm{e}} \mathrm{V}^{\mathrm{e}}$ s. ap. J.-C., celles-ci furent utilisées comme dépotoir. Au-delà des limites des remparts, se trouvaient des structures rurales, en particulier à $173 \mathrm{~m}$ vers le Sud un grand pressoir à vin, daté par les fouilleurs de la fin des IV $\mathrm{V}^{\mathrm{e}}-\mathrm{V}^{\mathrm{e}} \mathrm{s}$. ap. J.-C. Un autre complexe de ce type, datant de la première moitié du I ${ }^{\mathrm{er}} s$. ap. J.-C., fut découvert en 1993 sur le rivage à environ $0,6 \mathrm{~km}$ au Sud-Ouest de la forteresse.

Celle-ci eut une longue existence et fut plusieurs fois détruite, puis restaurée. Du $\mathrm{II}^{\mathrm{e}}$ au IV $\mathrm{IV}^{\mathrm{e}}$ s. ap. J.-C., elle fut, semble-t-il, abandonnée. Le dernier état de destruction date du troisième quart du $\mathrm{VI}^{\mathrm{e}} \mathrm{s}$. ap. J.-C., d'après le matériel qui comprend notamment un trésor de monnaies bosporanes tardives avec des solidi en or de Justinien I ${ }^{\text {er }}$.

\section{Travaux récents}

Il convient de souligner qu'au cours de ces nombreuses années l'attention des chercheurs s'était concentrée sur l'étude des vestiges de la citadelle et, avant tout, sur les structures situées à l'intérieur ; ces dernières, uniques par leur état de conservation, avaient été détruites en une fois au moment de l'assaut et de l'incendie de la citadelle dans le troisième quart du $\mathrm{VI}^{\mathrm{e}} \mathrm{s}$. La période plus ancienne de l'histoire du site avait été beaucoup moins étudiée. Cela confere d'autant plus d'importance aux fouilles limitées d'un complexe rural de la première moitié du $\mathrm{I}^{\mathrm{er}}$ s. ap. J.-C., menées en 1996-1997 sur l'escarpement du rivage, à environ $500 \mathrm{~m}$ au Nord-Ouest de la forteresse.

Malheureusement, les archéologues n'eurent accès à cette structure - qui se présentait comme une série de vestiges d'un bâtiment attaché à une ferme - qu'après que sa partie supérieure eut été détruite, jusqu'à la dernière assise du soubassement, par un chantier de construction. En outre, la partie Sud-Est du bâtiment resta en dehors des limites de la fouille, à cause de la présence d'une route menant du village d'Ilitch jusqu'au phare.

Ainsi put-on mettre au jour les assises inférieures en pierre du soubassement de cette construction, qui présentait un plan fermé quadrangulaire (seule la partie Nord fut fouillée) et au centre de laquelle, semble-t-il, se trouvait une cour entourée d'un côté, voire de plusieurs, par des rangées de pièces (fig. 36). Les murs du bâtiment sont orientés selon les points cardinaux. Un peu après la construction du bâtiment principal, fut édifié, à partir de l'angle Nord de celui-ci du côté Est, un autre local pourvu d'une entrée indépendante au Sud.

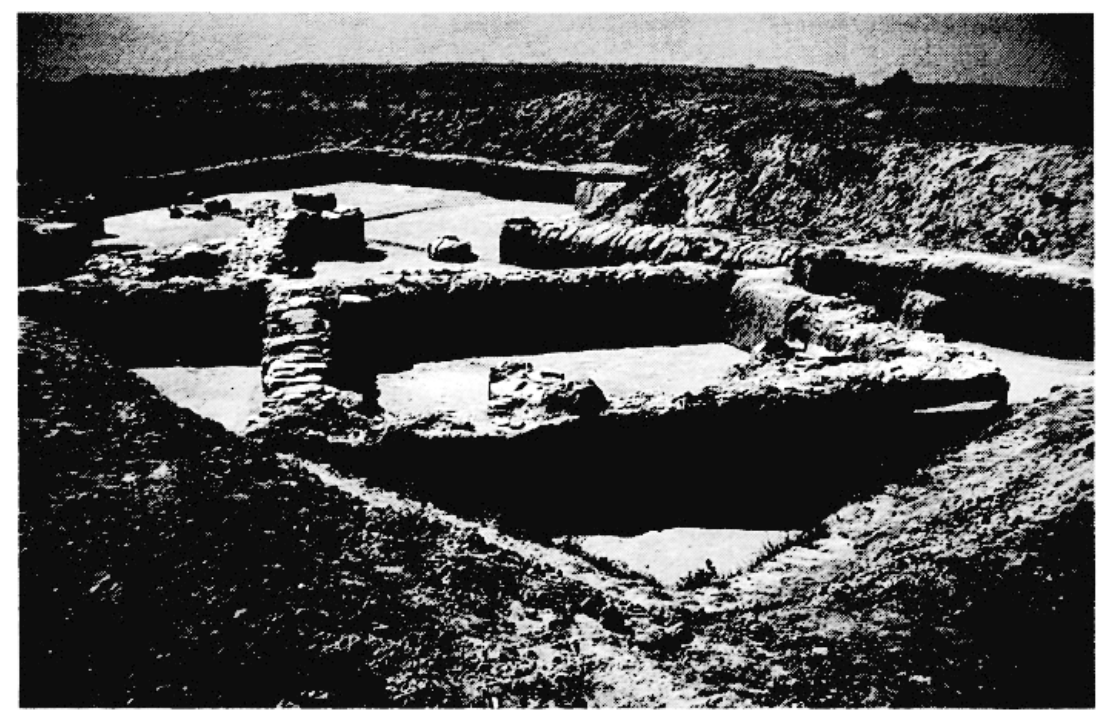

Fig. 36. Ilitchevskoe. Vue générale de la fouille de 1996-1997 depuis l'Est. 
Le matériel découvert dans la stratigraphie était peu abondant et relativement uniforme. Les amphores les plus importantes sur le plan chronologique étaient celles à pâte claire provenant d'un centre du Pont Sud : il s'agit d'amphores à col large et anses bifides (milieu du ${ }^{\text {cr }}$ s. av. J.-C.-milieu du I ${ }^{\text {er }}$ s. ap. J.-C.) et d'amphores à col étroit de type A (selon la classification de D. Chelov) de la première moitié du I ${ }^{\text {er }}$ s. ap. J.C. On rencontre également des fragments de plats à vernis rouge des $\mathrm{I}^{\mathrm{er}}$ s. av. J.-C.- $\mathrm{I}^{\mathrm{er}}$ s. ap. J.-C., de vaisselle de cuisine non tournée, de pithoi et de vaisselle tournée à usage culinaire et domestique, de production bosporane locale. Les monnaies sont rares : en dehors d'une monnaie qui n'a pas encore été restaurée, trois d'entre elles furent frappées sous Mithridate VIII (env. 39/40-41/2 ap. J.-C.), à quoi s'ajoute la découverte, en 1996, non loin de la fouille, d'une monnaie d'Amysos (env. 85-65 av. J.-C.).

Le caractère de la stratigraphie et la proximité de la forteresse laissent penser que les habitants de cet établissement rural vivaient là en général à la saison des travaux agricoles, tandis que durant l'automne et l'hiver (ou en cas de menace militaire) ils s'installaient à l'intérieur de la forteresse. Comme le complexe vinicole précédemment évoqué, l'établissement fut détruit au milieu du $\mathrm{I}^{\mathrm{er}} \mathrm{s}$. ap. J.-C. et ne fut jamais réutilisé. Il semble que sa destruction soit liée à la période du conflit entre Mithridate et son frère Cotys Ire qui monta sur le trône du Bosphore avec l'appui des forces romaines vers 45 ap. J.-C. Des traces de destruction de cette époque sont attestées sur d'autres sites du Bosphore. Indépendamment de cela, il convient de souligner que la destruction et l'abandon définitif par ses habitants d'un établissement situé à proximité d'une forteresse qui constituait un centre militaro-administratif majeur du Bosphore asiatique, marquent une nouvelle étape dans l'histoire de cette région. Pour savoir ce que fut cette étape, il faut se tourner vers les sites qui survécurent au cataclysme du ${ }^{\mathrm{er}}$ s. ap. J.-C. ou apparurent après, comme celui de Priazovsky 4 situé plus au Nord au bord de la mer d'Azov et qui s'épanouit de la fin du VI s. av. J.-C. au III s. ap. J.-C. [A. Zavoikine ${ }^{25}$ ].

- La mission archéologique locale, dirigée par le Musée de Taman, a mis au jour, à proximité de la batereika, en 1986, puis en 1991-1992, un grand pressoir des IVe-VI ${ }^{\mathrm{e}}$ s. ap. J.-C. : le bâtiment, d'une superficie d'environ $100 \mathrm{~m}^{2}$ était orné d'antéfixes représentant Dionysos et l'abondant matériel découvert compte de nombreuses pièces liées à la diffusion du christianisme. En 1996, au Sud du site, la même mission a fouillé un four de potier destiné à la cuisson des pithoi. TS 1 (1998), p. 78-81.

\section{Jubilejnoe}

\section{Situation géographique}

La presqu'île de Fontalovski a joué un rôle important dans l'histoire du Bosphore : elle était isolée et, en même temps, servait d'étape reliant le détroit au continent bosporan et aux steppes du Kouban et de l'Azov. C'est là que se dresse le mont Koukou-Oba, identifié par les sources antiques comme étant la tombe de Satyros, l'un des premiers rois du Bosphore. Aujourd'hui encore, on peut voir deux remparts, l'un à l'Est et l'autre au Sud-Est de l'île : le premier est construit à la frontière avec l'île de Tyrambé. Le deuxième, appelé Mur cimmérien, court le long d'un bras du Subbotin Erik : c'est au Nord de ce rempart que, de 1983 à 1993, une mission archéologique du Musée national des Beaux-Arts de Moscou a fouillé des fermes antiques. 


\section{Travaux récents (1983-1993)}

La mission a étudié les sites de Jubilejnoe I et II. Sur les photographies aériennes, ils étaient repérables sous la forme de taches claires. Sur le terrain, ils ne se distinguaient pas aussi bien, sinon par les pierres ramenées à la surface par un labourage récent et par les tessons dispersés sur $300 \mathrm{~m}$. Sous l'une et l'autre taches, on découvrit des vestiges d'habitations d'époque hellénistique tardive, distantes l'une de l'autre de $500 \mathrm{~m}$.

Dans la mesure où les lots agraires de Taman n'avaient pratiquement fait l'objet d'aucune étude, une attention particulière a été accordée au problème de la formation de la stratigraphie de ces fermes, à leur structure, ainsi qu'à la méthode et aux procédés de construction d'une maison grecque hors les murs de la cité. Il a été établi que les secteurs en question, comme la série des autres lots alentour, avaient été explojtés antérieurement, mais qu'il ne subsistait rien de l'étape initiale hormis de nombreuses fosses à usage domestique, pour la plupart vidées, remblayées et aplanies dans leur partie supérieure. Au-dessus de ces fosses, sur une superficie excédant celle de la future maison, avaient été édifiées des substructions en terre épaisses d'1 $\mathrm{m}$ environ, composées d'une alternance de couches irrégulières où se mêlaient des cendres et des fragments de briques crues. Pour remplir les fosses et niveler les couches de substruction, on a utilisé des amphores presque entières ou des gros fragments disposés en couches. Dans certains cas, lorsqu'une fosse se trouvait sous un angle de la future maison, elle était comblée par une grosse pierre.

Des substructions de ce type, découvertes par B. Farmakovsky, sont connues à Olbia, où elles coexistent avec d'autres types (dont les murs de fondations à assises régulières), à Képoi et, d'après nos propres observations, sur de nombreux sites du Bosphore asiatique (Hermonassa, Phanagorie, Gorgippia). L'homogénéité chronologique du remblai des sites de Jubilejnoe est prouvée par le fait que la couche d'amphores brisées du IVe s. av J.-C. (le plus souvent des amphores de Chios) est fréquemment recouverte d'une couche comprenant des objets des III ${ }^{\mathrm{e}}$-II ${ }^{\mathrm{e}}$ s. av. J.-C. (fragments de statuettes en terre cuite, céramique). De plus, dans le comblement des fosses, on a fait une découverte curieuse : des fragments de récipients non cuits et des masses informes d'argile destinées à leur fabrication, traces d'une production de céramique modelée. Plusieurs modèles de cette céramique sont inhabituels : les anses d'un récipient, déjà cuit et réalisé dans la même argile, sont décorées de petites têtes féminines modelées datant, d'après le style, des $\mathrm{III}^{\mathrm{c}}-\mathrm{II}^{\mathrm{c}} \mathrm{s}$. av. J.-C.

Comme on l'a déjà dit, des substructions artificielles étaient construites sous les fondations de la future maison. Ensuite, comme on peut en juger d'après la ferme Jubilejnoe I (fig. 37), mieux conservée, la surface du sol était soigneusement nivelée et le plan de la future maison y était tracé au cordeau, en tenant compte par avance des ouvertures de portes entre les pièces. Certaines données permettent de penser qu'avant le début de la construction, on procédait à un sacrifice : dans l'une des fosses situées sous le mur Nord de la maison, ont été retrouvés les squelettes de trois chiens et, non loin de là, 35 monnaies bosporanes de bronze portant des types de l'époque de la "crise monétaire".

Sur le site de Jubilejnoe I, les fondations des murs de la maison étaient faites en petits moellons sur tout le périmètre, celles du mur Nord ayant été construites en premier. Le caractère des assises laisse penser que deux artisans, qui travaillaient en même temps à des murs différents, ont participé à la construction. Les murs porteurs extérieurs avaient une largeur de $2 \mathrm{~m}$ et présentaient des particularités architectoniques renforçant la solidité du bâtiment. Ainsi, le mur Ouest est construit selon la technique dite "en dents de scie " (la face extérieure du mur disposée en créneaux) et l'angle Sud-Est, sous lequel se trouvait une grande fosse comblée d'une pierre, comportait plusieurs assises et était spécialement renforcé par des blocs plus importants. Ces fondations supportaient un soubassement de blocs de pierres d'une hauteur de $0,80 \mathrm{~m}$, conservé par endroits. La partie supérieure des murs était probablement en briques semi-cuites, à en juger par les nombreux fragments découverts, et s'élevait sur deux étages, comme l'indique la puissance des fondations. Ainsi, le bâtiment étudié peut s'apparenter au type des maisons-tours, très répandues dans la chôra de Chersonèse. 


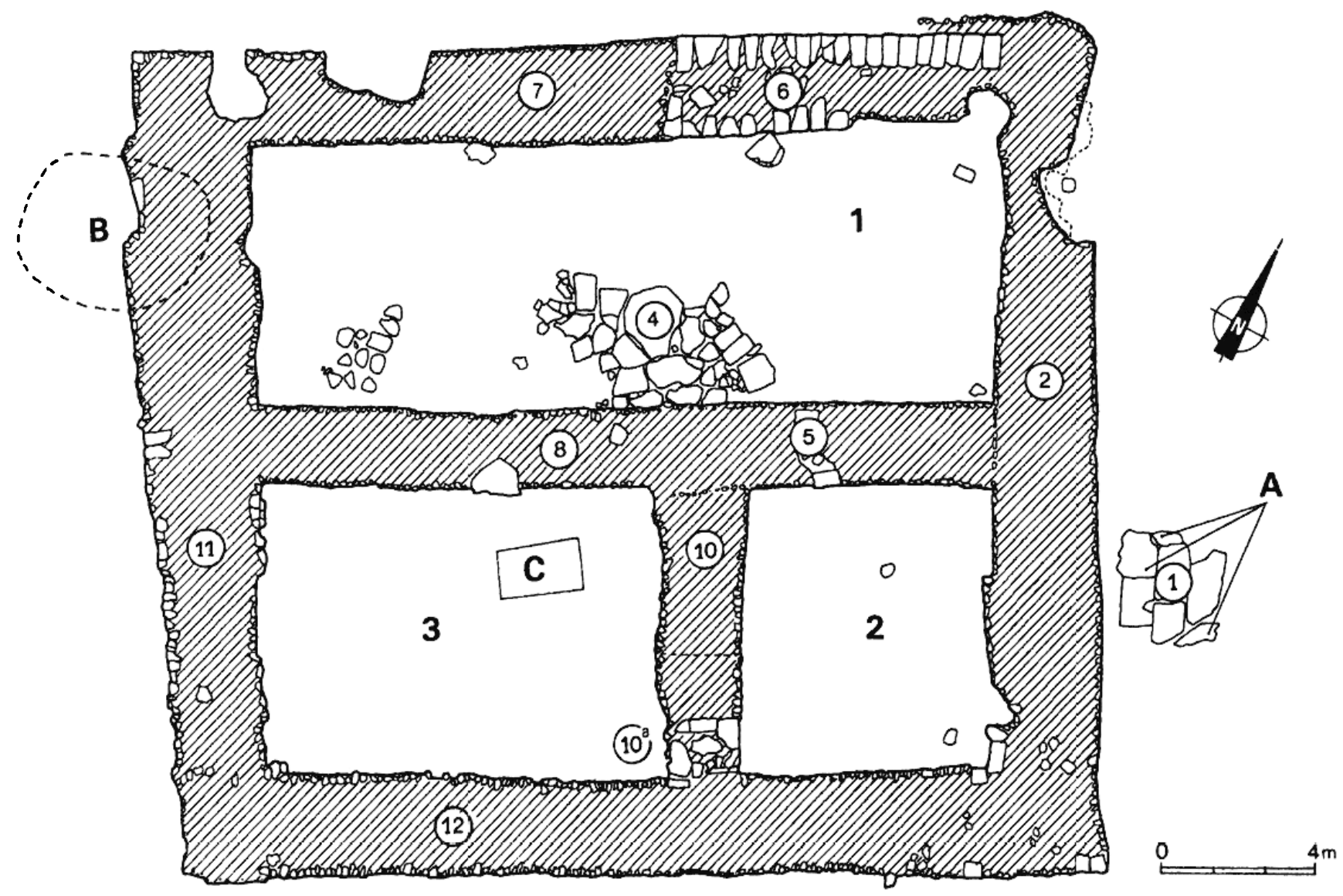

Fig. 37. Plan de Jubilejnoe I (d'après Revue archéologique 1987, p. 7, fig. 4).

La couche contemporaine de l'existence de la maison est datée de l'époque hellénistique tardive ( $\mathrm{I}^{\mathrm{er}} \mathrm{s}$. av. J.-C.- - ${ }^{\text {er }}$ s. ap. J.-C.), grâce à la présence de lampes à becs multiples à pâte grise et d'amphores à pâte claire et anses bifides. Cette couche a été passablement endommagée par les labours ultérieurs.

On notera plus particulièrement que presque tout le soubassement, ainsi que la majeure partie du dallage de la ferme elle-même et l'espace situé à l'Est de celle-ci, étaient faits à l'aide de pierres remployées, fragments architectoniques puissants et autres moellons spécialement retaillés en fragments plus petits. Il s'agit de blocs de calcaire équarris, de fragments de corniches, d'éléments de frontons, d'un fragment de frise ionique et d'une sima sculptée en forme de tête de lion. On a découvert là également quelques sculptures du IV s. av. J.-C.

En conclusion, compte tenu du fait que, d'après l'exemple de la Tholos de Taman, certaines terres ayant jadis appartenu à des sanctuaires étaient passées sous le contrôle des fermes, il n'est pas exclu que l'établissement de Jubilejnoe I ait, lui aussi été, au IV's. av. J.- C., une parcelle de terre sacrée, comme celle de la Tholos, située à la frontière de l'île, le long du Mur cimmérien. Mais ce n'est là qu'une hypothèse [E. Savostina ${ }^{26}$. 
— Les reliefs découverts lors de la fouille de la ferme ont été publiés en français par l'auteur de la précédente contribution. Revue archéologique 1987, p. 3-24.

- En 1991, pendant la fouille de la ferme de Jubilejnoe I, fut découvert dans le matériel de la substructure un trésor de 35 monnaies datant du début du III' $s$. av. J.-C. et 3 squelettes de chien, dépôts d'offrandes liés à la construction du bâtiment. $R A 1998 / 1$, p. 140-155.

\section{Blagovechenskoe}

\section{Situation géographique et travaux antérieurs}

La butte-témoin de Blagovechenskoe fait partie de la langue de terre ferme séparant le liman de Vitiazevo et celui de Kiziltasch. Elle se compose d'argiles quaternaires qui recouvrent des sables quartzeux tertiaires. Aujourd'hui, elle est reliée à la terre par les cordons sableux de Bougaz et de Vitiazevo et par les dépôts récents du Kouban. Ses contours ont été largement modifiés à cause de la transgression marine, de l'érosion du rivage et des processus d'alluvionnement et de creusement de chenaux du Kouban. À l'époque de la colonisation grecque, cette butte était une île située dans le bras du Kouban qui se jetait dans la mer Noire. L'emplacement géographique de l'île, très favorable, devait nécessairement attirer dès l'Antiquité les indigènes pour la pêche et les colons grecs pour la fondation de colonies.

Les explorations archéologiques antérieures, qui commencèrent vers 1920 dans le secteur de la stanitza dite Blagovcchenskaya, avaicnt plus d'une fois montré l'cxistence de vestigcs de sitcs ct dc kourgancs. À $1 \mathrm{~km}$ au Sud-Ouest de la stanitza, au bord du liman de Vitiazevo, on connaissait un site d'environ 12 ha, situé dans un vignoble, où avait été retrouvé un tambour de colonne en marbre et d'autres objets qui permirent de dater le site du $\mathrm{II}^{\mathrm{e}}$ s. ap. J.-C.

\section{Travaux récents}

En 1997, on a pu préciser la topographie de ce site, qui porte le nom de Blagovechenskoe 1. Sur la photographie aérienne, le site se présente comme une tache sans forme déterminée, largement détruit par les travaux agricoles et les processus naturels. Il est difficile de préciser sa taille, mais la dispersion du matériel archéologique et des vestiges de construction occupe, dans le vignoble, une superficie d'environ 10 ha. D'après le matériel de surface, le site doit être daté des $\mathrm{II}^{\mathrm{c}}-\mathrm{III}^{\mathrm{e}}$ s. ap. J.-C. et de l'époque médiévale.

Un peu plus au Nord-Est de la stanitza, avaient été découvertes de manière fortuite trois monnaies de bronze du IV s. av. J.-C. et une anse d'amphore de Sinope avec un timbre. À cet endroit, sur la berge Sud du liman de Kiziltash, nous avons découvert les vestiges du site de Blagovechenskoe 10, dont la majeure partie avait été détruite par la construction d'un réservoir de pétrole et la partie située en bord de mer par l'érosion. On n'a pu déterminer la superficie du site, mais l'épaisseur des dépôts archéologiques atteint au moins $1 \mathrm{~m}$.

Plus à l'Est de ce site, on a localisé les vestiges du groupe de kourganes Blagovechenskoe 6-9, situés sur une chaîne naturelle orientée d'Est en Ouest. Les kourganes sont arasés par les labours et leur partie Nord détruite par l'érosion.

Sur la berge Sud du liman de Kiziltash, à la périphérie Nord de la stanitza, on a mis au jour les vestiges de deux sites, Blagovechenskoe 11 et 12, d'une superficie d'environ 1-1,5 ha chacun. L'un est actuellement recouvert par un cimetière et l'autre par une habitation. Tous deux sont fortement victimes de l'érosion marine et datent des $\mathrm{II}^{\mathrm{e}}-\mathrm{V}^{\mathrm{e}}$ s. ap. J.-C. 
Dans la partie Sud de la butte, à $2 \mathrm{~km}$ de la stanitza, sur une chaîne naturelle, on a retrouvé, à $100 \mathrm{~m}$ l'une de l'autre, deux fermes, Blagovechenskoe 2 et 3, d'une superficie d'environ 1 ha chacune. Elles se présentaient comme deux petites hauteurs de 1 à $2 \mathrm{~m}$, séparées par un ravin peu profond. La collecte du matériel de surface a permis de dater les deux sites du IV s. av. J.-C. au III ${ }^{e}$ s. ap. J.-C. A l'Ouest de ces fermes, au bord de la mer Noire, on a localisé un kourgane d'une hauteur de $5 \mathrm{~m}$ et d'un diamètre d'environ $50 \mathrm{~m}$.

À $3 \mathrm{~km}$ à l'Ouest de la stanitza, sur le cap, est située une bourgade antique, victime de l'érosion de la mer Noire et du liman de Bougaz. Les recherches antérieures — dont les fouilles de 1968 - ont évalué la superficie du site à 15 ha et l'ont daté du $\mathrm{III}^{\mathrm{e}}$ s. ap. J.-C. Certains situent à cet endroit la cité d'Hermonassa ou de Corocondamé.

Ce site, appelé Blagovechenskoe 4, fut le principal objet de la campagne de 1997. Les photographies aériennes et l'extension des dépôts stratifiés laissent supposer qu'il s'étendait sur 20 ha environ. Le matériel collecté permet de dater son existence entre le VI' s. av. J.-C. et le III's. ap. J.-C. La cartographie des découvertes archéologiques a livré des informations sur la topographie du site. Il est hors de doute qu'il y avait là, à l'époque antique, un établissement grec important jouant un rôle de centre économique de transit dans le Kouban. C'est ce dont témoignent les fragments d'amphores de Clazomènes, Chios, Samos, Thasos, Rhodes, Cos, Héraclée, Sinope, Colchide et d'autres centres du Pont et de la Méditerranée. Il n'est pas exclu que l'île de Blagovechenskoe ait servi de tremplin à la pénétration des colons grecs dans cette partie de la mer Noire.

Outre cela, ont été effectués des travaux d'archéologie sous-marine dans les limans de Kiziltash et de Bougaz : il s'agissait d'obtenir des informations sur le caractère et l'état des vestiges submergés du fait de la transgression marine et sur les couches stratigraphiques, remaniées par l'érosion du rivage, des sites de Blagovechenskne. Au Sud et au Sud-Ouest de la butte, dans la merr Noire, on a étudié une plate-forme côtière ainsi que le banc rocheux dit de Marie-Madeleine, où l'on trouve souvent des objets antiques et médiévaux provenant de naufrages, et récolté de la céramique des $\mathrm{IV}^{\mathrm{e}}-\mathrm{III}^{\mathrm{e}} \mathrm{s}$. av. J.-C. en rapport, semble-t-il, avec un naufrage antique [Y. Gorlov ${ }^{27}, \mathrm{M}$. Abramzon ${ }^{28}$, A. Efimov ${ }^{29}$ ].

\section{Sud-Ouest de la péninsule de Taman}

- En 1996 a vu le jour une mission archéologique russo-polonaise (Musée de l'Hermitage, Institut de la culture matérielle de Saint-Pétersbourg et université de Varsovie), baptisée "l'île de la Sindikè ", dont le but est la prospection détaillée, au moyen de toutes les technologies possibles, de la partie Sud-Ouest de la péninsule de Taman. Les deux premières campagnes ont fait l'objet d'un rapport préliminaire, qui consiste essentiellement en un bref rapport de fouilles du site Volna 1 , situé à $4 \mathrm{~km}$ au Sud du village actuel de Taman (anc. Hermonassa) et déjà fouillé deux fois depuis 1954. On y a mis au jour, grâce notamment à une prospection géophysique, le soubassement de deux bâtiments ruraux (avec cour), qui se succèdent dans le temps mais appartiennent tous deux, d'après le matériel découvert, aux II $^{\mathrm{c}}-\mathrm{III}^{\mathrm{e}} \mathrm{s}$. ap. J.-C. Par ailleurs, une trentaine de sites d'époque antique et médiévale ont été prospectés au bord de la mer Noire, du lac Salé et des limans de Bougaz et Tsokour. TS 1 (1998), p. 37-47. 


\section{Région de Novorossiisk}

\section{Travaux antérieurs}

Si l'une des premières mentions concernant les antiquités découvertes dans la baie Tsemesskaya se trouve dans les communications de G. Taitbout de Marigny en 1844 et si les premières fouilles des environs de Novorossiisk eurent lieu dans les années 1880 , l'exploration systématique de la région ne commença qu'en 1954 avec la mission de l'Institut archéologique de Moscou, sous la direction de V. Blavatsky, dont les travaux furent poursuivis par N. Onaiko jusqu'au début des années 1980.

\section{Travaux récents}

Depuis le début des années 1980, la carte archéologique de la région s'est enrichie de nouveaux sites antiques, grâce à l'accroissement du nombre de fouilles, surtout dans les années 1990 , et par là même de la quantité de matériel archéologique mis au jour.

Commençons par les sites liés à la culture locale. Entre le $\mathrm{VV}^{\mathrm{e}}$ et le I ${ }^{\mathrm{er}} \mathrm{s}$. av. J.-C., d'après les auteurs anciens, le territoire qui s'étend d'Anapa à Gelendjik était habité par des tribus de Kerkètes et de Taures ${ }^{30}$. Les sites occupés par ces tribus ne sont pas encore étudiés. Mieux connues sont leurs constructions funéraires : caissons de pierre placés dans des monuments en forme de tours, construits à l'aide de blocs non équarris ou de blocs erratiques polis par la mer, non liés par du mortier. En général, il s'agit de sépultures familiales, où ont été retrouvés de un à cinq squelettes humains. Pendant la période considérée, on a étudié toute une série de monuments de ce type (fig. 38, $\mathrm{n}^{\text {os }} 1,2$ et 3). L'un d'eux fut découvert à l'embouchure de la Lobanova Chel, située à $1,5 \mathrm{~km}$ du cap Outrichonok. Ce défilé assez profond coupe la pente Sud de la chaîne du Navagir qui s'étend d'Anapa à Abrau-Diourso. À la sortie du défilé, le versant droit est en pente douce, tandis que le versant gauche est abrupt. Il se termine, du côté de la mer, par un escarpement qui subit chaque année une érosion marine intensive.

En 1984, A. Dimitriev découvrit, dans l'escarpement du versant droit, des caissons de

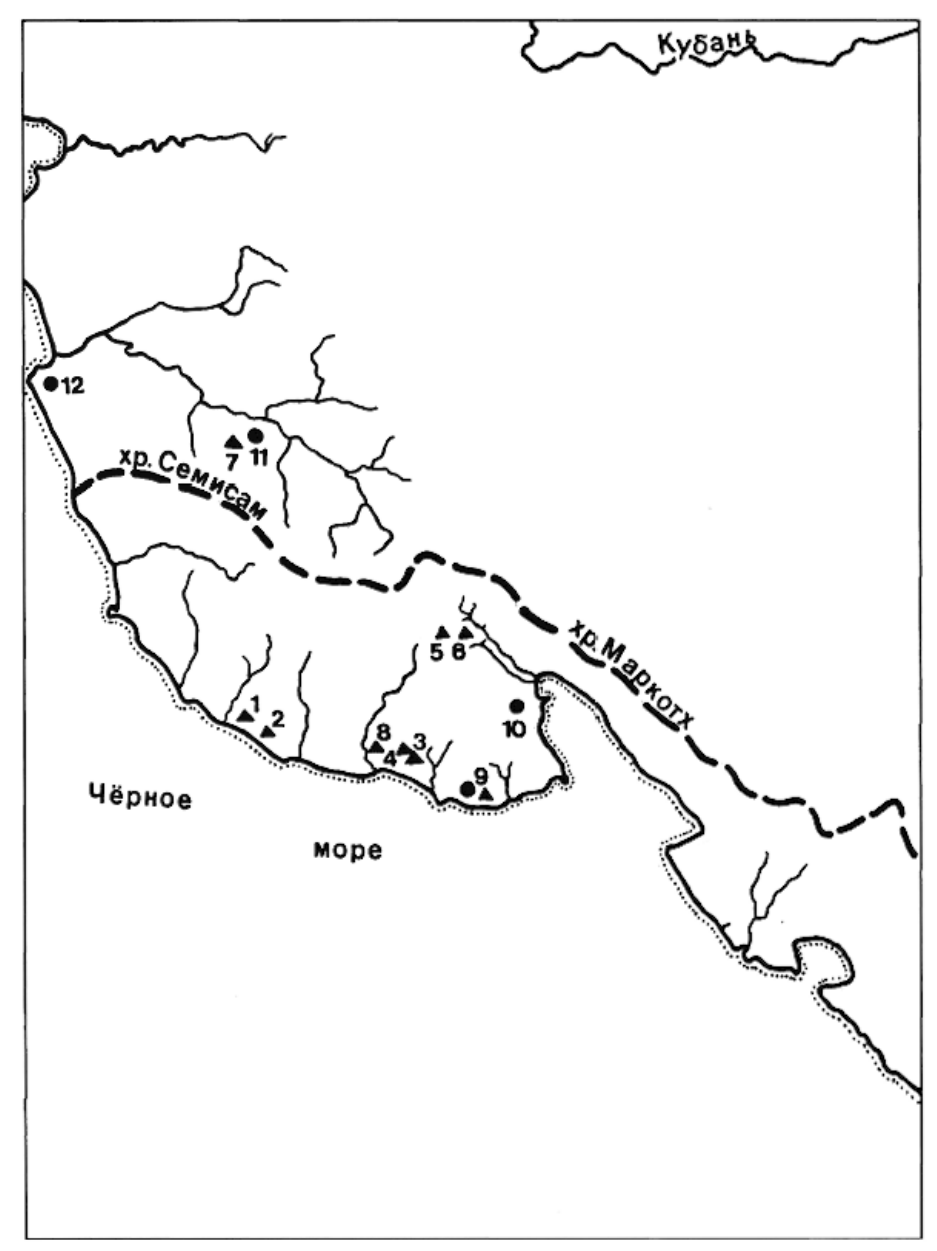

Fig. 38. Carte des sites antiques dans les environs de Novorossiisk. 1 : Lobanova Chel; 2 : Lac Salé ; 3 : Chirokaya Balka (nécropole d'époque scythe); 4 : Chirokaya Balka (nécropole d'époque romaine); 5 : Tsemdolina 1 (époque scythe); 6 : Tsemdolina 2 (époque romaine); 7 : nécropole de Raevsky; 8 : nécropole de loujnaia Ozereika; 9 : Myskhako (site et nécropole antiques); 10 : Bata; 11 : site de Raevsky; 12 : Gorgippia. 


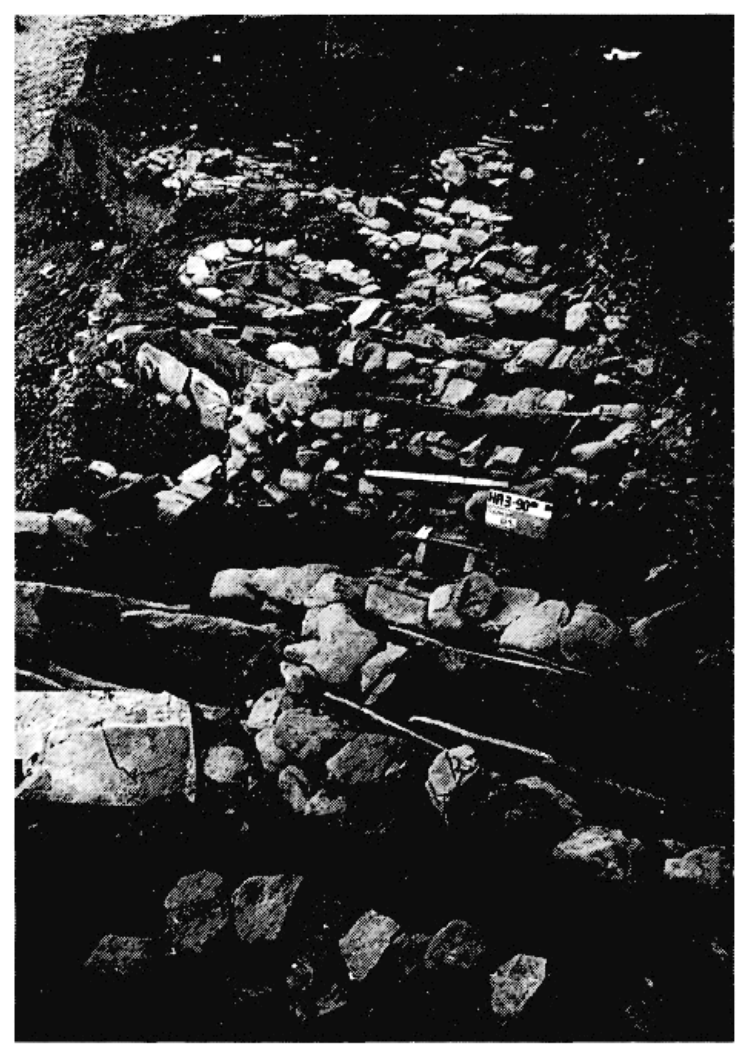

Fig. 39. Vue générale des constructions funéraires de Lobanova Chel.

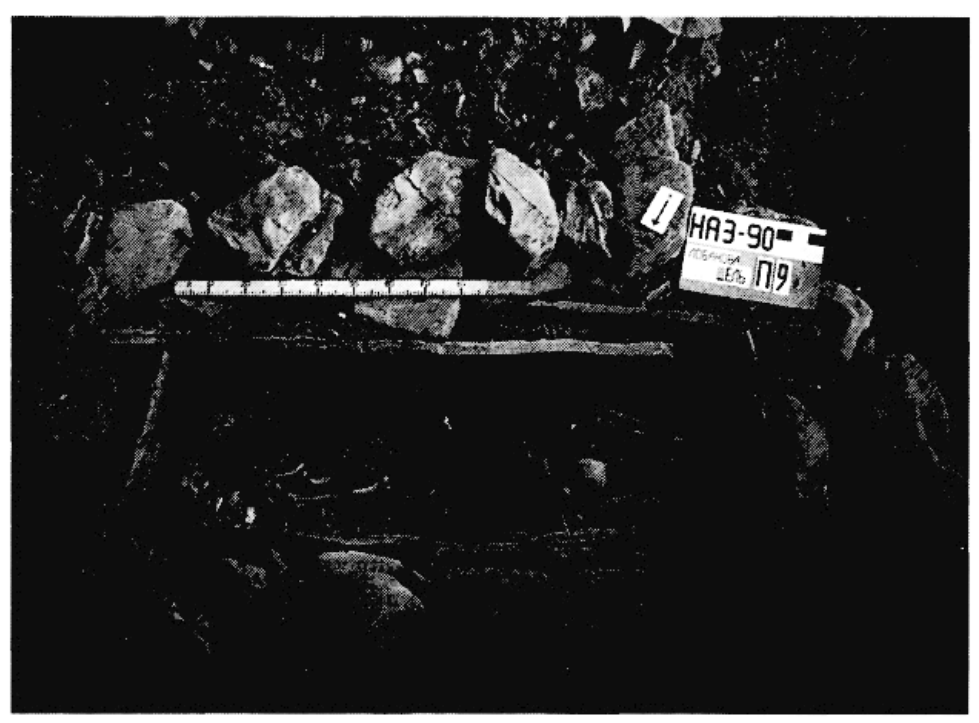

Fig. 40. Tombe de la nécropole de Lobanova Chel.

pierre à demi détruits. Le tombeau était lui-même recouvert d'un amoncellement de pierres, consécutif à un tremblement de terre postérieur au IX $\mathrm{C}^{\mathrm{e}}$ s. ap. J.-C., date fournie par l'habitat médiéval situé sous l'éboulement. Les fouilles menées en 1984, puis en 1990, ont permis l'étude de quinze sépultures (fig. 39 à 41), disposées en rangs en travers de la pente. L'inventaire du mobilier funéraire, qui compte un grand nombre d'objets importés, permet de dater la nécropole des $V^{\text {ve }}-^{\text {er }}$ s. av. J.-C. (fig. 42). En outre, la stratigraphie du tombeau a livré du matériel (fragments d'amphores de Clazomènes et protothasiennes) manifestement en rapport avec des banquets commémoratifs et datant d'une époque plus ancienne (fin du $\mathrm{Vl}^{e} \mathrm{~s}$. av. J.-C.). Les habitants du lieu étaient donc déjà entrés en contact avec le monde antique à l'époque de la colonisation de la mer Noire par les Grecs. Le matériel le plus abondant date du IV ${ }^{\mathfrak{c}}$ s. av. J.-C. et comprend notamment trois monnaies de Panticapée de la fin du IV ${ }^{e}$ s.-III ${ }^{e} s$. av. J.-C. (fig. 43). Les objets de la vie quotidienne sont représentés par des plats non tournés (fig. 44), des meules, des bijoux (fig. 45) et des armes. L'activité économique de la population était étroitement liée à la mer, ce dont témoignent des pesons de filet en pierre et des arêtes de poisson.

Les recherches de ces dernières années ont montré l'originalité du rituel funéraire des tombeaux de la vallée de la Tsemesskaya aux époques scythe et antique. L'un des tombeaux d'époque scythe, celui de Tsemdolina, ouvert par N. Onaiko en 1972, fut étudié dans sa totalité en 1995 par l'auteur de ces lignes (fig. 38, $\mathbf{n}^{\circ}$ 5). Il est situé à $500 \mathrm{~m}$ à l'Ouest du village de Tsemdolina sur un petit replat du versant d'une superficie d'environ $300 \mathrm{~m}^{2}$. Les sépultures étudiées étaient disposées régulièrement, en rangées qui s'étendaient manifestement le long de la pente. Comme il est de règle, des assises de grosses pierres entouraient les sépultures, mais certaines d'entre elles étaient de simples fosses creusées en pleine terre. La plupart ne contenaient qu'un corps et deux seulement renfermaient des restes de plusieurs individus. Les objets tels que pointes de flèches en fer, akinakès (cimeterres) et défenses de sangliers ornées étaient liés aux tombes masculines, tandis que les 
tombes féminines recelaient des bracelets en bronze, des bagues ornées de pierres, des coquilles et des objets de fer en forme d'entonnoirs. On note en particulier la découverte d'ornements de harnachement et de plaques en bronze provenant d'une cuirasse (env. 1000 pièces), datant de la fin du Ve s. av. J.-C.

Selon toute vraisemblance, au $\mathrm{III}^{\mathrm{e}}$ siècle av. J.-C., dans les plaines et les vallées de ce secteur (actuel district de Novorossiisk), apparaît un autre type de sépulture qui se maintient jusqu'au milieu du III $^{\mathrm{e}} \mathrm{s}$. ap. J.-C. (fig. 38, n $^{\text {os }} 4,6,7,8$ et 9). Le plus ancien de ces monuments, qui date des III $^{\text {e }}$ II $^{\text {er }}$ s. av. J.-C., a été découvert dans les environs de la stanitza Raevskaya, pendant les fouilles menées par A. Dmitriev en 1984-1985 (fig. 38, $\mathbf{n}^{\circ}$ 7). Les sépultures étaient des fosses en pleine terre. Les observations stratigraphiques faites lors de l'étude du tombeau de Tsemdolina (début $\mathrm{I}^{\mathrm{er}}-\mathrm{IV}^{\mathrm{e}}$ s. ap. J.-C. ; cf. fig. $38, \mathbf{n}^{\circ} \mathrm{6}$ ), fouillé par A. Malyshev en 1991, ont permis d'analyser la construction avec élargissement latéral des chambres funéraires. Le matériel funéraire - surtout les nombreux objets importés — permet de dater le fonctionnement

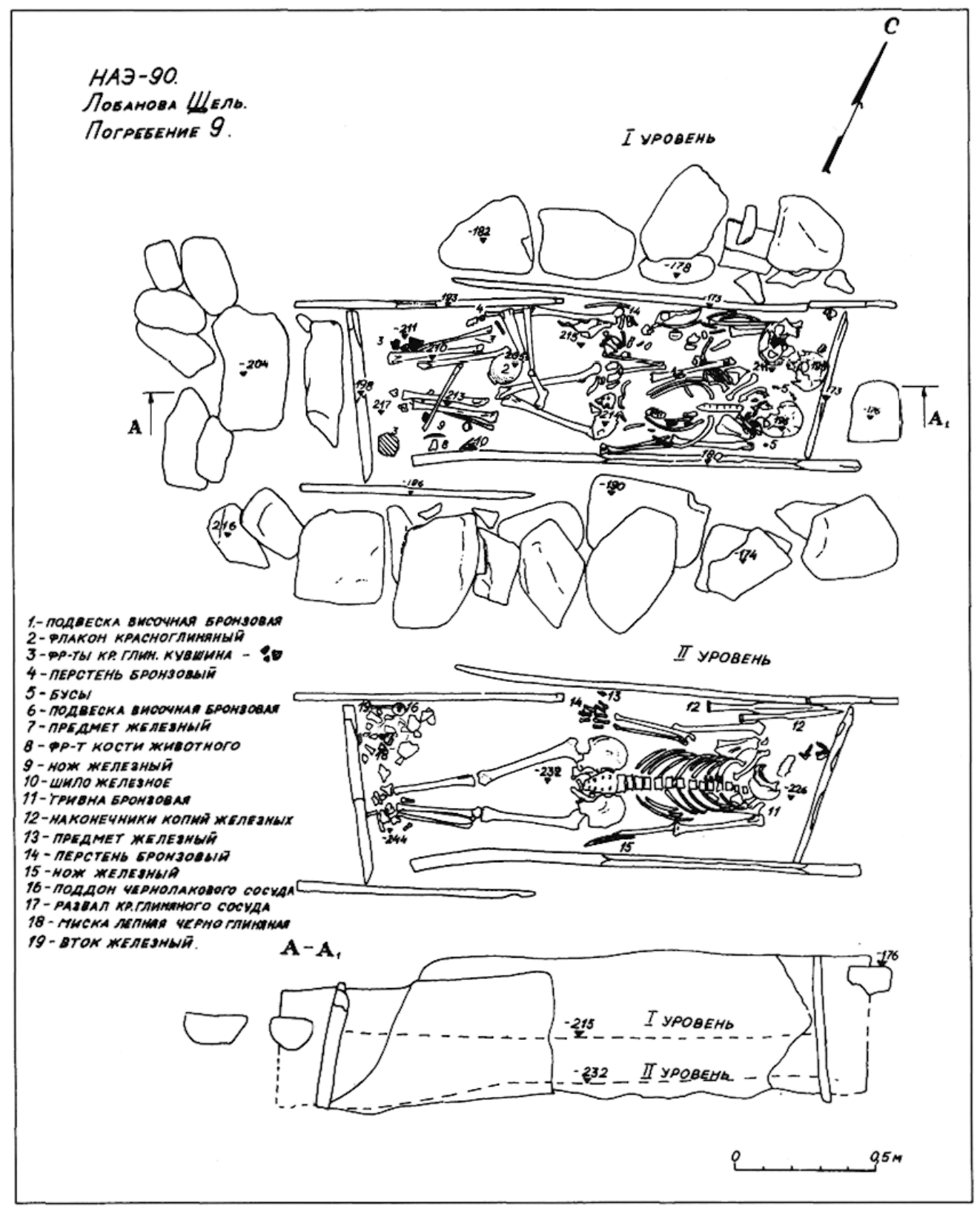

Fg. 41. Plan d'une tombe de Lobanova Chel. 


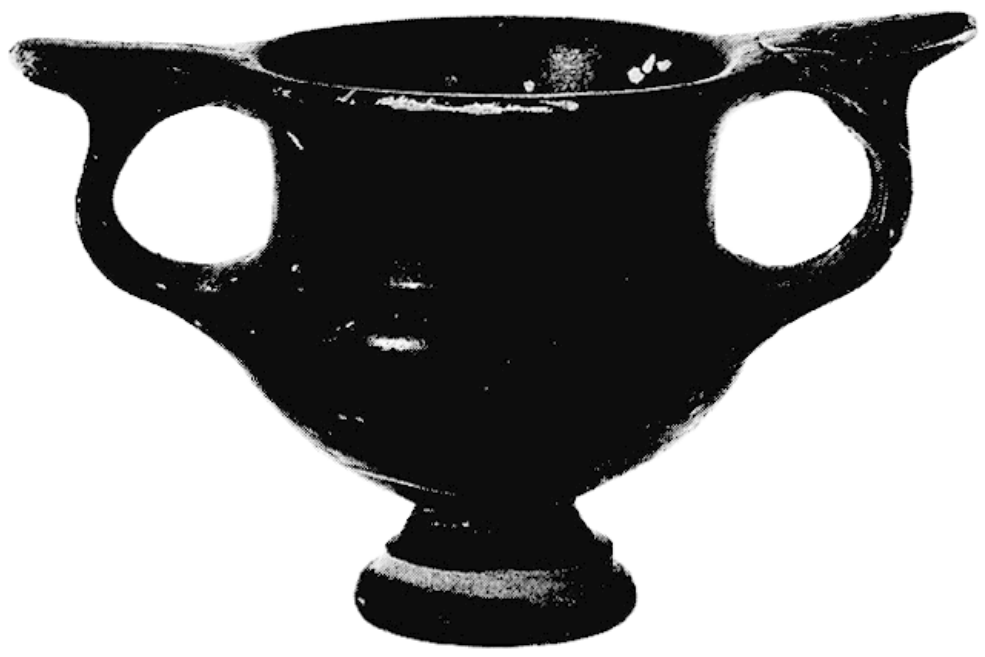

Fig. 42. Canthare à vernis noir provenant d'une tombe de la nécropole de Lobanova Chel.

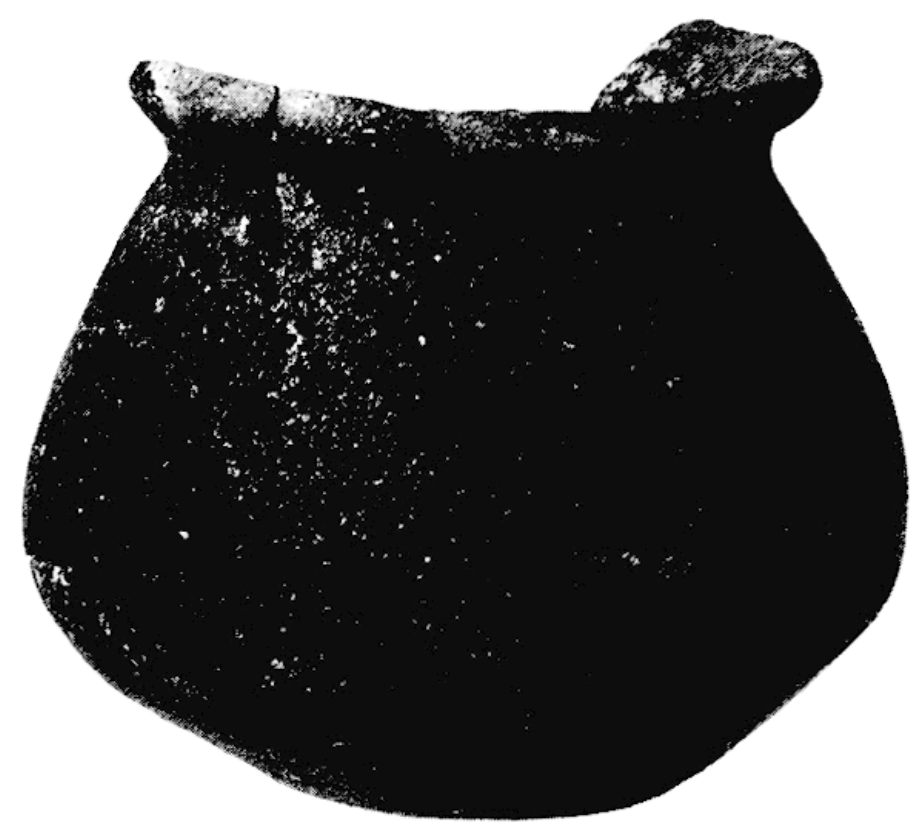

Fig. 44. Vase non tourné d'une tombe de Lobanova Chel.

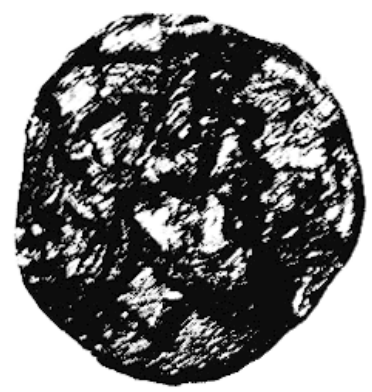

Fig. 43. Monnaie de Panticapée en bronze (Ive s. av. J.-C.) de Lobanova Chel.

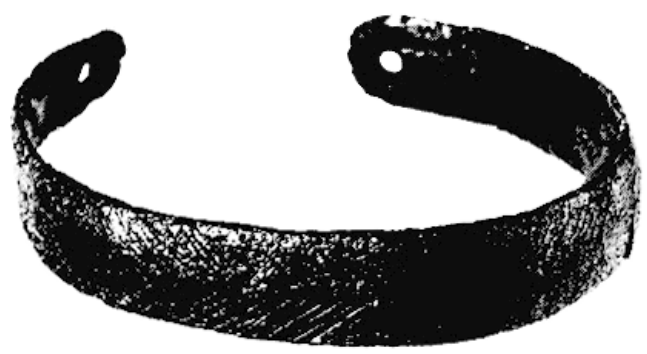

Fig. 45. Bracelet en bronze d'une tombe de Lobanova Chel.

des tombes de ce type du III ${ }^{c}$ s. av. J.-C. (ou de la fin du IVe ?) jusqu'au début du III ${ }^{\mathrm{e}}$ s. ap. J.-C. Les sépultures hellénistiques sont caractérisées par leur orientation à l'Est, tandis qu'à l'époque romaine se développe l'orientation à l'Ouest. Un indice stable du rituel funéraire de cc groupc rćsidc dans le dépôt de plats à pâte grise et, plus tard (à partir du I ${ }^{\text {cr }}$ s. ap. J.-C.), de plats en verre et à vernis rouge en guise d' "oreillers ": on en trouve à raison de $40 \%$ sur le site de Raevsky, 14,5\% sur celui de Chirokaya Balka, $35 \%$ sur celui de Tsemdolina. On constate la présence de galets en pierre dans les sépultures. Un autre signe constant est le dépôt de viande animale dans la tombe, au fond de la fosse d'entrée.

Un site semblable a été ouvert et étudié dans la périphérie Nord du bourg de Ioujnaia Ozereika, à $10 \mathrm{~km}$ au Sud-Ouest de Novorossiisk (fig. 38, $\mathrm{n}^{\circ}$ ), où ont été explorées 126 sépultures dont la densité au sein de l'ensemble funéraire n'est pas régulière : elles different, en effet, par le rituel et l'orientation et l'on peut distinguer trois groupes principaux. 
Le plus nombreux d'entre eux (67 sépultures) est regroupé au centre, au Nord et au Nord-Est de l'aire étudiée. Il s'agit de tombes à fosse simple de forme ovale ou rectangulaire, pourvues ou non d'un socle en pierre et orientées au Nord, au Nord-Est ou à l'Est. Le rituel funéraire de ce groupe se caractérise par le dépôt d'un vase sous le crâne du défunt. Autre pratique habituelle: l'ensevelissement d'animaux en même temps que celui d'êtres humains : chevaux, gros bétail à cornes, moutons et chiens. Le matériel découvert dans ce groupe est homogène : céramique à pâte grise sur pied circulaire (plats, canthares...), miroirs et bijoux (fig. 46). Dans une série de sépultures, on a découvert des armes: lances (8), épées (3), haches de guerre (2) et pointes de flèches (5). Grâce aux trouvailles monétaires et aux plats en verre, on date ce groupe entre le $\mathrm{I}^{\mathrm{er}} \mathrm{s}$. av. J.-C. et le début du $\mathrm{II}^{\mathrm{e}} \mathrm{s}$. ap. J.-C.

Les sépultures du deuxième groupe (27 ensembles) sont situées, pour l'essentiel, dans la partie orientale de l'aire étudiée. Il s'agit de sépultures formées de caissons en pierre, tous pillés, semble-t-il dès l'Antiquité. Le matériel et l'orientation des sépultures sont semblables à ceux du premier groupe, ce qui a permis de les dater entre le ${ }^{\text {er }}$ s. av. J.-C. et le

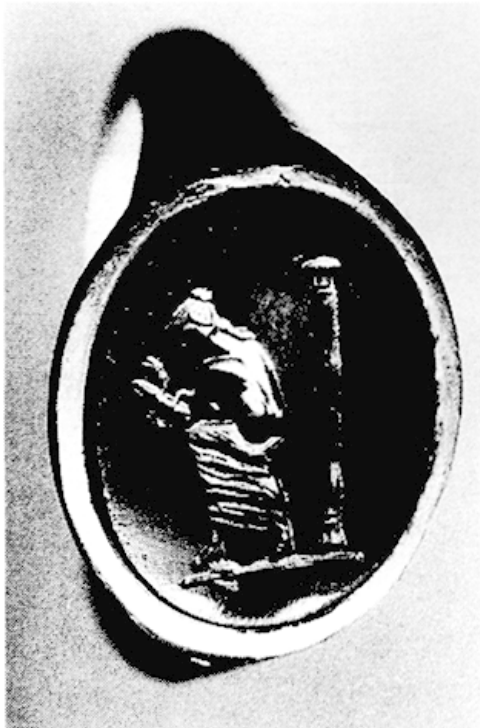

Fig. 46. Bague avec gemme provenant d'une tombe de loujnaia Ozereika II $^{e}$ s. ap. J.-C.

Les sépultures du troisième groupe (32 ensembles) sont situées dans la partie occidentale de la zone. Il s'agit de tombes à fosse simple en pleine terre, de forme ovale ou rectangulaire, dont la plupart avaient été pillées. Elles sont orientécs à l'Oucst ct lcur mobilicr (fibulcs, boucles ct monnaies) permet de les dater des II - IV s. ap. J.-C.

Selon l'auteur anonyme du Périple du Pont-Euxin ${ }^{31}$ ( $\mathrm{V}^{\mathrm{e}}$ s. ap. J.-C.), vivaient dans les territoires jadis occupés par les Kerkètes et les Taures ceux que l'on appelait les Eudosiens, qui parlaient la langue gothe ou taure. Plus tard, ils furent repoussés par la tribu adyguéenne des Zykhes, mentionnée par Procope de Césarée au VI ${ }^{e}$ s. ap. J.-C. Des complexes funéraires de cette époque ont été mis au jour sur le site de Tsemdolina, ainsi que sur celui de Ioujna Ozereika.

Le deuxième point intéressant concerne les données relatives à la diffusion de l'influence antique dans la région. Selon l'opinion d'un certain nombre de chercheurs, à la fin du IV ${ }^{e} s$. av. J.-C. et au début du III ${ }^{c}$ s., les frontières du Bosphore s'élargirent considérablement au Sud-Est. En dehors de la titulature des rois bosporans, les données archéologiques témoignent également de ce phénomène, avec la diffusion des monnaies du Bosphore et la fondation d'un établissement bosporan sur le site de Raevsky au IV s. av. J.-C. $\mathrm{Au} \mathrm{I}^{\mathrm{er}}$ s. av. J.-C., surgit en différents endroits de la région un réseau de fermes fortifiées dotées de murs épais, qui disparaît, vraisemblablement au milieu du ${ }^{\mathrm{er}}$ s. ap. J.-C. À l'époque romaine, il existe deux sites, clairement liés au Bosphore : celui de Raevsky et celui de Myskhako, tous deux situés aux confins de la région.

Myskhako est le site le mieux étudié en ce qui concerne la période antique (fig. $38, \mathbf{n}^{\circ}$ 9). L'établissement est situé au Sud-Ouest de la baie Tsemesskaya, au pied du Mont Kaldoun, sur deux petites hauteurs entaillées chacune par un ravin. La proximité de la pleine mer et l'existence de pentes barrant la route aux vents de Nord-Est créent ici un microclimat plus doux que dans la baie Tsemesskaya. Dans l'Antiquité, le site était infiniment plus étendu : en 2000 ans, la ligne de rivage a été modifiée d'au moins $200 \mathrm{~m}$ par 
l'action de la mer. La topographie du site, malgré l'importance du secteur étudié, n'est pas encore claire. Il est possible que le site antique ait été fondé sur le promontoire, au Ir s. av. J.-C. ou au début du I ${ }^{\mathrm{er}} \mathrm{s}$. ap. J.-C. Pus tard, la superficie de l'établissement s'agrandit considérablement, englobant même une partie de la nécropole du I ${ }^{\text {er }}$ s. ap. J.-C. On ne sait pas non plus clairement si l'établissement était pourvu de constructions défensives, dans la mesure où l'on a découvert peu d'assises en pierre sur le site. L'une d'elles a été mise au jour dans la partie Sud-Ouest du site. Le mur, construit à sec, faisait $2 \mathrm{~m}$ de large sur $14 \mathrm{~m}$ de long et était constitué de blocs marins polis de forme presque régulière.

Comme il est de règle, les vestiges de maisons se présentent sous la forme d'amas d'enduit brûlés. Les empreintes visibles dans certaines parties de l'enduit permettent de conclure que les parties essentielles de cette construction étaient en torchis, c'est-à-dire qu'elles étaient composées d'une armature en bois, faite de verges de 1,8 à $2 \mathrm{~cm}$ d'épaisseur ou de minces billots enduits d'argile mêlée de roseau haché.

La stratigraphie et le remplissage de toute une série de fosses correspondaient à une couche d'incendie. Sur toute la surface étudiée durant les fouilles de 1996, furent découvertes des fosses avec des squelettes humains - de femmes et d'enfant surtout - dans le fond. La position peu naturelle des squelettes ainsi que leur nombre (jusqu'à cinq dans certaines fosses) reflètent le caractère massif de la destruction du site. Des ossements humains ont été découverts dans l'amas d'enduit, témoignant de la présence d'une construction. Le matériel de remplissage des fosses permet de dater l'événement après le milieu du II $\mathrm{s}$. ap. J.-C. La céramique des fosses présente des analogies avec le matériel des constructions de Gorgippia à l'époque de sa destruction, en 240 ap. J.-C.

La nécropole du site de Myskhako est la plus hellénisée de la région et peut être mise en parallèle avec les nécropoles des cités du Bosphore, comme en témoigne la large diffusion du rituel funéraire bosporan : fréquentes inhumations dans des cercueils en bois (on a retrouvé des clous dans 37 sépultures), obole de Charon (monnaies présentes dans 22 tombes), faible importance numérique de la céramique à pâte grise par rapport à la diversité et à la quantité de vaisselle à vernis rouge et en verre. La nécropole témoigne de la continuité d'occupation du site sur trois siècles. L'une des sépultures les plus tardives est datée par un statère de Sauromate III (vers 230 ap. J.-C.).

En dehors de la nécropole, les liens du site avec le Bosphore sont attestés par les nombreuses découvertes d'amphores bosporanes et l'ensemble des monnaies mises au jour. En trois siècles, cet établissement s'est avéré le plus éloigné du centre en direction du Sud-Est : peut-être s'agissait-il d'un avant-poste du Bosphore dans cette région. À propos de son statut dans le système de l'État bosporan, on ne peut pour le moment qu'émettre des hypothèses. Certains chercheurs avaient naguère proposé d'identifier ce site avec celui de l'antique Bata. Mais la majorité des chercheurs situe aujourd'hui la cité de Bata, fondée par les Grecs $^{32}$, sur la rive occidentale de la baie Tsemesskaya. On considère que les ruines de Bata ont été recouvertes par la construction d'une forteresse génoise. Par la suite, ses vestiges auraient été ensevelis sous le béton lors de la construction du port de Novorossiisk. L'existence, à cet endroit, d'un site antique est attestée par la découverte, lors de travaux de terrassement dans la ville, de couches d'époque hellénistique et d'une nécro-

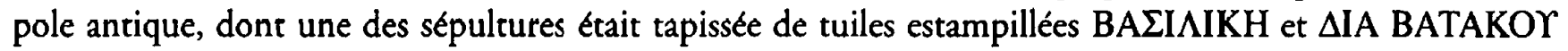
[A. Malyshev ${ }^{33}$ ]. 
- Publication détaillée du tombeau d'époque romaine de Tsemdolina fouillé en 1991 par A. Malyshev (cf. supra, dans sa contribution). BS 5 (1994), p. 59-86.

- Compte rendu des travaux menés en 1992 sur le site de Myskhako et publication du matériel d'une série de fosses qui permet de dater l'existence du site entre le ${ }^{\text {er }}$ s. av. J.-C. et le IV s. ap. J.-C. BS 4 (1994), p. 141-152.

- Publication d'une statuette de bronze, trouvée à Myskhako, d'une hauteur de $22 \mathrm{~cm}$ dont 19 conservés, et présentant d'une part des attributs héracléens (léontè...), d'autre part l'attitude de Poséidon. Il s'agit sans doute de l'image héroïsée d'un hellenistic ruler, peut-être Mithridate Eupator, dans la tradition de l'image d'Alexandre et datant du début du I ${ }^{\text {er }}$ s. av. J.-C. RA 1998/4, p. 160-173. 